http://dx.doi.org/10.11646/phytotaxa.96.1.1

\title{
Venation patterns of neotropical blueberries (Vaccinieae: Ericaceae) and their phylogenetic utility
}

\author{
PAOLA PEDRAZA-PEÑALOSA ${ }^{1 *}$, NELSON R. SALINAS ${ }^{1,2} \&$ WARD C. WHEELER ${ }^{3}$ \\ ${ }^{I}$ The New York Botanical Garden, Institute of Systematic Botany, Bronx, NY 10458, U.S.A. \\ ${ }^{2}$ City University of New York, The Graduate Center, 365 Fifth Avenue, New York, NY 10016, U.S.A. \\ ${ }^{3}$ American Museum of Natural History, Division of Invertebrate Zoology, Central Park West at 79th Street, New York, NY 10024, \\ U.S.A. \\ *Corresponding author: ppedraza@nybg.org
}

\begin{abstract}
The description of venation patterns in neotropical Vaccinieae has been problematic because of the lack of an operational definition. Moreover, the underlying homologies remain unknown across and within lineages, thus precluding the use of venation characters in phylogenetic analyses. Venation patterns are often obscured in herbarium and living specimens due to the characteristic coriaceous and thick nature of Ericaceae leaves. Therefore, to obtain an unobstructed view of the veins, leaf clearings of 16 putative generic lineages of Vaccinieae were prepared and described. The main venation patterns were then defined and traditional definitions of venation were discussed in the light of the observed patterns. Selected characters were scored and the evolution of venation characters was discussed using a phylogenetic framework derived from molecular data analyzed under Maximum Likelihood. Venation descriptions and photographs are provided for 33 species.
\end{abstract}

\section{Introduction}

Neotropical Vaccinieae (30 genera, ca. 800 species) is one of the most diversified groups of Ericaceae and an important component of the biological diversity of the rich tropical montane ecosystems (Luteyn 2002). The venation of their leaves, the most commonly observed/collected organs, is mostly described as either pinnate or plinerved (e.g. triplinervis for leaves with 3 strong nerves, 5-plinerved for those with 5, etc.) (see Smith 1932). However, the current definition of these main venation frameworks is loose and rather informal, leading to contradictory and subjective assignment of venation types in Ericaceae; this has made difficult the exploration of venation characters in both taxonomy and phylogenetics. Disambiguation between venation types is fundamental for the accuracy and standardization of morphological descriptions and the understanding of the underlying homologies in neotropical Vaccinieae.

In neotropical Vaccinieae, the primary venation is some times determined by employing both vein diameter and hierarchy as criteria, while in other occasions the vein course is the most determining factor; thus, an unambiguous and unified criterion is currently lacking. Luteyn $(1983,1996)$, who followed Smith's venation nomenclature throughout his many years of taxonomic work with neotropical Ericaceae, further elaborated that pinnate leaves are camptodromous while plinerved leaves are those that are acrodromous. Here, plinerved is then defined as an over-broad concept that includes palmate-acrodromous leaves with multiple primary veins of equivalent diameter, as well as leaves with a single midvein (as in pinnate) flanked by one or more pairs of basal nerves that stand out in both gauge and course (ascending; as in for example, triplinervis). The nature and origin of these basal, lateral, prominent, and ascending nerves are at the heart of the problem; there is not an operational definition that allow us to unambiguously say whether they are 
equivalent to one of the multiple primaries of an acrodromous leaf, ramifications of the midvein of a pinnate leaf, or just thick secondary veins.

The difficulties determining vein frameworks in Vaccinieae are exacerbated by the absence of reference studies and the generally coriaceous nature of their leaves that makes the venation inconspicuous in both living and dried material. Thus, working without cleared material is not a trivial task. In phylogenetic analyses, for example, venation characters are seldom used and when included, ambiguities have resulted in the coding of non-homologous characters states, the use of blurred boundaries (e.g. camptodromous/ actinodromous vs. parallel; more or less palmate vs. more or less parallel), or even in the inconsistent codification of certain taxa across studies (Powell et al. 1996, Kron et al. 1999, Kron et al. 2002b, Jordan et al. 2010).

A better understanding of the venation patterns of neotropical Vaccinieae is also important for phylogenetic work as it is related to character homology: a rationale for the delimitation of venation characters will allow testing of their phylogenetic value. This will set the foundations to explore the evolution of different venation characters/patterns within this diverse group of plants and determine whether certain characters/patterns have originated independently or are exclusive to certain clades. Because of the predominance of non-monophyletic genera within neotropical Vaccinieae (Kron et al. 2002a, Powell \& Kron 2003, Pedraza-Peñalosa 2009, 2010a), there is a growing need for both revising current statements of primary homology and discovering morphological characters that explain the evolutionary relationships that emerge from the analyses of molecular data. There is special interest in finding characters that would help to diagnose major clades, especially within the neotropical taxa, which is the group more subjected to phylogenetic analyses (see Kron et al. 2002a, Powell \& Kron 2003, Pedraza-Peñalosa 2009, 2010a). However, before assessing the phylogenetic and taxonomic value of leaf venation and its evolution, it is necessary to investigate the underlying hypotheses of homology: whether all the most prominent veins of an acrodromous/ plinerved leaf belong to the same venation order and how they are related to each other regarding gauge and spatial distribution.

In this paper, we will first investigate in detail the leaf venation of neotropical Vaccinieae through leaf clearings, which provide us with an accurate and unobstructed view of the veins. Secondly, we will attempt to define the main venation frameworks based on observations across different lineages. Thirdly, we will employ guidelines recently proposed for the study of leaf venation (i.e., Ellis et al. 2009), to assess the incorporation of vein gauge as the determining factor of primary venation. Lastly, we will address the phylogenetic value of selected characters, as well as the evolution of venation patterns along the major clades of neotropical Vaccinieae through phylogenetic analyses.

\section{Methods}

\section{Leaf Clearings}

Taxon sampling.-A total of 33 species and 18 putative genera of Vaccinieae were studied (Table 1). Species exhibit different trends in leaf morphology, as well as represent the major clades so far recovered within Neotropical Vaccinieae (Kron et al. 2002a, Powel \& Kron, 2003). For example, selected taxa include members of the Disterigma (Klotzsch) Niedenzu s.s. clade (Pedraza-Peñalosa 2010b: 27), as well of two segregated Disterigma lineages (Pedraza-Peñalosa 2009, 2010a, 2010b). Tissue samples were taken from herbarium specimens deposited at the New York Botanical Garden (NY). Only complete, mature, and healthy leaves were selected for the clearing process. In the case of species with wide geographic distribution or with apparently variable venation patterns (based on literature and study of herbarium specimens), multiple populations were cleared. A total of 42 leaf samples were treated. Additionally, a few young leaves were cleared to check for age-related variation in selected species. 
TABLE 1. Species of Vaccinieae studied with their corresponding voucher specimens and GenBank accession numbers (ITS, matK, $n d h F) . \mathrm{m}=$ missing.

\begin{tabular}{|c|c|c|}
\hline Species & DNA sample (GenBank) & $\begin{array}{l}\text { Herbarium sample } \\
\text { at NY }\end{array}$ \\
\hline Anthopterus revolutus (Wilbur \& Luteyn) Luteyn & $\begin{array}{l}\text { Powell } 20 \text { (AY331866, AY331893, } \\
\text { AY331920) }\end{array}$ & Ramírez 13222 \\
\hline Anthopterus wardii Ball & $\begin{array}{l}\text { Luteyn } 15191 \text { (AF382656, AF382746, } \\
\text { AY331921) }\end{array}$ & Pedraza 1893 \\
\hline Cavendishia micayensis A.C.Smith & Luteyn 15171 (AF382659, AF382748, m) & Valenzuela 586 \\
\hline Ceratostema megabracteatum Luteyn & Luteyn 15037 (AF382661, AF382750, m) & Luteyn 15343 \\
\hline Ceratostema rauhii Luteyn & $\begin{array}{l}\text { Rauh } 68468 \text { (AY331871, AY331898, } \\
\text { AY331927) }\end{array}$ & Pedraza 1886 \\
\hline Demosthenesia mandonii (Britton) A.C.Smith & Luteyn 15433 (AF382664, AF382751, m) & Pedraza 1544 \\
\hline Demosthenesia spectabilis (Rusby) A.C.Smith & Luteyn 15474 (AF382665, AF382753, m) & Pedraza 1539 \\
\hline Diogenesia alstoniana Sleumer & Luteyn 15196 (AF382672, AF382759, m) & Luteyn 6868 \\
\hline Diogenesia racemosa (Herzog) Sleumer & $\begin{array}{l}\text { Luteyn } 15462 \text { (AF382673, AF382760, } \\
\text { AY331931) }\end{array}$ & Luteyn 15462 \\
\hline Disterigma agathosmoides (Weddell) Niedenzu & $\begin{array}{l}\text { Pedraza 1001/Luteyn } 15191 \text { (FJ001671, } \\
\text { KC175470, FJ001710) }\end{array}$ & Pedraza 1001 \\
\hline Disterigma parallelinerve Pedraza & Betancur $12532(\mathrm{KC} 175459, \mathrm{~m}, \mathrm{~m})$ & Luteyn 10684 \\
\hline Disterigma pentandrum S.F.Blake & $\begin{array}{l}\text { Pedraza 1201/Luteyn } 15085 \text { (FJ001693, } \\
\text { KC175465, FJ001733) }\end{array}$ & $\begin{array}{l}\text { Luteyn } 15085 \\
14701\end{array}$ \\
\hline Disterigma pseudokillipiella Luteyn & $\begin{array}{l}\text { Pedraza 1143, } 1066 \text { (FJ001694, KC175471, } \\
\text { FJ001735) }\end{array}$ & Pedraza 1617 \\
\hline Disterigma rimbachii (A.C.Smith) Luteyn & $\begin{array}{l}\text { Pedraza } 1018 \text { (FJ001695, KC175463, } \\
\text { FJ001736) }\end{array}$ & Pedraza 1018 \\
\hline Disterigma trimerum Wilber \& Luteyn & $\begin{array}{l}\text { Luteyn } 15568 \text { (FJ001700, KC175464, } \\
\text { FJ001741) }\end{array}$ & Luteyn 15568 \\
\hline Gaylussacia baccata K.Koch & Floyd $858(\mathrm{AF} 273713, \mathrm{~m}, \mathrm{~m})$ & Allen s.n. \\
\hline Gonocalyx costaricensis Luteyn & Luteyn 15228 (AF382678, AF382764, m) & Haber 10520 \\
\hline Gonocalyx megabracteolatus (Wilbur \& Luteyn) Luteyn & Luteyn 14817 (AF382682, AF382767, m) & van der Werff 6631 \\
\hline Macleania bullata Yeo & $\begin{array}{l}\text { Luteyn } 15724 \text { (AF382679, U89758, } \\
\text { AY331937) }\end{array}$ & $\begin{array}{l}\text { Pedraza } 1895 \\
\text { Luteyn } 13908\end{array}$ \\
\hline Macleania coccoloboides A.C.Smith & $\begin{array}{l}\text { Luteyn 15852A (AF382680, AF382765, } \\
\text { AY331938) }\end{array}$ & Pedraza 1890 \\
\hline Macleania cordifolia Benth. & $\begin{array}{l}\text { Pedraza 1884 (AY331877, AY331904, } \\
\text { AY331939) }\end{array}$ & Pedraza 1884 \\
\hline Macleania rupestris (Kunth) A.C.Smith & Pedraza 1879 (KC175462, m, KC175457) & Davidse 5537 \\
\hline Notopora schomburgkii Hook.f. & $\begin{array}{l}\text { Luteyn } 15275 \text { (AF382683, AF382768, } \\
\text { AF419728) }\end{array}$ & Steyermark 131992 \\
\hline Orthaea apophysata (Griseb.) A.C.Smith & van der Kloet 37694 (AF382685, AF382770, m) & Britton 1814 \\
\hline Orthaea venamensis Maguire, Steyermark \& Luteyn & Luteyn 15277 (AF382687, AF382772, m) & Luteyn 15277 \\
\hline Orthaea sp. 2 & $\begin{array}{l}\text { Luteyn } 15671 \text { (KC175460, KC175469, } \\
\text { KC175454) }\end{array}$ & Luteyn 15671 \\
\hline Pellegrinia coccinea (Hoerold) Sleumer & $\begin{array}{l}\text { Luteyn } 15646 \text { (KC175461, KC175468, } \\
\text { KC175453) }\end{array}$ & Luteyn 15646 \\
\hline Pellegrinia hirsuta (Ruiz \& Pavon ex G.Don) Sleumer & $\begin{array}{l}\text { Luteyn } 15644 \text { (KC175458, KC175466, } \\
\text { KC175455) }\end{array}$ & Luteyn 15644 \\
\hline Psammisia amazonica Luteyn & $\mathrm{m}, \mathrm{m}, \mathrm{m}$. & Argent 39 \\
\hline Psammisia sodiroi Hoerold & $\begin{array}{l}\text { Luteyn } 8021 \text { (AY331878, AY331905, } \\
\text { AY331943) }\end{array}$ & Holm-Nielsen 5969 \\
\hline Satyria boliviana Luteyn & $\begin{array}{l}\text { Luteyn 15481 (AF382693, AF382778, } \\
\text { AY331946) }\end{array}$ & Pedraza 1892 \\
\hline Themistoclesia sp. 1 & Luteyn 15653 (m, KC175467, KC175456) & Luteyn 15656 \\
\hline Vaccinium crenatum (G.Don) Sleumer & $\begin{array}{l}\text { Luteyn } 14171 \text { (AF382719, VCU89761, } \\
\text { AF419742) }\end{array}$ & Pedraza 1195 \\
\hline
\end{tabular}


Clearings. - The protocol is largely based on Ellis et al. (2009), with modifications from Ruzin (1999). Neotropical Ericaceae leaves, independent of their size or habitat, are difficult to clear and need longer soaking times than many other tropical groups. Leaves were treated with $10 \% \mathrm{NaOH}$ for $1-2$ weeks at $37^{\circ} \mathrm{C}$, with changes every three days or so. Thicker leaves that did not clear within reasonable time underwent additional treatment with Stockwell's bleach $(90 \mathrm{ml}$ water, $10 \mathrm{ml}$ glacial acetic acid, $1 \mathrm{gr}$ potassium dichromate, 1 gr chromic acid; Johansen 1940). Stockwell treatment varied from a few minutes to two hours. Although this solution accelerated the clearing process, its use was minimized as it strikingly weakened the tissue. Afterwards, leaves were treated with sodium hypochlorite until almost white (ca. $1 \mathrm{~min}$ ) and then were rinsed with tap water thrice.

Prior to staining, leaves were pretreated with $50 \%$ ethanol. Vascular tissues were stained with $1 \%$ acid fuchsin (3-8 $\mathrm{min})$. Then, leaves were dehydrated in a progressive series of ethanol solutions (50\%, 95\%, $100 \%$ ) and stored at $100 \%$ ethanol. To increase contrast, two drops of $\mathrm{HCl}(35 \%)$ were added. Prior to mounting, leaves were dehydrated with one bath of xylene/ethanol 1:1 and two baths of xylene (15 min each). Cleared leaves were mounted with permount.

Morphological assessment.-Morphological character definitions largely follow the leaf architecture manual by Ellis et al. (2009). Only mature leaves were described. The assessment of the main venation pattern based on leaf clearings was later contrasted with direct observations of herbarium specimens. Veins of leaf clearings were measured using a stereoscope and their gauge was determined at the point of divergence from the widest primary or at its widest point.

\section{Phylogenetic analyses}

Taxon sampling.-Only two species from the leaf clearings were not represented in the molecular data matrix. Sequence data from 32 terminals, belonging to 18 putatively different generic lineages, were analyzed (Table 1). Emphasis was placed on neotropical Vaccinieae (27 species and 15 putative generic lineages), the ingroup, mostly composed by species of Andean and Caribbean/Meso-American origin. Five species from the Americas, which are consistently resolved outside of the Caribbean/Mesoamerican and Andean clades (Kron et al. 2002a), were selected as outgroups. These taxa are more specifically distributed in North America [Gaylussacia baccata Koch (1872: 93)], Guyana Shield [Notopora schomburgkii Hooker (1876: 53), Orthaea venamensis Maguire et al. (1978: 174)], and the South American páramos [Vaccinium crenatum (Don 1834: 859) Sleumer (1935: 291)]. Trees were rooted with Gaylussacia baccata, which is basal with respect to all New World taxa (Kron et al. 2002a).

DNA extraction and sequencing.-A combination of nuclear (ITS, 637 aligned bp) and plastid (5' end of $n d h F$, ca. 1224 aligned bp; matK, 1331 aligned bp) markers were selected because of their high number of phylogenetically informative characters in previous studies (Kron et al. 2002a, Powell \& Kron 2003, Pedraza-Peñalosa 2009, 2010a). All procedures used during the DNA extraction and sequencing were already published in Pedraza-Peñalosa (2009). The material was sequenced on an ABI 377 XL automated sequencer and a 3730xl Capillary DNA Analyzer. Sequences were edited with Sequencher 4.5 (Gene Codes Corporation). Nineteen sequences were produced for this study (DTSA 033 SFF Galeras y otros; Acceso a Recursos Genéticos Res. 734 de 30 de Abril de 2007; 35-2005-INRENA-IFFS-DCB); all used sequences are available in GenBank (Table 1).

Analytical methods. - A multiple sequence alignment was produced with MUSCLE (Edgar 2004) and the model of sequence evolution was estimated with jModelTest 2 (Darriba et al. 2012, Guindon \& Gascuel 2003). Maximum Likelihood (ML) estimation of the phylogenetic relationships was conducted using two implementations. First, one thousand replicates with stepwise random taxon addition, starting MP trees, the GTRGAMMA model of evolution, and 1000 rapid bootstraps (BS) inferences (Stamatakis et al. 2008) were run in RAxML (Stamatakis 2006). Secondly, a traditional ML analysis with static characters was run in POY 5.0.1 Alpha (Varón et al. 2010), using the following search strategy: build (1000), swap (), select (), perturb (iterations:100, ratchet:(0.2,3)), fuse (iterations:200, swap()), select (), transform (likelihood:(gtr,rates:(gamma:(4)),priors:(estimate), gap:(missing), mal)), swap 
(spr,optimize:(model:(max_count:5),branch:join_region)), select (best:1). Nodal support was assessed through 1000 bootstrap replicates.

Morphological characters.-Ten morphological characters were selected for the analyses and polymorphisms were not excluded (Table 2). Characters were coded as non-additive (Appendix 1) and optimized over the combined tree using Fitch maximum parsimony algorithm (Fitch 1971), as implemented in Winclada (Nixon 2002).

TABLE 2. Description of morphological characters coded from the leaf clearings of Vaccinieae. For figures illustrating these characters see figures $5-37$.

0 . Primary vein framework: acrodromous (0), pinnate (1), parallelodromous (2), mixed (3). Determined by the course and gauge of the main veins. See discussion for detailed explanation. For examples see figures 7, 17, $21,27$.

1. Attachment of dominant lateral veins: basal (0), suprabasal (1). In acrodromous and mixed leaves, this refers to the attachment of the prominent lateral veins to the midvein. Inapplicable in pinnate and parallelodromous leaves. For examples see figures 8, 9.

2. Venation symmetry: symmetrical (0), asymmetrical (1). Comparison of the general distribution and course of secondary veins on each side of the midvein. Secondaries attached to the midvein with an alternating pattern are not considered the basis of asymmetry. For examples on asymmetry see figures 21,35 .

3. Secondary vein framework: broquidodromous (0), eucamptodromous (1), semicraspedodromous (2). In broquidodromous leaves, the tips of the secondary veins join the adjacent secondary vein forming loops of secondary gauge and without reaching the margin. In eucamptodromous leaves, major secondaries and their branches do not reach the margin and loss gauge by attenuation. In semicraspedodromous leaves, the secondaries branch dichotomously near the margin, one branch terminates at the margin, while the other joins the closest secondary. For examples see figures 14, 28, 37.

4. Highest vein order: (integer). Category of the finest venation framework, that is, the order of Freely Ending Veinlets (FEVs).

5. FEVs idioblast presence: absent (0), present (1). FEVs usually have a group of distinctive sclerotized cells—or idioblast—at their tips. For examples see figures 11, 33.

6. FEVs terminal shape: clavate (0), oblong (1), tapering (2). Independent of the presence of idioblasts. For examples see figure 34 for clavate; 7 and 15 for oblong; and 19 and 11 for tapering.

7. FEV s branching pattern: simple (0), branched (1). FEVs can remain unbranched or branch one or more times. For examples see figures 14, 31.

8. Laminar glands presence: absent (0), present (1). Glandular tissue can be observed on the abaxial surface of the lamina, in the form of darkened spots. Glands are evenly distributed across the entire lamina or are largely restricted to the basal quarter of the leaf. For examples see figures 5, 24, 33.

9. Marginal glands presence: absent (0), present (1). Glandular tissue is embedded in the very margin of the lamina, right at the junction with the petiole, or in the petiole itself. These glands appear as either protruding bodies or as hemicircular, and usually torn, shapeless notches. For examples see figure 29. 


\section{Results}

The results of the direct measurements and phylogenetic analyses are illustrated in figures 1-3; observations from living material supporting the anatomical findings are also included (fig. 4). The venation patterns are described and fully illustrated for all species in figures 5-37. The following is a summary of the general trends observed.

\section{Patterns of leaf venation}

Within species, venation pattern neither varied with age (mature vs. younger leaves), nor across populations. In the few polymorphic species, variation was often confined to a single character and observed only in one or two specimens; therefore, although present, polymorphisms were rare and not problematic for species characterization.

Midvein and prominent-basal lateral vein diameters, obtained from direct measurements of the leaf clearings, varied continuously across all studied species and no obvious discontinuity was observed between the gauge of the midvein and basal lateral veins (fig. 1). Consequently, the prominent-lateral/midvein diameter ratio was not used to discriminate between the presence of one or more primary veins.

As for other higher order venation patterns, almost all sampled taxa had broquidrodomous secondary venation. However, other patterns were also observed such as semicraspedodromous (Vaccinium crenatum, fig. 37) and eucamptodromous [Disterigma agathosmoides (Weddell 1860: 179) Niedenzu (1889: 224), fig. 14; D. pentandrum Blake (1926: 364), fig. 16, note that this species is polymorphic for this character with also broquidodromous leaves].

More variation was found at smaller venation orders. Freely Ending Veinlets (FEVs) are usually the veins with the finest gauge and correspond to the highest venation order. As its name indicates, FEVs have a free termination and do not cross the areoles that contain them. In general, most of the sampled species had FEVs corresponding to the fourth order (16 out of 30 species). FEVs were either unbranched or branched within the same leaf. Their terminations were clavate in most of the species (17 spp.), but oblong or tapering FEVs were also recorded. FEVs bearing tracheoid idioblasts (with enlarged tracheal cells) at the apex were also common [e.g., Macleania bullata Yeo (1967: 47), Orthaea sp. 2; figs. 23, 30, respectively]. A few species had simple FEVs without sclerotized idioblasts with the vein final extremity widening (e.g., Ceratostema rauhii Luteyn (1922: 314), Pellegrinia hirsuta (Ruiz \& Pavon ex Don 1834: 863) Sleumer (1935: 288); figs. 9, 32, respectively) or tapering (e.g., Demosthenesia spectabilis (Rusby 1907: 404) Smith (1936: 311), fig. 11). Only in Disterigma paralellinerve Pedraza-Peñalosa (2010b: 93) (fig. 15), Disterigma pseudokillipiella Luteyn (1996: 285) (fig. 17), Disterigma pentandrum (fig. 16), Disterigma rimbachii (Smith 1935: 130) Luteyn (1996: 258) (fig. 18), and Gonocalyx costaricensis Luteyn (1976a: 40) (fig. 21) the FEVs had the tendency to be oriented toward the base of the leaf. Although the latter character was recorded in species with similar external morphology (growth form, leaf size, etc.), most of them represent different lineages (PedrazaPeñalosa 2009, 2010a, 2010b).

\section{Foliar glands}

Glands in the leaves were observed in $26 \%$ of the studied species. Glands are mostly laminar (fig. 33) and mainly restricted to the basal quarter of the leaf (basilaminar) (fig. 5), or marginal in Orthaea venamensis (fig. 29) and O. apophysata (Grisebach 1859: 143) Smith (1932: 516). Basilaminar or marginal glands were observed in up to three pairs, with three pairs of glands being very rare. Marginal glands were located at the lamina base, close to the petiole or sometimes on the petiole itself. In dried specimens of $O$. venamensis, these marginal glands were inconspicuous, hemicircular, and usually torn, resembling a small, shapeless notch (fig. 29). Whereas, in O. apophysata, the marginal glands are similar to those of O. venamensis or sometimes are like protuberances embedded in the tissue, somehow resembling the glandular cap of a theoid teeth.

Basilaminar glands are usually small, rounded to elliptic, and brown to black in herbarium material. The much larger basilaminar glands of the species of Anthopterus Hooker (1840: plate 243) were vascularized, particularly concave, with a defined edge in both herbarium specimens and leaf clearings (figs. 5, 6). 
However, in Themistoclesia sp. 1, though the glands are externally rounded and well defined in herbarium material, in the leaf clearings they were not clearly vascularized and instead were surrounded by a diffuse mesophyll that stains dark pink and is probably glandular in nature (fig. 36).

Other laminar glands were evenly distributed throughout the entire abaxial surface of the leaf and were noticeable in both fresh and dried specimens. These glands were numerous and rounded, but very small and with blurred edges; thus, they have been largely overlooked in descriptive works. Laminar glands can be vascularized or not, and both types can even co-occur within the same leaf [e.g., Psammisia amazonica Luteyn (1987: 117), fig 33].

\section{Phylogenetic analyses}

Each marker was separately analyzed and no topological incongruence was found (trees not shown). Each separate marker, as well as the combined plastid and chloroplast analyses coincided in recovering, with high bootstrap support, the three main clades formed by taxa native to the Neotropics. For that reason the results and discussion will focus on the most likely tree obtained from the combined analysis (figs. 2, 3).

Both RAxML and POY 5.0.1 Alpha analyses converged to nearly identical topologies and discrepancies were only found in the placement of a few taxa. However, it must be noted that none of the alternative placements have bootstrap support $>50 \%$ and therefore, they are not of great significance. In fact, the position of the disputed clade, Disterigma s.s. (fig. 2), remained unresolved even after exhaustive analyses of both molecular and morphological evidence under 29 different transformation cost matrices and using a much larger dataset (Pedraza-Peñalosa 2010a). Thus, disagreement in the placement of this clade between implementations is not surprising. The remaining differences were minor and concerned with the relationships of Psammisia Klotzsch (1851: 42), Ceratostema Jussieu (1789: 163), and Macleania Hooker (1837: plate 109), which were paraphyletic in POY's most likely tree while in RAxML they resulted as sister taxa(Ceratostema (Psammisia, (Macleania)) - however, both placements had low support.

The topology of both reconstructions is highly congruent and both analyses have similar bootstrap values, however, as RAxML reconstruction has a slightly higher likelihood score ( $\ln L=-8817.105059$ vs. 8822.18034066 in POY 5.0.1 Alpha), we will use it for the character reconstruction. Nevertheless, it must be clarified that identical scores between these implementations are not expected given differences in the numerical approach. They were here both employed more in the spirit of independent inference corroboration.

The most basal clade corresponds to the sampled species of extra-neotropical origin from the Guyana Shield (Orthaea spp. and Notopora schomburgkii), along with Vaccinium crenatum, a high-altitude species from the páramos (alpine-like vegetation) of South America (fig. 2). This morphologically heterogeneous group is sister to the neotropical clade, which comprises a large Andean clade, sister to a much smaller Mesoamerican/Caribbean clade. In general, this topology and that obtained for the less inclusive clades both agree with the findings of published studies at the tribal, Andean, and generic levels (Kron et al. 2002a, Powell \& Kron 2003, Pedraza-Peñalosa 2009, 2010). The only major difference was found in the position of the clade containing representatives of Anthopterus, Diogenesia Sleumer (1934: 121), Themistoclesia Klotzsch (1851: 41), and Demosthenesia Smith (1936: 310), which in previous studies was basal to the clade containing Cavendishia Lindley (1836: sub plate 1791) (Powell \& Kron 2003, Pedraza-Peñalosa 2009, 2010a), whereas in this analysis they are sister taxa. However, one should be careful when interpreting these differences because the taxon sampling employed here is limited and has a purpose different from that of solving generic placement.

Sampled species of Pelligrinia Sleumer (1935: 279) are monophyletic (fig. 2) and related to Demosthenesia, the only analyzed species of Themistoclesia (an undescribed species) and some representatives of Diogenesia. The latter genus was found to be non-monophyletic, with Diogenesia racemosa (Herzog 1915: 22) Sleumer (1978: 256) apparently more closely related to Demosthenesia (but with low bootstrap support) than to other sampled members of the genus. All the aforementioned taxa are restricted to the Central Andes (Bolivia and Peru), and the Colombian species, Diogenesia alstoniana Sleumer (1978: 257), is basal to all of them. 
A phylogenetic position is here suggested for the first time for Pelligrinia, a small genus endemic to Peru. Smith (1936), who erected Demosthenesia, thought that some species of Pelligrinia and Demosthenesia closely resembled each other, however he hypothesized that their common characters had arisen independently. Thus far, our data supports this assertion given that they are not sister groups; however, sampling and bootstrap support are still a limiting factor and more species/lineages need to be analyzed before drawing definitive conclusions.

\section{Discussion}

\section{Recognizing venation patterns}

The recognition of vein orders, or hierarchic categories, is the first step in describing venation patterns. Veins of the same order are expected to have similar developmental origin and function. When several prominent veins originate near the leaf base, the diameter ratio between the midvein and the prominent lateral veins has been traditionally used as the criterion to determine the number of primary veins present. Ellis et al. (2009) proposed the 0.75 ratio as the operational cut off; thus, any basal vein $\geq 75 \%$ the gauge of the midvein is considered a primary vein too. However, the distribution of the prominent-lateral lateral/midvein diameter ratio obtained from the leaf clearings of Vaccinieae did not support the proposed cut off diameter ratio. In fact, no discontinuity was observed in the distribution of that diameter ratio, instead, it varied continuously across all studied species (fig. 1).

Given that the prominent-lateral/midvein diameter ratio cannot be objectively employed to establish the presence of more than one primary vein in Vaccinieae - that is, whether the primary framework is palmate or pinnate-we invoke Hickey's (1973) classification of the architecture of dicotyledonous leaves in which acrodromous leaves do not need to have more than one primary vein. Under this concept acrodromous leaves are those with one or more pairs of veins running in convergent arches and these can be either primary or strongly developed secondary veins. In the case of the species studied here, almost all fit the acrodromous pattern with the caveat that all the lateral, basal, and prominent veins are considered secondaries because they are different from the midvein in both diameter and course. The only exception found is Disterigma agathosmoides (fig. 14), in which the prominent basal veins are also considered primary veins as they have a gauge almost identical to that of the midvein. This species is one of the smallest-leaved neotropical Vaccinieae [lamina (2.8-)3.2-9(-11) $\times(0.4-) 0.8-2(-2.6) \mathrm{mm}$ ] and has its entire venation practically reduced to three equally thick primary veins.

Primary frameworks.-In the 18 phylogenetically distinct generic lineages of Vaccinieae studied, the primary venation can be defined as follows:

1. Simple pinnate: secondary veins emerging more or less perpendicularly along the entire length of a dominant midvein and pointing toward leaf margins; secondaries relatively evenly spaced. Examples: Notopora schomburgkii (fig. 27), Psammisia sodiroi Hoerold (1909: 306) (fig. 34).

2. Acrodromous: one or more pairs of prominent, basal secondary veins, or primary veins-like in the case of Disterigma agathosmoides - running in convergent arches toward the leaf apex. These prominent veins are concentrated in the basal third of the leaf lamina and are seldom present in the lamina's midsection or apex. Acrodromous venation is called basal when the midvein and the prominent secondary veins originate at the leaf base (D. agathosmoides; fig. 14) or suprabasal when they originate slightly above the base (e.g., $D$. rimbachii, Macleania bullata, Psammisia amazonica; figs. 18, 23, 33). Suprabasal acrodromous and plinerved framework are considered equivalent terms. However, plinerved has been traditionally employed in neotropical Vaccinieae to describe the presence of prominent basal lateral veins, independently of their point of origin (see Luteyn 1976b, 1983, 1996).

3. Parallelodromous: midvein and prominent secondary veins running parallel to each other. The parallelodromous Vaccinieae so far sampled represent a special case of parallel venation in which the prominent secondary veins do not diverge from a single point, but instead originate through a series of 
branching events (i.e., Disterigma parallelinerve, D. pseudokillipiella; figs. 15, 17, respectively). Parallelodromous venation has not been formally recognized before in neotropical Vaccinieae, although Pedraza-Peñalosa (2010b) noted that the leaves of $D$. pseudokillipiella have parallel veins abaxially. In general, the venation of these species has been mistakenly described as plinerved.

4. Mixed venation: a characteristic mixture between acrodromous and pinnate patterns was found across different lineages of Vaccinieae and was also easily observed in herbarium specimens. Melville (1976) in his revision of angiosperm leaf terminology proposed the term "palmati-pinnate" for leaves with leaves that are palmate in the base and pinnate in the apex. In neotropical Vaccinieae with mixed venation, the basal half of the leaf has pairs of arching and prominent lateral veins. However, contrary to typical acrodromous venation, secondary veins are also present in the apical and mid sections of the leaf and they are more or less evenly spaced and with the orientation of a secondary in a pinnate leaf (figs. 21,35). Mixed venation has not been formally recognized before in descriptive studies of neotropical Vaccinieae, perhaps causing part of the current ambiguity and difficulty in describing venation patterns.

Macleania rupestris (Kunth in Humboldt et al. 1818: 270) Smith (1935: 131) and M. coccoloboides Smith (1952: 69) have polymorphic primary venation and such polymorphism was also evident in herbarium specimens throughout their entire range. Although polymorphism was not found outside of Macleania, not all the species within the group have polymorphic primary venation.

As for the use of the more traditional primary vein frameworks here also recognized, pinnate venation is a rather straightforward concept that has been used consistently, probably across all Ericaceae. However, as pointed out earlier, acrodromous venation has been loosely defined and its concept ambiguously applied. In fact, to avoid ambiguity and the uncertainty of defining venation patters in the absence of studies of cleared leaves, in the classic taxonomic literature, oftentimes the pattern of primary vein framework was not described and the venation description was reduced to simply counting the number of main veins at the base of the leaf (see Sleumer 1941).

In the literature, the term plinerved has been used to describe leaves with more than one prominent vein at the base (Smith 1932, Luteyn 1996). The more specific terms triplinervis (triplinerved, 3-plinerved) or quintuplinervis (5-plinerved) designate leaves with one or more pairs of prominent veins that emerge from the midvein above the base (Moreno 1984, Stern 1992, Font Quer 1993, Harris \& Harris 1999). Luteyn (e.g. Luteyn 1996) used plinerved in a broader sense, also including cases in which all basal veins originate at the base (i.e., trinerved), therefore, Luteyn's interpretation of that term should be understood as acrodromous s.l. In this study, we advocate for a distinction between basal and suprabasal acrodromous venation attempting to add more precision to description and avoiding further ambiguities.

Secondary framework.- The secondary venation is predominantly broquidodromous (independently of the primary pattern) with the secondaries branching into multiple sets of loops of secondary gauge (festooned brochydodromous sensu Ellis et al., 2009) (fig. 24). Basal secondaries festoon more profusely than distal secondaries. Intersecondary veins were observed in several pinnate-leaved species (and only in acrodromous Orthaea sp. 2), though they are not numerous when present.

The prominent basal lateral veins of acrodromous and parallelodromous leaves diverge at more acute angles (compared to the most basal secondaries) and have a distinctive ascending course that runs more or less parallel to the margin, almost reaching the leaf apex. Also, in acrodromous and parallelodromous leaves, secondaries do not occur along the entire midvein, they are rather restricted to the basal half of the lamina (fig. 17).

In pinnate leaves secondary veins are usually evenly distributed and have a similar course and insertion angle (e.g. Psammisia sodiroii, fig. 34). Variation of this general pattern occurs when a basal pair of secondaries stands out because of its ascending course as in Anthopterus revolutus (Wilbur \& Luteyn 1981: 164) Luteyn (1996: 387) (fig. 5) and Pellegrinia coccinea (Hoerold 1909: 317) Sleumer (1935: 288) (fig. 31); this is reminiscent of the acrodromous framework, but it is not accompanied by gauge variation.

Tertiary framework.-Tertiary veins in neotropical Vaccinieae commonly branch and form intertwining networks. Intercostal veins are usually present and run perpendicularly to the veins that originate them. However, patterns of tertiary venation are diverse across taxa and also include cases in which: 
a) tertiary veins are free and branch without anastomosing or forming areoles (e.g., D. rimbachii, tertiaries are mostly basiscopic, fig. 18). In Ceratostema rauhii, tertiary veins occasionally intertwine forming large and inconspicuous areoles (fig. 9).

b) tertiaries of parallelodromous leaves are also parallel and form networks; areoles are then narrow and longitudinally oriented (Disterigma parallelinerve, D. pseudokillipiella; figs. 15, 17, respectively).

The distal shape of the FEVs and the presence of associated idioblasts seem to be characteristic of certain clades, independent of the categorical complexity of the network. Unfortunately, undamaged leaf clearings are absolutely necessary to properly observe these fine characters and further study them.

Two species have sheathed veins or veins with aggregated accompanying cells. In Gaylussacia baccata, the FEVs are covered by a continuous, single layer of thick-walled, anisodiametric cells. On the other hand, Notopora schomburgkii has aggregated spherical cells that cover the entire venation, regardless of the vein order, but only on the adaxial side of the leaf (fig. 27). Unlike sheathing cells, the aggregated cells of $N$. schomburgkii are spherical and extremely thick-walled, to the point of staining dark pink. This feature has also been reported in other tribes of Ericaceae, however, to our knowledge is restricted to the subfamily Vaccinioideae [i.e. Pernettya Gaudichaud \& Mirbel (1825:102), Leucothoë Don (1834: 59), and Lyonia Nuttall (1818: 266)] (Rao \& Chakraborti 1985).

Observable patterns in herbarium material.-When the herbarium specimens were reexamined, it was possible to assign them to each one of the primary venation types described from the leaf clearings. The exceptions were species with leaves more coriaceous than usual (most neotropical Ericaceae are characterized by coriaceous leaves) and those somewhat succulent. Coriaceous/succulent samples required more aggressive treatments for clearing, resulting in some tissue damage or still unsatisfactory clearings (e.g. Disterigma pentandrum, Orthaea apophysata, Themistoclesia sp. 1). Secondary venation was still very hard to characterize despite the increased understanding of underlying patterns. The general features of the prominent basal secondaries were observable, but not always did all secondaries manifest in herbarium material. In general, secondary veins are better observed in young leaves, especially on their adaxial surface, while higher venation orders are not usually evident.

\section{Foliar glands}

Although the study of foliar glands was beyond the aim of this project, leaf clearings facilitated their observation. Extra-floral nectaries are not mentioned in descriptions of neotropical Vaccinieae and glands are seldom mentioned, even when prominent on the specimens. With the leaf clearings, it became apparent that they are much more common than previously thought and that they are differentiated into different types.

Although the ecological role of laminar glands has not been studied in Neotropical Vaccinieae, it can be anticipated they provide protection against herbivores. Extrafloral nectaries have been reported to increase defensive strategies in several groups of plants, particularly in arid ecosystems or in the canopy of tropical rainforests (Blüthgen et al. 2000, Schoereder et al. 2010). In the case of neotropical Vaccinieae, groups with and without glands co-occur in the same type of habitats, being those high or low altitude cloud forests, premontane forests, páramos, punas, savannas, or tepuis tops, thus their occurrence or type of gland does not seem to be associated with environmental factors. Sugar-rich secretions from extrafloral nectaries facilitate mutualistic relations between plants and ants, and in some cases aphids as well (Blüthgen \& Reifenrath 2003, Katayama \& Suzuki 2010). In some plants, diversification has been driven by these glandular structures, serving as key innovations that have triggered adaptive radiations (e.g., see Marazzi \& Sandaerson 2010).

The vascularized glands recorded in the leaf clearings could be associated with nectar secretion and in fact, Macleania pentaptera Hoerold (1909: 299) has been observed producing abundant sugary secretions in indoor conditions (fig. 4). It is very likely that the presence of these rather inconspicuous extra-floral nectaries has passed undetected because of the humid conditions and constant rain that characterize the habitat of Vaccinieae, where plants are often damp or wet. 


\section{Evolution of venation patterns}

Most of the coded characters are homoplastic and the venation characters that support robust clades are scattered through different hierarchical levels. The discussion will be mostly centered on clades with moderate to high support (above 70\% BS), emphasizing on the evolution of the major trends.

Pinnate venation (e.g. figs. 27, 34) is the most ancestral primary framework and acrodromous venation (e.g. figs. 14, 18, 23, 33) supports the neotropical clade of Vaccinieae (char. 0, all optimizations; 98\% BS) (figs. 2, 3); this character is homoplastic as it is also present in Orthaea apophysata (fig. 28), a species of extra-neotropical origin from the Guyana shield (fig. 2).

Although most neotropical Vaccinieae do have acrodromous primary framework, several transformations occurred within the clade (figs. 2). A reversal to pinnate primary framework arose in Pelligrinia (char. 0, all optimizations; 99\% BS) (figs. 2, 3, 31, 32), whereas parallelodromous venation appears to be exclusive of the Disterigma parallelinerve-D. pseudokillipiella clade (char. 0, non-homoplastic; 72\% BS) (figs. 2, 3, 15, 17). No other parallelodromous Vaccinieae are known to us in the Neotropics, but similarly looking venation occurs in the distantly related tribe Styphelieae (Ericaceae: Styphelioideae).

Mixed primary venation evolved independently in Gonocalyx costaricensis, from the Mesoamerican/ Caribbean clade, and in Satyria boliviana Luteyn (1987: 124) (char. 0, for both) (figs. 2, 3, 21, 35), a species from the Central Andes that has been proposed to be excluded from the Satyria s.s. clade based on molecular data (Kron et al. 2002a). The venation of the leaves of these two mixed species is also longitudinally asymmetric (figs. 21,35), with part of the secondaries exhibiting slightly different courses on each side of the lamina; however, mixed venation and asymmetry do not seem to be correlated as asymmetric leaves also occur in acrodromous and pinnate leaves.

Polymorphism in the primary vein framework is rare, but consistent in Macleania rupestris and $M$. coccoloboides (fig. 2); the pinnate form is apparently more common in M. rupestris, while acrodromous leaves seem to dominate $M$. coccoloboides.

The attachment of the prominent lateral veins of acrodromous leaves (char. 1) is mainly suprabasal (e.g. fig. 8) and only reversed once within the Andean clade. Under fast optimization, suprabasal attachment supports the Orthaea-Cavendishia-Anthopterus-Diogenesia-Pellegrinia-Demosthenesia-Themistoclesia group (94\% BS) (fig. 3).

Venation with four orders of vein hierarchy (char. 4) has four independent origins along the tree and in almost all cases it diagnoses a well-supported node: the Andean Macleania (97\% BS), the páramo-Guyana shield clade (98\% BS), and Gonocalyx Planchon \& Linden (1856: 152) (96\% BS) (figs. 2, 3). More complex venation patterns were reveled in the Psammisia-Ceratostema-Macleania clade (93\% BS) (figs. 2, 3), diagnosed by venation with 5 orders, the highest recorded for the study group.

Gonocalyx, within the well-supported Mesoamerican/Caribbean clade, is also diagnosed by the presence of idioblasts at the tip of FEVs (char. 5) (figs. 3, 21, 22). Idioblasts are also characteristic of the species of Orthaea Klotzsch (1851: 23) from the Guyana shield (figs. 29, 30). This last clade is also diagnosed by FEVs distally clavate (char. 6), a shape that represents a reversal from the tapering form that is diagnostic of the entire páramo-Guyana shield clade that contains Orthaea. Although FEVs morphology is diverse in Vaccinieae and characteristic of some groups, the shape of the termination of the FEVs is homoplastic. For example, oblong FEVs are diagnostic of both Disterigma s.s. (100\% BS) and the D. rimbachii-D. pentandrum clade (100\% BS), two phylogenetically unrelated lineages (char. 6) (fig. 3). Nevertheless, Disterigma s.s. is further diagnosed by FEVs that are predominantly non-branching (char. 7). Disterigma rimbachii and $D$. pentandrum were segregated from Disterigma s.s. (Pedraza-Peñalosa 2010b) and are likely to represent an undescribed genus; however, their exact phylogenetic placement within the Andean clade remains uncertain (Pedraza-Peñalosa 2009, 2010a).

As for the remainder of the well-supported clades with diagnostic morphological characters, these are characterized by the gain or loss of glandular bodies. Glands dispersed in the lamina (e.g. fig. 33) or concentrated in its basal quarter (e.g. figs. 5, 6) are the most common type recorded. These laminar glands are more or less circular, often small (but characteristically prominent in some Anthopterus, figs. 5, 6) and in 
herbarium specimens have darker colorations. Their presence (char. 8) is diagnostic of the AnthopterusDiogenesia-Pellegrinia-Demosthenesia-Themistoclesia clade (93\% BS) (fig. 3). In this large clade, glands are concentrated toward the base of the leaves and better described as basilaminar; only in Diogenesia alstoniana they are dispersed in the basal half of the lamina. Although glandular bodies are characteristic of the large clade that contains Pellegrinia Sleumer (1935: 279) and Demosthenesia (99\% and 81\% BS, respectively), they are absent in these genera. These two taxa from the Central Andes are present in the same kind of humid, montane ecosystems that are preferred by their Andean counterparts with glands.

In the Vaccinieae in general, at least three independent origins of laminar glands were uncovered (char. 8; fig. 3), spanning all major clades, except for the Mesoamerican/Caribbean group. Glands are present throughout the entire lamina of Psammisia sodiroi (and of other species of Psammisia as well) (figs. 33, 34), toward the base of the leaves of one the Guyanese species of Orthaea studied (figs. 28, 29), and in members of the Anthopterus-Diogenesia-Pellegrinia-Demosthenesia-Themistoclesia clade (e.g. fig. 12).

Marginal glands (char. 9) are characteristic of the species of Orthaea from the Guyana shield (100\% BS, figs. 28, 29), and this is one of the few characters that is non-homoplastic (figs. 2, 3). The position and morphology of these glands seems to be unique to this group and so far the strongest morphological character that may help to differentiate among the clades that make up this polyphyletic genus. In this respect, it is worth noting that glands in general are characteristically absent in the Orthaea of Andean origin (fig. 30).

\section{Conclusions}

The course of the most prominent veins of a leaf is the best criterion to define the primary vein pattern of Vaccinieae, as the ratio of the gauge of the most prominent-lateral veins and the midvein cannot, be used to establish the presence of multiple primary veins unambiguously. Clearly, an even greater array of venation patterns needs to be studied before any generalizations can be drawn for the classification of venation patterns of all vascular plants.

Four primary venation frameworks are defined here for neotropical Vaccinieae: pinnate, acrodromous, parallelodromous and mixed. Pinnate venation is the most basal framework and acrodromous venation, which supports the Caribbean/Mesoamerican and Andean clades, and characterize the majority of the studied Vaccinieae, is derived within the tribe. Acrodromous venation also evolved independently in taxa from the Guyana shield. However, future studies should also include Vaccinieae from the Old World to further test the origin of acrodromous patterns.

Parallelodromous and mixed venation in neotropical Vaccinieae have not been formally recognized until now, perhaps causing some of the ambiguity observed in the description of venation patterns. Parallelodromous leaves are strongly diagnostic, but of rare occurrence; they seem to be restricted to Disterigma s.s. and are a synapomorphy of the Disterigma parallelinerve-D. pseudokillipiella clade. Mixed venation within a single leaf represent a mixture attributes similar to those of acrodromous and pinnate frameworks; nevertheless, phylogenetically speaking, mixed venation does not represent an intermediate state between acrodromous and pinnate leaves, but rather a distinct pattern with two independent origins within the neotropical clade.

There is less variation in the secondary framework as the great majority of the taxa are broquidodromous and festooned and only a few characters of phylogenetic utility where identified at this level. More morphological variation was found among tertiary veins, but most specifically among the veins of the highest order.

While primary venation can be also determined with the appropriated herbarium material, except for species with extremely coriaceous and/or succulent leaves, leaf clearings are instrumental to the study of detailed venation patterns. Despite the fact that homoplasy was found in many venation characters, these serve to characterize major clades and radiations within neotropical Vaccinieae. Moreover, leaf clearings also revealed novel and promising characters, which their further study will be very helpful to the understanding of 
the morphological analysis of polyphyletic genera. Such is the case of the unique marginal glands found in the Orthaea of extra-neotropical origin (glands absent in Andean Orthaea), a character until now unknown. Glands in general have been routinely overlooked in Vaccinieae; leaf clearings have shown that they are evolutionary informative and that could be more diverse than described here.

Neotropical Ericaceae have well defined ecological restrictions and many species of different genera cooccur in places with the appropriated climatic conditions. Thus, no correlations between environment and venation patterns could be made at the time and at the large taxonomical scale here employed. However, future studies should address whether there are not environmental correlations with genera or specific lineages.

\section{Acknowledgements}

We are grateful to: Marcela Thadeo and Alejandra Vasco who provided valuable training in anatomy and sample preparation techniques; Douglas Daly for providing insightful discussion on venation patterns and leaf clearing techniques; the Structural Botany Laboratory at the New York Botanical Garden and to Lisa Campbell for providing materials; the Science Computer Cluster Facility at the American Museum of Natural History and Nicholas Lucaroni for access to the computer cluster and helping with analytical issues; and to the reviewers and editor for their valuable input. This research was partially funded by the National Science Foundation DDIG 0607528.

\section{References}

Blake, S.F. (1926) Notes on Disterigma. Journal of the Washington Academy of Sciences 16: 361-365.

Blüthgen, N. \& Reifenrath, K. (2003) Extrafloral nectaries in an Australian rainforest: structure and distribution. Australian Journal of Botany 51: 515-527. http://dx.doi.org/10.1071/BT02108

Blüthgen, N., Verhaagh, M., Goitía, W., Jaffé, K., Morawetz, W. \& Barthlott, W. (2000) How plants shape the ant community in the Amazonian rainforest canopy: the key role of extrafloral nectaries and homopteran honeydew. Oecologia 125: 229-240.

Darriba, D., Taboada, G.L., Doallo, R. \& Posada, D. (2012) jModelTest 2: more models, new heuristics and parallel computing. Nature Methods 9: 772.

Don, D. (1834) An attempt at a new arrangement of the Ericaceae. Edinburgh New Philosophical Journal 17(33): 150160.

Don, G. (1834) A general history of the dichlamydeous plants: comprising complete descriptions of the different orders...the whole arranged according to the natural system 3. J.G. \& F. Rivington et al., London, pp. 1-867.

Edgar, R.C. (2004) MUSCLE: a multiple sequence alignment method with reduced time and space complexity. $B M C$ Bioinformatics 5: 113.

Ellis, B., Daly, D.C., Hickey, L.J., Johnson, K.R., Mitchell, J.D., Wilf, P. \& Wing, S.L. (2009) Manual of leaf architecture. Cornell University, Ithaca, $190 \mathrm{pp}$.

Fitch, W.M. (1971) Toward defining the course of evolution: minimum change for specific tree topology. Systematic Zoology 20: 406-416. http://dx.doi.org/10.2307/2412116

Font Quer, P. (1993) Diccionario de botánica. Editorial Labor S. A., Barcelona, 1244 pp.

Gaudichaud, M. \& Mirbel, M. (1825) Rapport sur la flore de iles Malouines. Annales des Sciences Naturelles (Paris) 5: 89-110.

Grisebach, A.H.R. (1859) Flora of the British West Indian Islands 2. L. Reeve \& Co., London, 789 pp.

Guindon, S. \& Gascuel, O. (2003) A simple, fast and accurate method to estimate large phylogenies by maximumlikelihood. Systematic Biology 52: 696-704.

Harris, J.G. \& Harris, M.W. (1999) Plant identification terminology: an illustrated glossary. Spring Lake, Payson, Utah, $98 \mathrm{pp}$.

Herzog, T. (1915) Die von Th. Herzog auf seiner zweiten Reisen durch Bolivien in den Jahren 1910 und 1911 gesammelten Pflanzen, II. Mededeelingen van 's Rijks-Herbarium 27: 1-90. 
Hickey, L.J. (1973) Classification of the architecture of dicotyledonous leaves. American Journal of Botany 60: 17-33. http://dx.doi.org/10.2307/2441319

Hoerold, R. (1909) Systematische Gliederung und geographische Verbreitung der amerikanischen Thibaudieen. Botanische Jahrbücher für Systematik, Pflanzengeschichte und Pflanzengeographie 42: 251-334.

Hooker, W.J. (1837) Icones Plantarum 2(3). Longman, Rees et al., London, pp. 101-150.

Hooker, W.J. (1840) Icones Plantarum 3(5). Longman, Rees et al., London, pp. 201-250.

Hooker, J.D. (1876) Icones Plantarum 12. Longman, Rees et al., London, pp. 1-90.

Humboldt, A. von, Bonpland, A. \& Kunth, K.S. (1819) Nova genera et species plantarum (quarto ed.) 3. Librairie Grecque-Latine-Allemande, Paris, pp 263-294.

Johansen, D.A. (1940) Plant microtechnique. McGraw-Hill Book Company, New York, 523 pp.

Jordan, G.J., Bannister, J.M., Mildenhall, D.C., Zetter, R. \& Lee, D.E. (2010) Fossil Ericaceae from New Zealand: deconstructing the use of fossil evidence in historical biogeography. American Journal of Botany 97: 59-70. http://dx.doi.org/10.3732/ajb.0900109

Jussieu, A.L. de (1789) Genera plantarum secundum ordines naturales disposita, juxta methoclum in horto regio parisiensi exaratum. Viduam Herissant and Theophilum Barrois, Paris, 498 pp.

Katayama, N. \& Suzuki, N. (2010) Extrafloral nectaries indirectly protect small aphid colonies via ant-mediated interactions. Applied Entomology and Zoology 45: 505-511. http://dx.doi.org/10.1303/aez.2010.505

Klotzsch, J.F. (1851) Studien über die natürliche klasse Bicornes Linné. Linnaea 24: 1-88.

Koch, K. (1872) Zweite Abtheilung. Pflanzen mit einblätteriger blumenkrone. Monopetaleae. In: Koch, K. (ed.) Dendrologie, 2. Ferdinand Enke, Erlangen, 1-665.

Kron, K.A., Judd, W.S. \& Crayn, D.M. (1999) Phylogenetic analyses of Andromedeae (Ericaceae subfam. Vaccinioideae). American Journal of Botany 86: 1290-1300.

Kron, K.A., Powell, E.A. \& Luteyn, J.L. (2002a) Phylogenetic relationships within the blueberry tribe (Vaccinieae, Ericaceae) based on sequence data from $m a t K$ and nuclear ribosomal ITS regions, with comments on the placement of Satyria. American Journal of Botany 89: 327-336. http://dx.doi.org/10.3732/ajb.89.2.327

Kron, K.A., Judd, W.S., Stevens, P.F., Crayn, D.M., Anderberg, A.A., Gadek, P.A., Quinn, C.J. \& Luteyn, J.L. (2002b) Phylogenetic classification of Ericaceae: molecular and morphological evidence. Botanical Review 68: 335-423. http://dx.doi.org/10.1663/0006-8101(2002)068[0335:PCOEMA]2.0.CO;2

Lindley, J. (1836) Edward's Botanical Register 21. James Ridgway and sons, London, pp. 1742-1828.

Luteyn, J. L. (1976a) Notes on neotropical Vaccinieae (Ericaceae), I. Gonocalyx-a genus new to Central America. Brittonia 28: 37-41. http://dx.doi.org/10.2307/2805557

Luteyn, J.L. (1976b) A revision of the Mexican-Central American species of Cavendishia (Vacciniaceae). Memoirs of the New York Botanical Garden 28: 1-183.

Luteyn, J.L. (1983) Ericaceae: part I. Cavendishia. Flora Neotropica Monographs 35: 1-289.

Luteyn, J. L. (1987) New species and notes on neotropical Ericaceae. Opera Botanica 92: 109-130.

Luteyn, J.L. (1992) A new Ceratostema (Ericaceae: Vaccinieae) from northern Peru. Bulletin of the Torrey Botanical Club 119: 314-315.

Luteyn, J.L. (1996) Ericaceae. In: Harling, G. \& Andersson, L. (eds.) Flora of Ecuador 54. Department of Systematic Botany, Goteborg University, Copenhagen, pp. 1-404. http://dx.doi.org/10.2307/2996763

Luteyn, J.L. (2002) Diversity, adaptation, and endemism in neotropical Ericaceae: Biogeographical patterns in the Vaccinieae. Botanical Review 68: 55-87. http://dx.doi.org/10.1663/0006-8101(2002)068[0055:DAAEIN]2.0.CO;2

Maguire, B., Steyermark, J.A. \& Luteyn, J.L. (1978) Ericaceae. Memoirs of the New York Botanical Garden 29: 139203.

Marazzi, B. \& Sanderson, M.J. (2010) Large-scale patterns of diversification in the widespread legume genus Senna and the evolutionary role of extrafloral nectaries. Evolution 64: 3570-3592. http://dx.doi.org/10.1111/j.1558-5646.2010.01086.x

Melville, R. (1976) The terminology of leaf architecture. Taxon 25: 549-561. http://dx.doi.org/10.2307/1220108

Moreno, N.P. (1984) Glosario botánico ilustrado. Instituto Nacional de Investigación sobre Recursos Bióticos. Compañía Editorial Continental S.A., México, 300 pp.

Niedenzu, F. (1889) Über den anatomischen Bau der Laubblätter der Arbutoideae und Vaccinioideae in Beziehung zu ihrer systematischen Gruppierung und geographischen Verbreitung. Botanische Jahrbücher für Systematik, Pflanzengeschichte und Pflanzengeographie 11: 134-263.

Nixon, K.C. (2002) WinClada ver. 1.00.08. Published by the author, Ithaca, NY. 
Nuttall, T. (1818) The genera of North American Plants and a catalogue of the species, to the year 1817 1. D. Heartt, Philadelphia, $312 \mathrm{pp}$.

Pedraza-Peñalosa, P. (2009) Systematics of the neotropical blueberry genus Disterigma (Ericaceae). Systematic Botany 34: 406-413. http://dx.doi.org/10.1600/036364409788606352

Pedraza-Peñalosa, P. (2010a) Insensitive blueberries: a total evidence analysis of Disterigma s.l. (Ericaceae) exploring transformation costs. Cladistics 26: 388-407. http://dx.doi.org/10.1111/j.1096-0031.2009.00293.x

Pedraza-Peñalosa, P. (2010b) Disterigma (Ericaceae: Vaccinieae). Flora Neotropica Monographs 108: 1-126.

Planchon, J.E. \& Linden, J.J. (1856) New plants. The Gardeners' Chronicle and Agricultural Gazette. $1856: 152$.

Powell, E.A. \& Kron, K.A. (2003) Molecular systematics of the northern Andean blueberries (Vaccinieae, Vaccinioideae, Ericaceae). International Journal of Plant Sciences 164: 987-995. http://dx.doi.org/10.1086/378653

Powell, J.M., Crayn, D.M., Gadek, P.A., Quinn, C.J., Orrison, D.A. \& Chapman, A.R. (1996) A re-assessment of relationships within Epacridaceae. Annals of Botany 77: 305-315.

Rao, T.A. \& Chakraborti, S. (1985) The veinlet syndrome in the tribe Andromedeae (Ericaceae). Proceedings of the Indian Academy of Sciences 94: 639-654.

Rusby, H.H. (1907) An enumeration of the plants collected in Bolivia by Miguel Bang, 4. Bulletin of the New York Botanical Garden 4: 309-470.

Ruzin, S.E. (1999) Plant microtechnique and microscopy. Oxford University Press, New York, $322 \mathrm{pp}$.

Schoereder, J.H., Sobrinho, T.G., Madureira, M.S., Ribas, C.R. \& Oliveira, P.S. (2010) The arboreal ant community visiting extrafloral nectaries in the Neotropical cerrado savanna. Terrestrial Arthropod Reviews 3: 3-27.

Sleumer, H.O. (1934). Ericaceae americanae novae vel minus cognitae, I. Notizblatt des Botanischen Gartens und Museums zu Berlin-Dahlem 12(112): 119-140. http://dx.doi.org/10.2307/3995031

Sleumer, H.O. (1935) Ericaceae americanae novae vel minus cognitae, II. Notizblatt des Botanischen Gartens und Museums zu Berlin-Dahlem 12(113): 277-294.

Sleumer, H.O. (1941) Vaccinioideen-Studien. Botanische Jahrbücher für Systematik, Pflanzengeschichte und Pflanzengeographie 71: 375-510.

Sleumer, H.O. (1978) A revision of the genus Diogenesia. Notes from the Royal Botanic Garden, Edinburgh 36: 251258.

Smith, A.C. (1932) The American species of Thibaudieae. Contributions from the U.S. National Herbarium 28: $311-$ 547.

Smith, A.C. (1935) Studies of South American plants, IV. New Monimiaceae, Trigoniaceae, and Vacciniaceae. Phytologia 1: 126-132.

Smith, A.C. (1936) Studies of South American plants, V. Additional notes on Thibaudieae. Bulletin of the Torrey Botanical Club 63: 307-316. http://dx.doi.org/10.2307/2481157

Smith, A.C. (1952) Plants collected in Ecuador by W. H. Camp - Vacciniaceae. Memoirs of the New York Botanical Garden 8: 41-85.

Stamatakis, A. (2006) RAxML-VI-HPC: maximum likelihood-based phylogenetic analyses with thousands of taxa and mixed models. Bioinformatics 22: 2688-2690. http://dx.doi.org/10.1093/bioinformatics/bt1446

Stamatakis, A., Hoover, P. \& Rougemont, J. (2008) A rapid bootstrap algorithm for the RAxML web servers. Systematic Biology 57: 758-771.

Stern, W.T. (1992) Botanical latin. Timber Press, Inc., Portland, 546 pp.

Varón, A., Vinh, L.S. \& Wheeler, W.C. (2010) POY version 4: phylogenetic analysis using dynamic homologies. Cladistics 26: 72-85.

Weddell, H.A. (1860) Chloris andina, essai d'une flore de la région alpine des Cordilleres de l'Amerique du Sud 2(1213): $1-316$.

Wilbur, R.L. \& Luteyn, J.L. (1981) Additions to the Ericaceae of Panama. Annals of the Missouri Botanical Garden 68: 154-166. http://dx.doi.org/10.2307/2398818

Yeo, P.F. (1967) Notes on some species of Macleania (Ericaceae). Baileya 15: 45-59. 


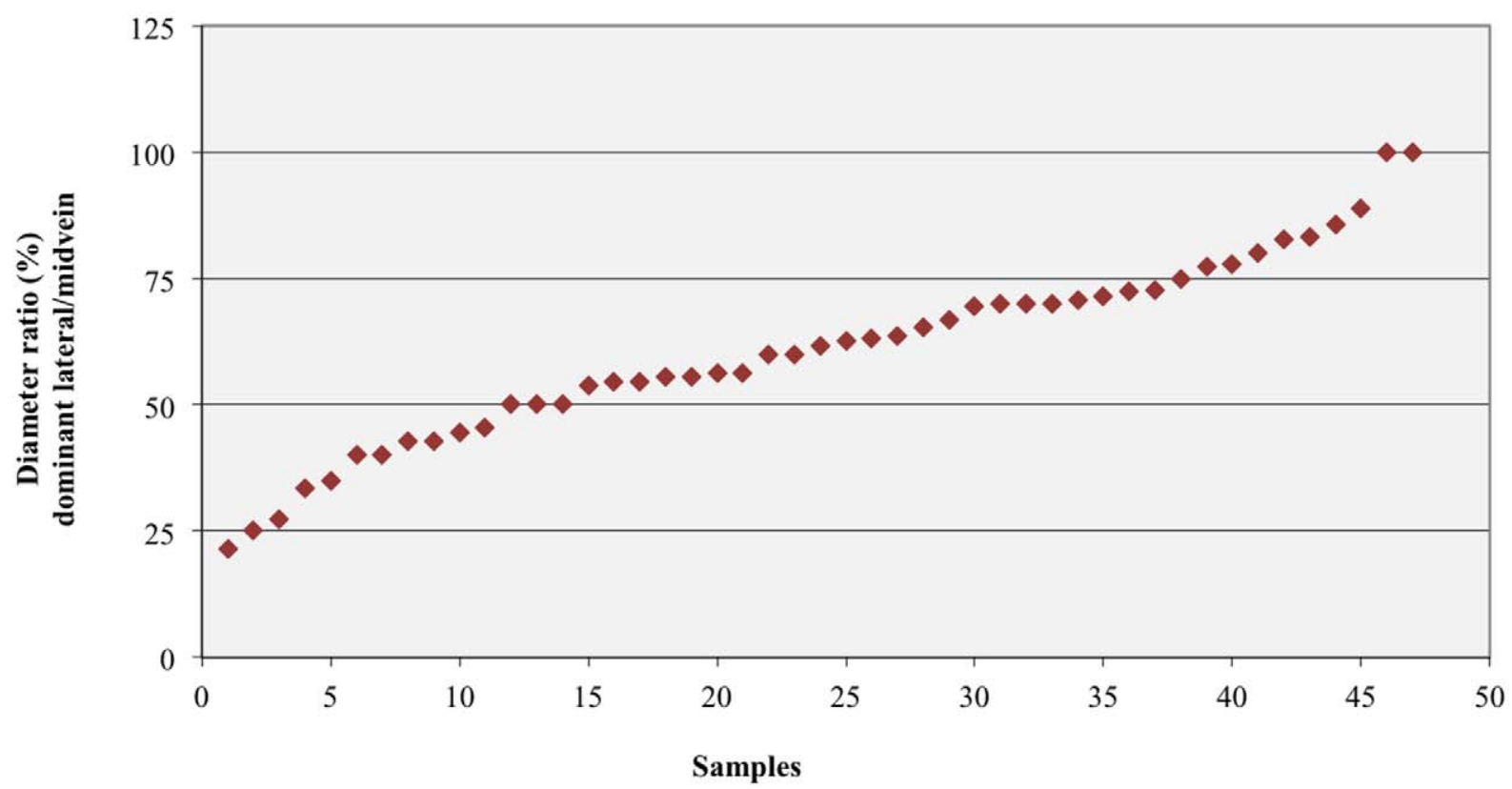

FIGURE 1. Variation of the prominent-lateral/midvein diameter ratios of 33 species of Vaccinieae. Measurements obtained directly from leaf clearings. 


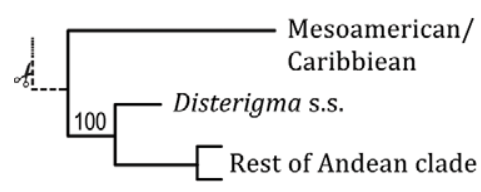

(b)

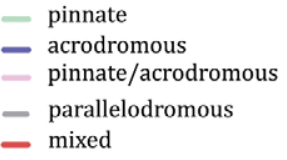

(a)
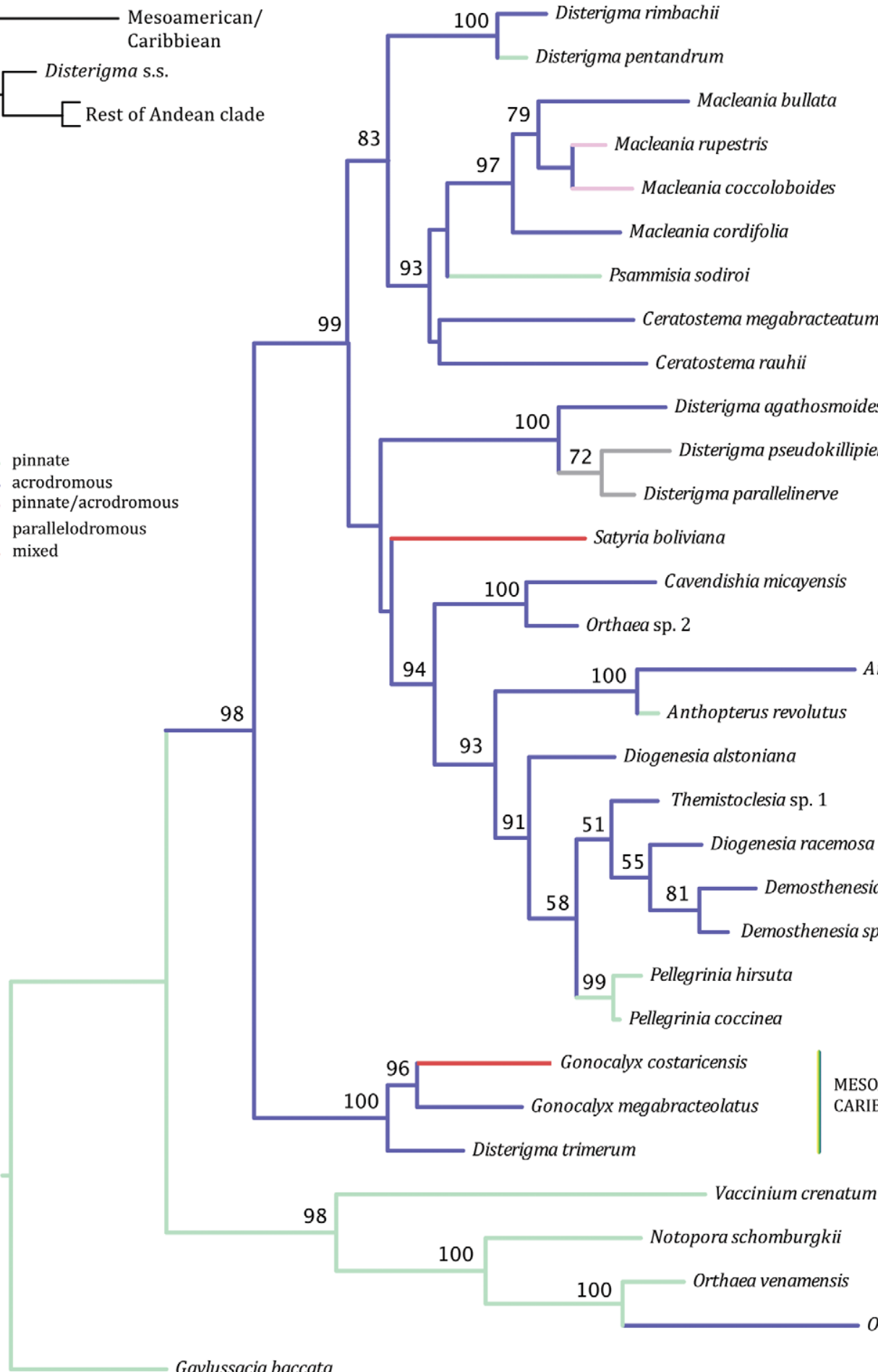

Anthopterus wardii

94

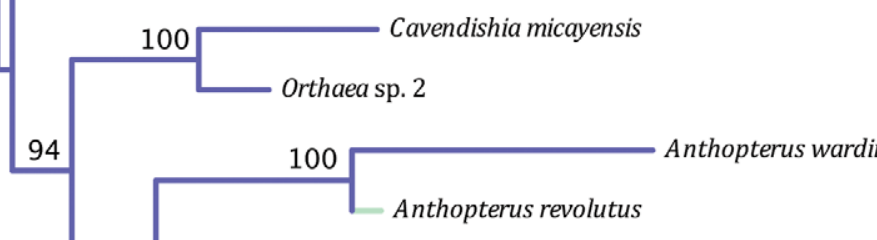

93

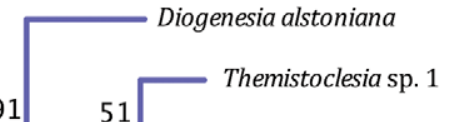

91

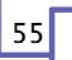

- Diogenesia racemosa

58

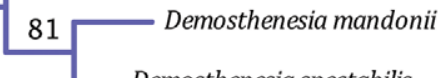

8

Demosthenesia spectabilis

99 Pellegrinia hirsuta

Pellegrinia coccinea

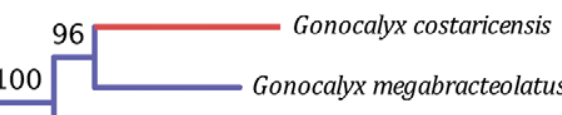

Disterigma trimerum

ERICAN

CARIBBEAN

98

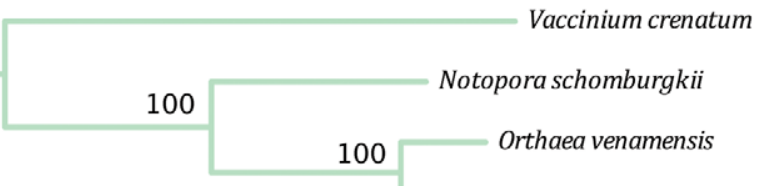

Orthaea apophysata

Gaylussacia baccato

0.0050

FIGURE 2. Maximum likelihood hypotheses based on nuclear and plastid sequence data of 32 species of Vaccinieae. Bootstrap support values greater than $50 \%$ are shown. A. Hypothesis obtained with RAxML $(\ln L=-8817.105059)$; primary frameworks reconstructed using Fast Optimization. B. Detail of the main topological difference in the hypothesis obtained with POY 5.0.1 Alpha $(\ln L=-8822.18034066)$. 


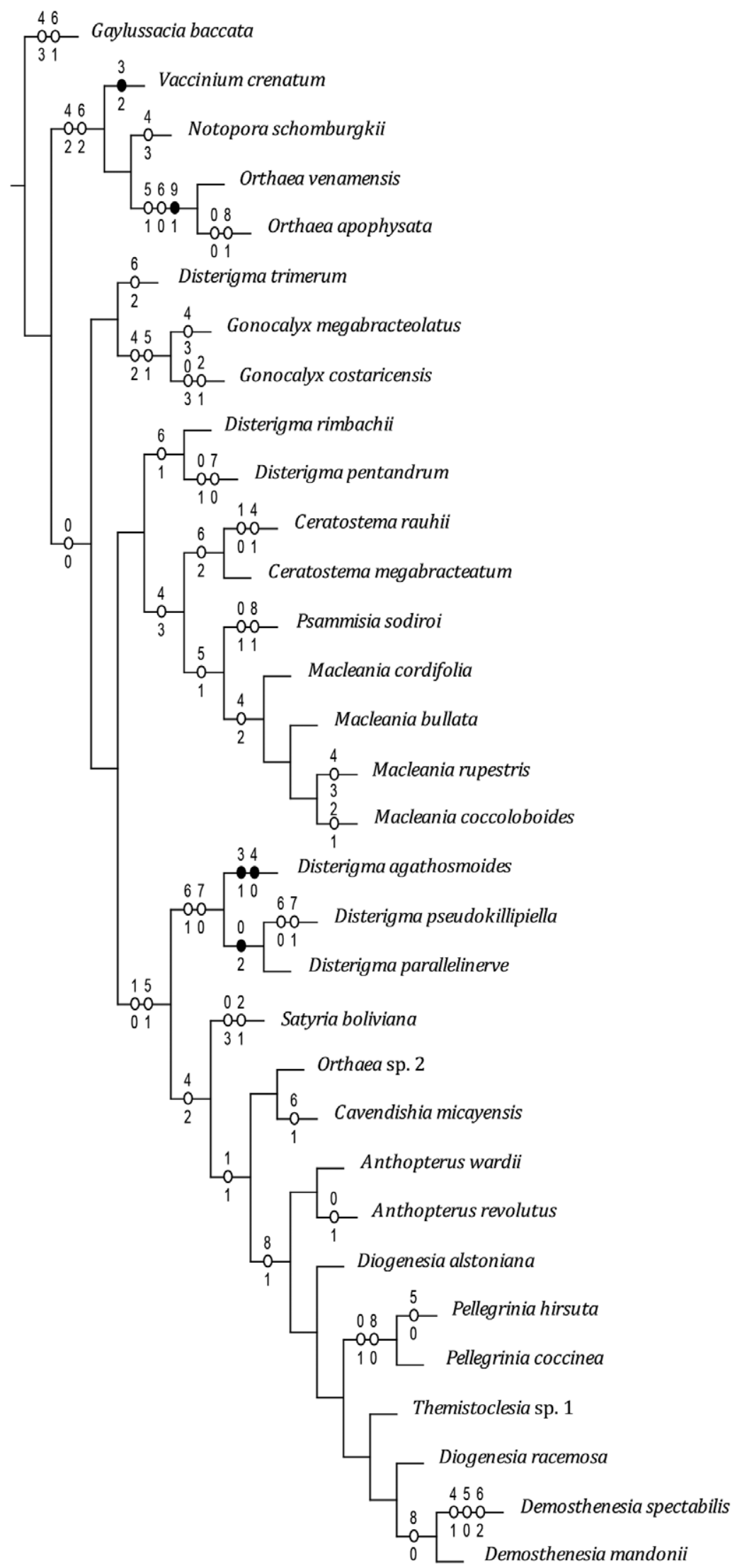

FIGURE 3. Character state distribution on the maximum likelihood hypotheses based on nuclear and plastid sequence data of 32 species of Vaccinieae. Fast Optimization. Open circles are homoplasious characters, closed circles are non-homoplasious characters. Character number is above circles, character state number below (see Table 2 for character descriptions). Hypothesis obtained with RAxML. 


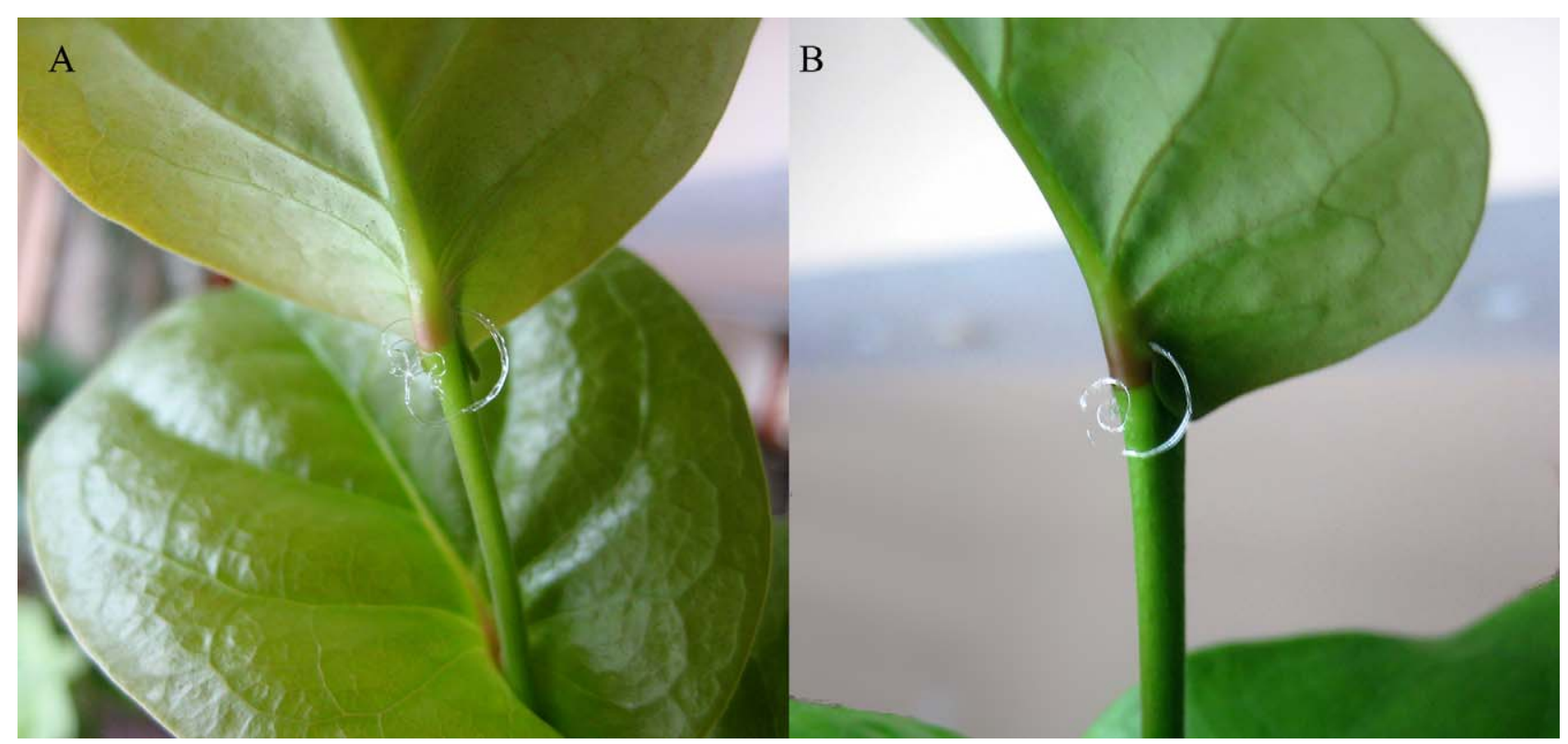

FIGURE 4. Nectar secretions of the basilaminar glands of Macleania pentaptera Hoerold (growing indoors). A. Abaxial view of leaf. B. Lateral view of leaf. Photos by James L. Luteyn. 


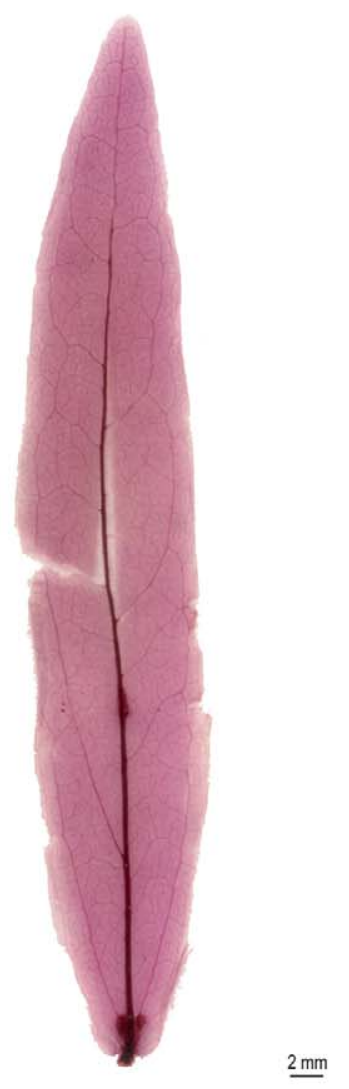

A. Leaf view.

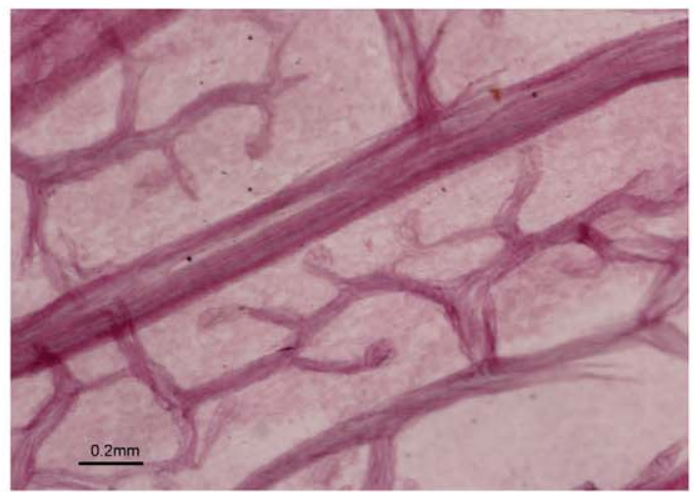

C. Freely ending veinlets.

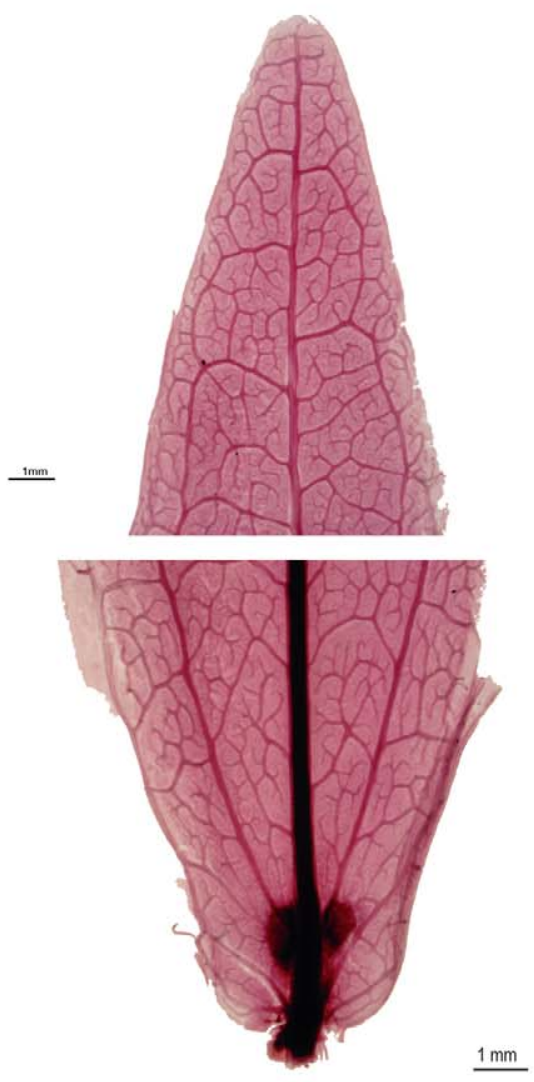

B. Detail of leaf apex and base.

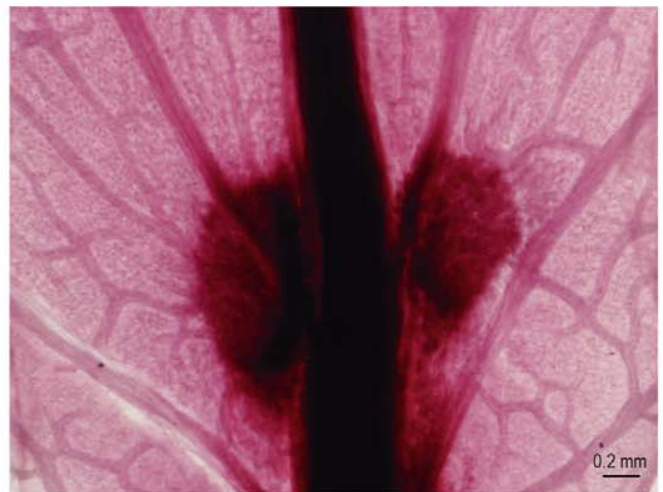

D. Basilaminar glands.

\section{Venation description}

1. Primary framework: pinnate.

2. Diameter ratio basal lateral vein/midvein: $0.21-0.25$.

3 . Midvein apex: reaching the margin.

Secondary veins

4. Number: $7-8$ per side.

5. Insertion: opposite or alternate.

6. Spacing: dispersed along midvein.

7. Course: basal veins pointing toward apex, apical veins toward margin.

8. Insertion angle: ascendant to diffuse.

9. Insertion angle variability: mixed.

Minor orders

10. Number of vein orders: four.

11. Intramarginal secondaries: absent.
12. Interior secondaries: present.

13. Intersecondaries: present.

14. Course: brochidodromous.

15. Areolation: irregular.

Freely Ending Veinlets (FEVs)

16. FEVs branching: one branched, dichotomous, or dendritic.

17. FEVs termination: tracheoid idioblast.

Margin

18. Shape: entire

19. Sclerotization: not lignified.

20. Marginal ultimate venation: present.

Glands

21. Glandular bodies: basilaminar.

FIGURE 5. Leaf venation of Anthopterus revolutus (Wilbur \& Luteyn) Luteyn 


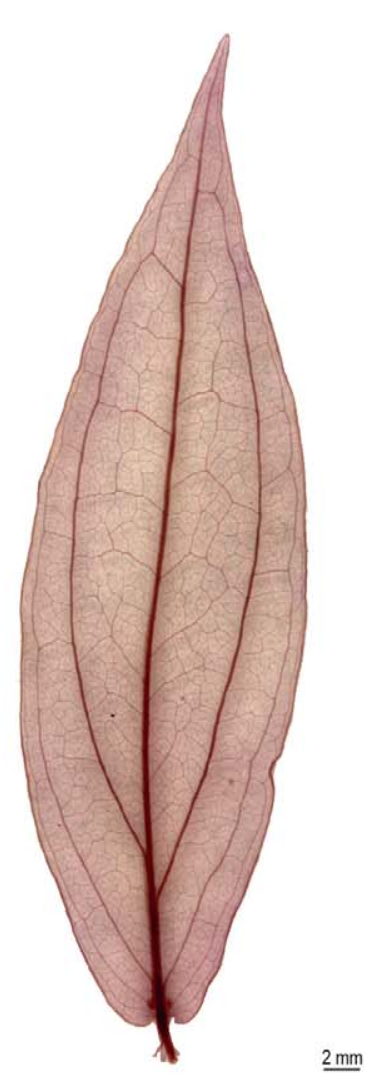

A. Leaf view.

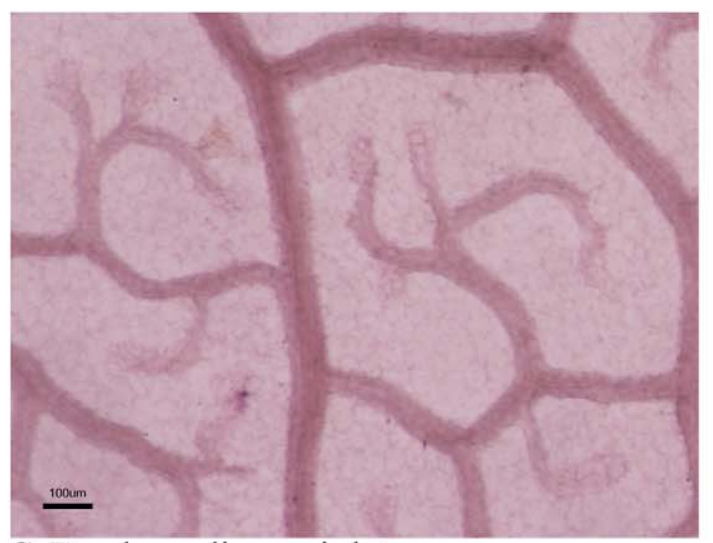

C. Freely ending veinlets.

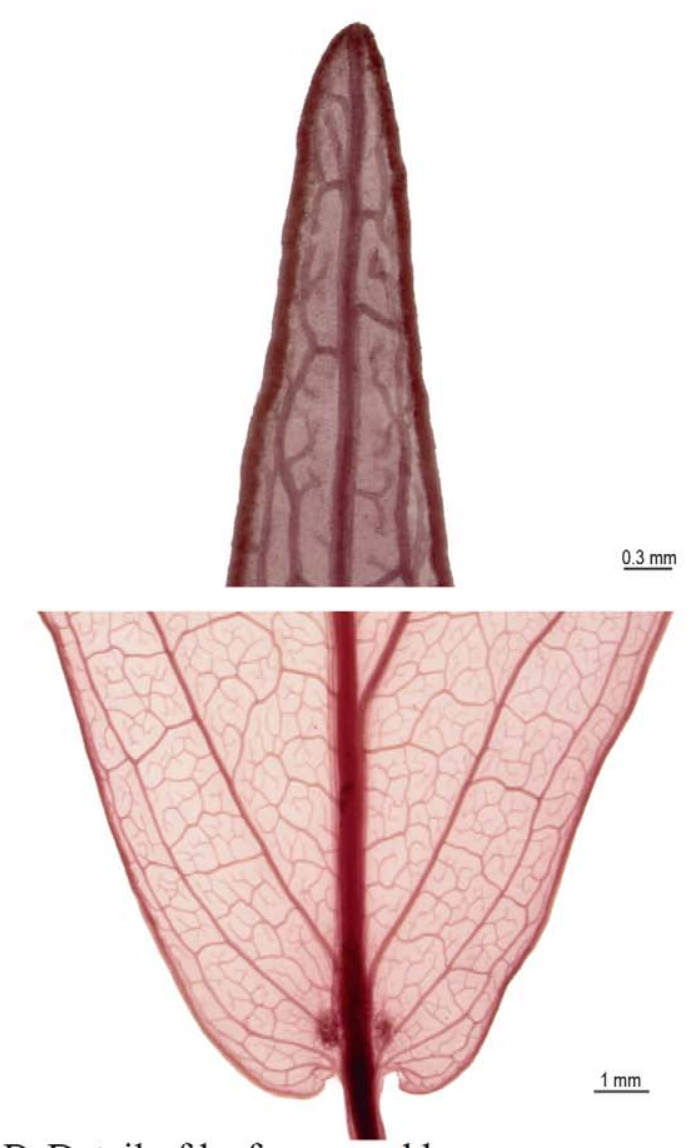

B. Detail of leaf apex and base.

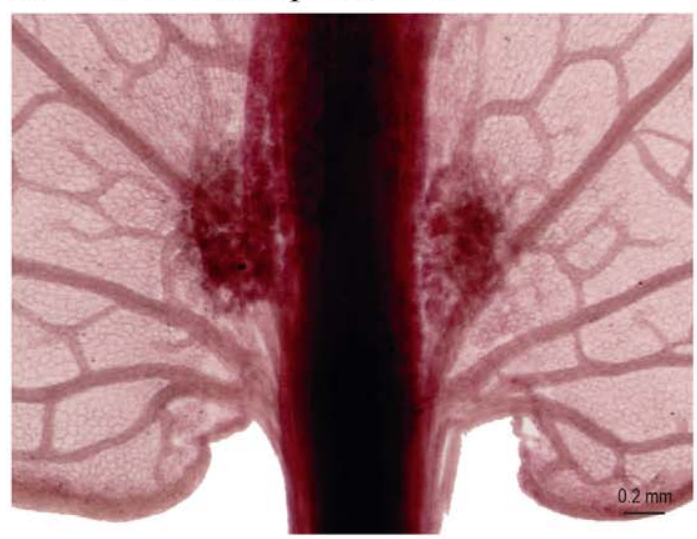

D. Basilaminar glands.

\section{Venation description}

1. Primary framework: acrodromous suprabasal.

2. Diameter ratio basal lateral vein/midvein: $0.4-0.6$.

3. Midvein apex: reaching the margin.

Secondary veins

4. Number: 3 per side.

5. Insertion: subopposite.

6. Spacing: concentrated in the basal fifth.

7. Course: pointing to the apex.

8. Insertion angle: ascendant to diffuse.

9. Insertion angle variability: increasing proximally. Minor orders

10. Number of vein orders: four.

11. Intramarginal secondaries: absent.
12. Interior secondaries: present.

13. Intersecondaries: absent.

14. Course: brochidodromous.

15. Areolation: irregular.

Freely Ending Veinlets (FEVs)

16. FEVs branching: simple or branched.

17. FEVs termination: tracheoid idioblast.

Margin

18. Shape: entire.

19. Sclerotization: lignified.

20. Marginal ultimate venation: absent or present.

Glands

21. Glandular bodies: basilaminar.

FIGURE 6. Leaf venation of Anthopterus wardii Ball 


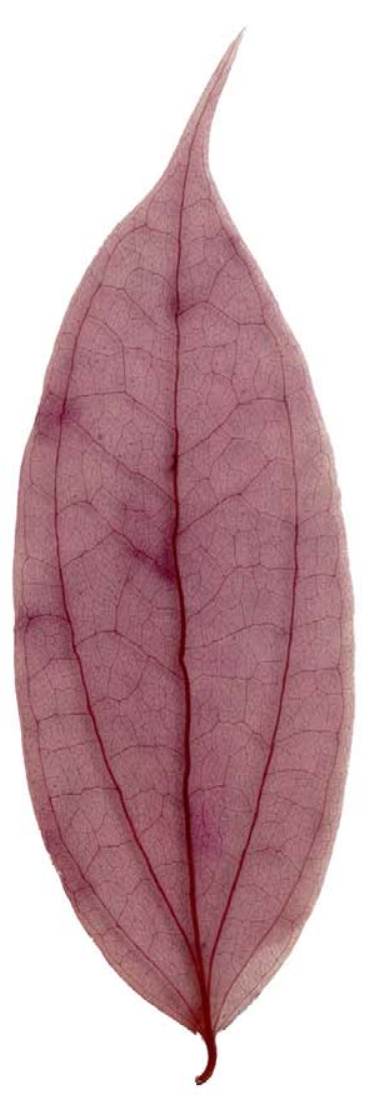

$\underline{5 \mathrm{~mm}}$

A. Leaf view.

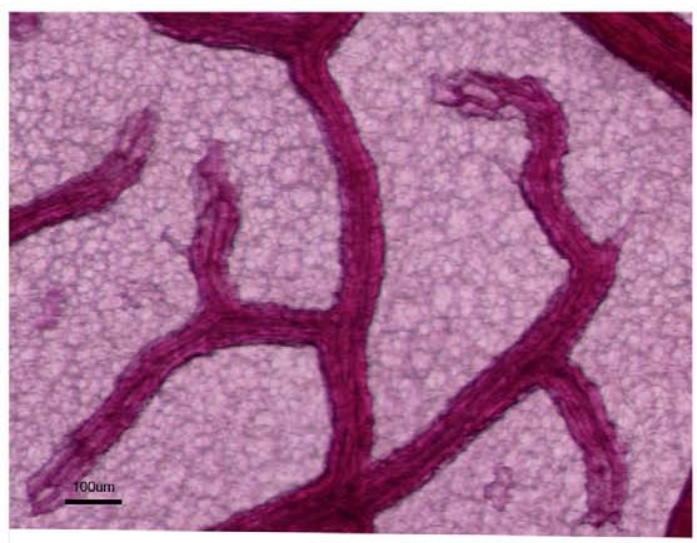

C. Freely ending veinlets.
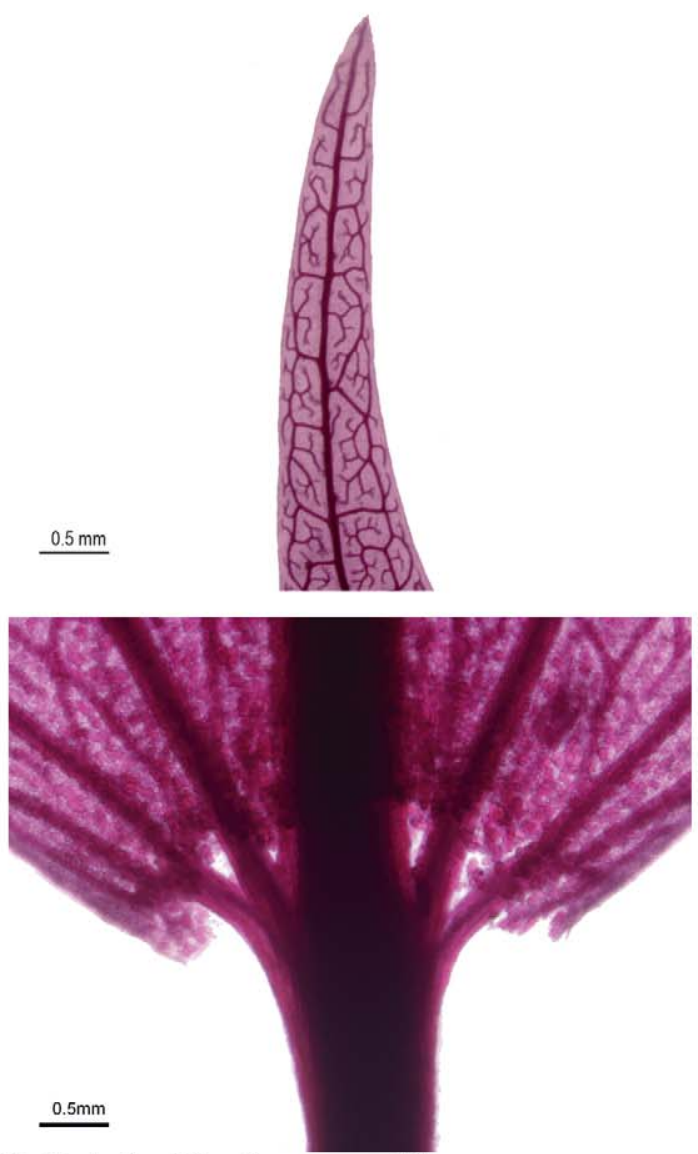

B. Detail of leaf apex and base.

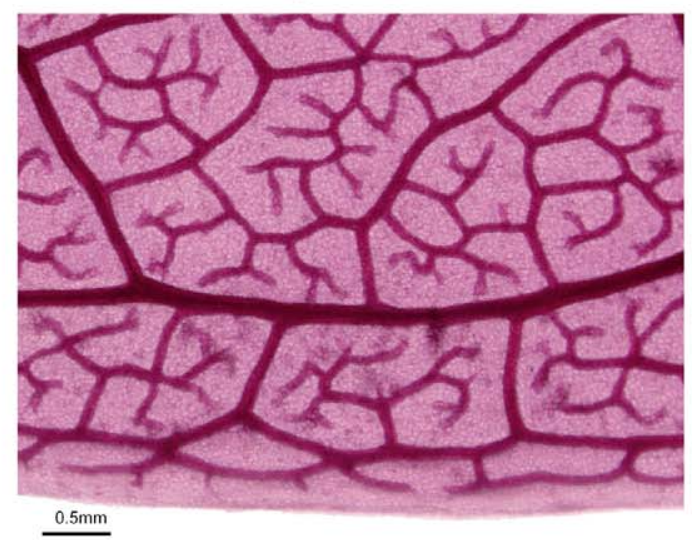

D. Detail of leaf margin.

\section{Venation description}

1. Primary framework: acrodromous suprabasal.

2. Diameter ratio basal lateral vein/midvein: 0.86 .

3. Midvein apex: reaching the margin.

Secondary veins

4. Number: 2 per side.

5. Insertion: opposite or alternate.

6. Spacing: concentrated in the basal fourth.

7. Course: pointing toward apex.

8. Insertion angle: ascendant.

9. Insertion angle variability: increasing proximally.

Minor orders

10. Number of vein orders: four.

11. Intramarginal secondaries: absent.

12. Interior secondaries: present.

13. Intersecondaries: absent.

14. Course: brochidodromous.

15. Areolation: irregular.

Freely Ending Veinlets (FEVs)

16. FEVs branching: simple or branched.

17. FEVs termination: tracheoid idioblast.

Margin

18. Shape: entire.

19. Sclerotization: not lignified.

20. Marginal ultimate venation: present.

Glands

21. Glandular bodies: absent.

FIGURE 7. Leaf venation of Cavendishia micayensis A.C.Smith 


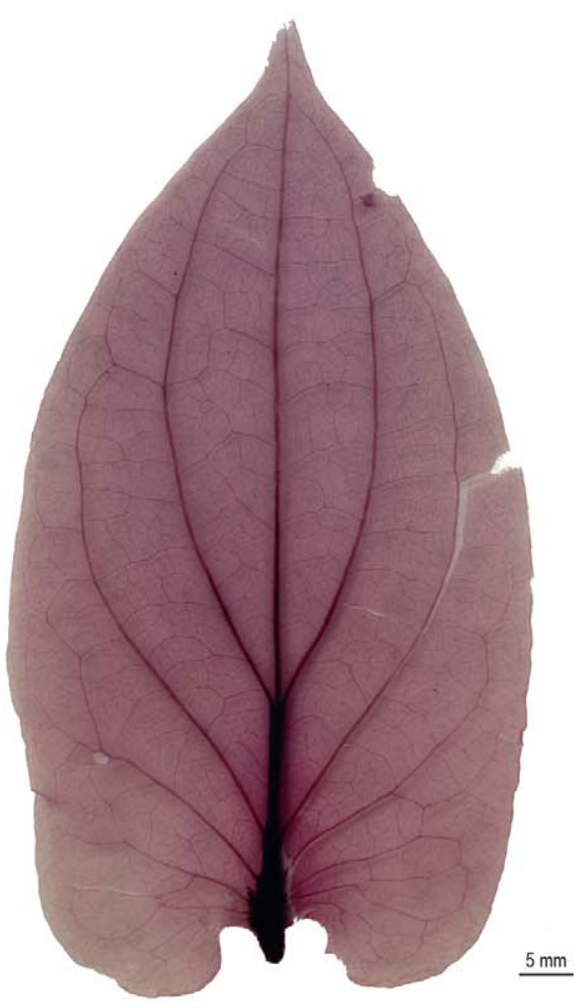

A. Leaf view.

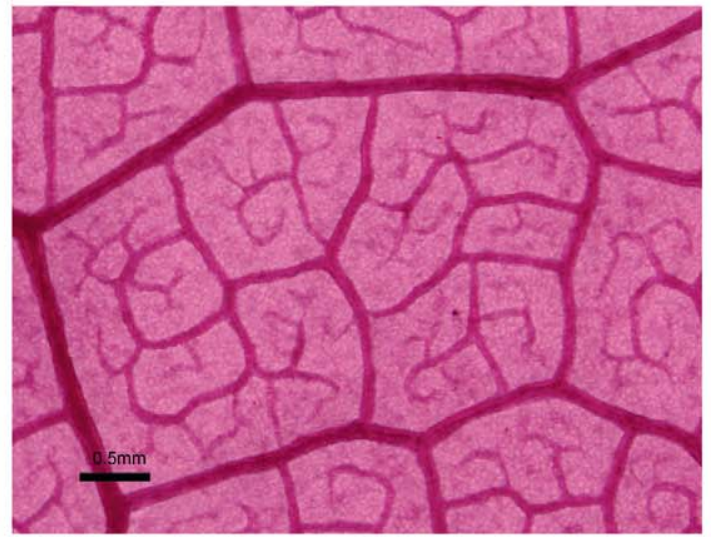

C. Freely ending veinlets.
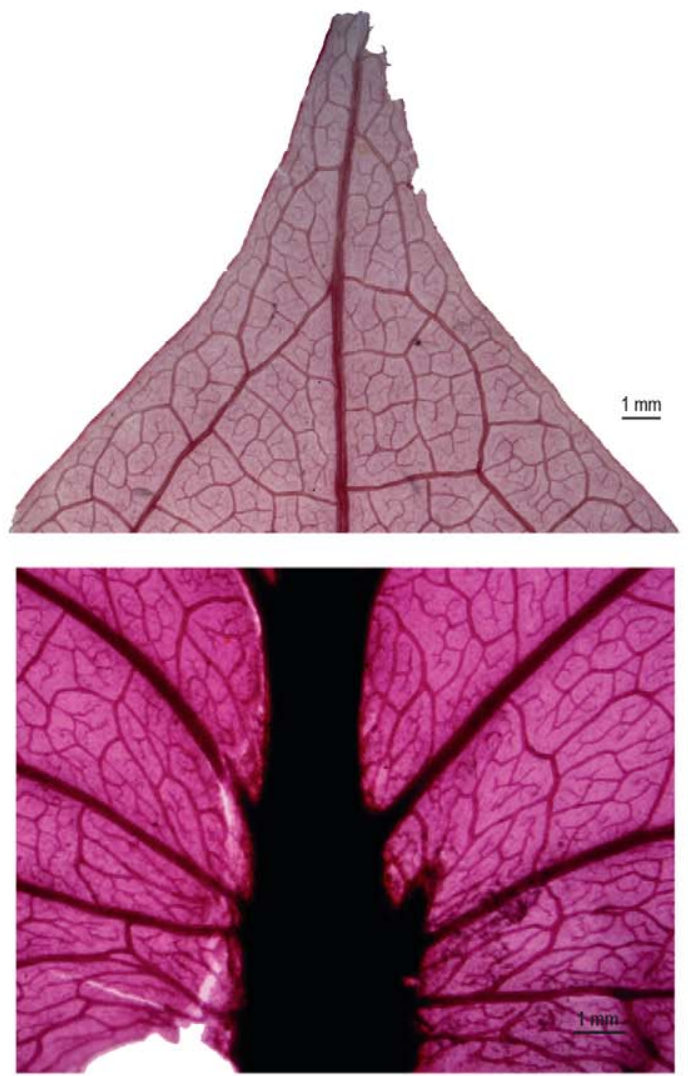

B. Detail of leaf apex and base.

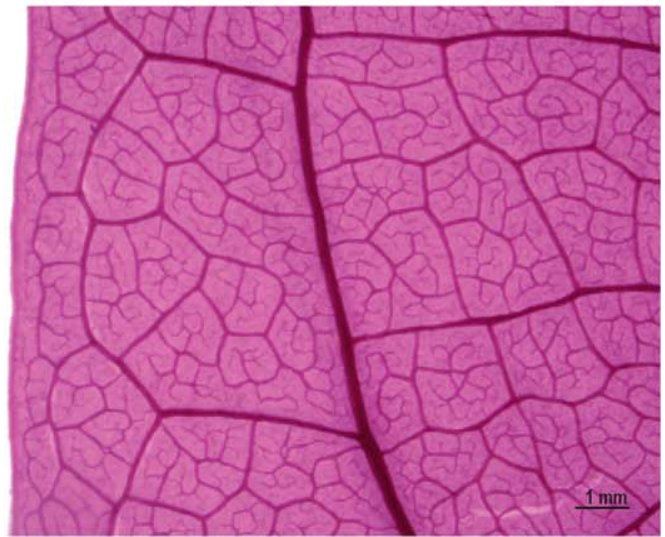

D. Detail of leaf margin.

\section{Venation description}

1. Primary framework: acrodromous suprabasal.

2. Diameter ratio basal lateral vein/midvein: 0.77 .

12. Interior secondaries: present.

13. Intersecondaries: absent.

3. Midvein apex: not observed.

Secondary veins

4. Number: 5 per side.

5. Insertion: opposite.

6. Spacing: concentrated in the basal fourth.

7. Course: apical veins pointing toward apex,

basal veins pointing toward margin.

8. Insertion angle: ascendant to diffuse.

9. Insertion angle variability: increasing proximally.

Minor orders

10. Number of vein orders: five.

11. Intramarginal secondaries: absent.

14. Course: brochidodromous.

15. Areolation: irregular.

Freely Ending Veinlets (FEVs)

16. FEV branching: simple, or branched

17. FEVs termination: simple.

Margin

18. Shape: entire.

19. Sclerotization: not lignified.

20. Marginal ultimate venation: present.

Glands

21. Glandular bodies: absent.

FIGURE 8. Leaf venation of Ceratostema megabracteatum Luteyn 


\section{A. Leaf view.}

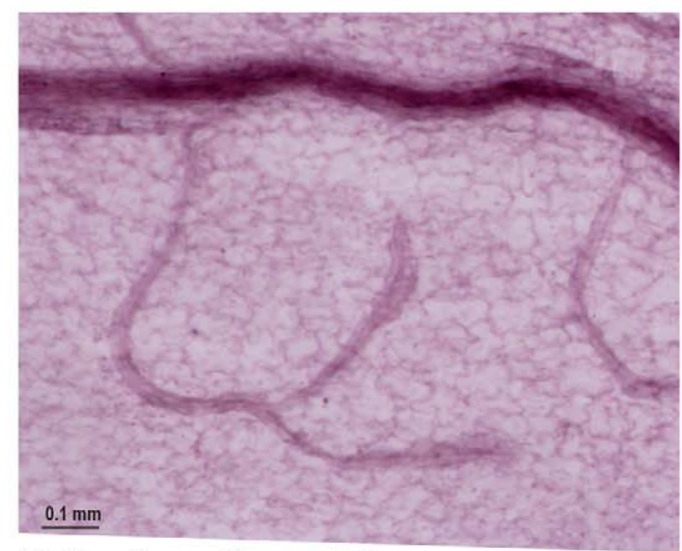

C. Freely ending veinlets.

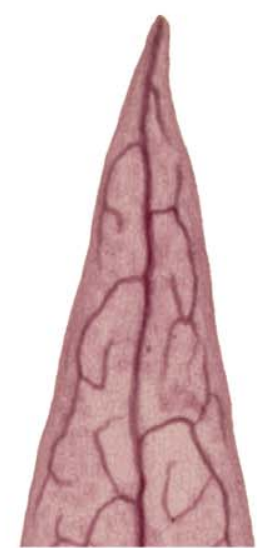

$\underline{0.2 \mathrm{~mm}}$

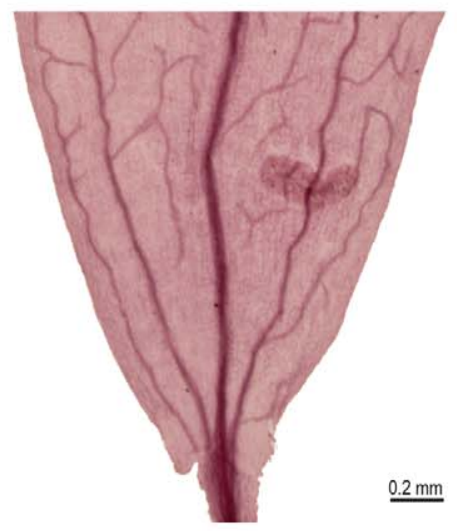

B. Detail of leaf apex and base.

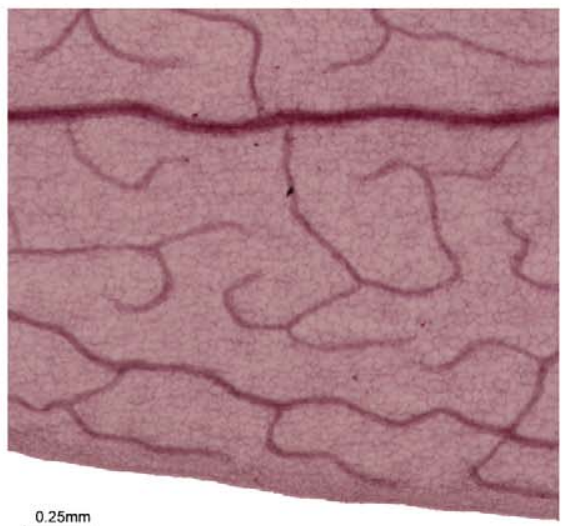

D. Detail of leaf margin.

\section{Venation description}

1. Primary framework: acrodromous basal.

2. Diameter ratio basal lateral vein/midvein: 0.71 .

3. Midvein apex: reaching the margin.

Secondary veins

4. Number: 1 per side.

5. Insertion: opposite.

6. Spacing: concentrated in the basal tenth.

7. Course: pointing toward apex.

8. Insertion angle: adpressed.

9. Insertion angle variability: inapplicable.

Minor orders

10. Number of vein orders: three.

11. Intramarginal secondaries: absent.
12. Interior secondaries: present.

13. Intersecondaries: absent.

14. Course: brochidodromous.

15. Areolation: irregular.

Freely Ending Veinlets (FEVs)

16. FEV branching: simple or branched.

17. FEVs termination: simple.

Margin

18. Shape: entire.

19. Sclerotization: not lignified.

20. Marginal ultimate venation: present.

Glands

21. Glandular bodies: absent.

FIGURE 9. Leaf venation of Ceratostema rauhii Luteyn 


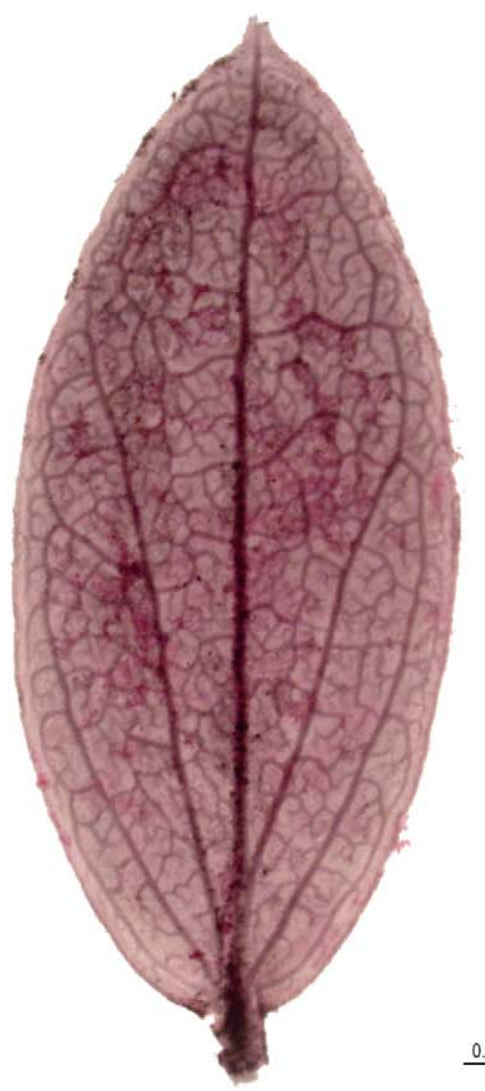

$\underline{0.5 \mathrm{~mm}}$

\section{A. Leaf view.}

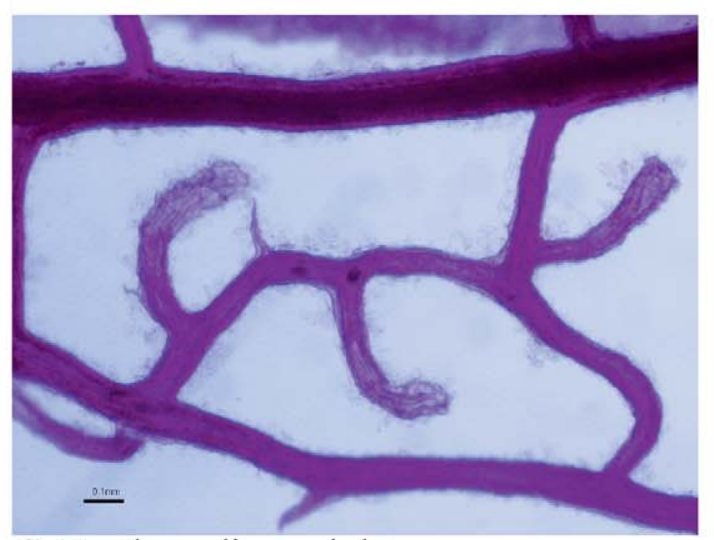

C. Freely ending veinlets.
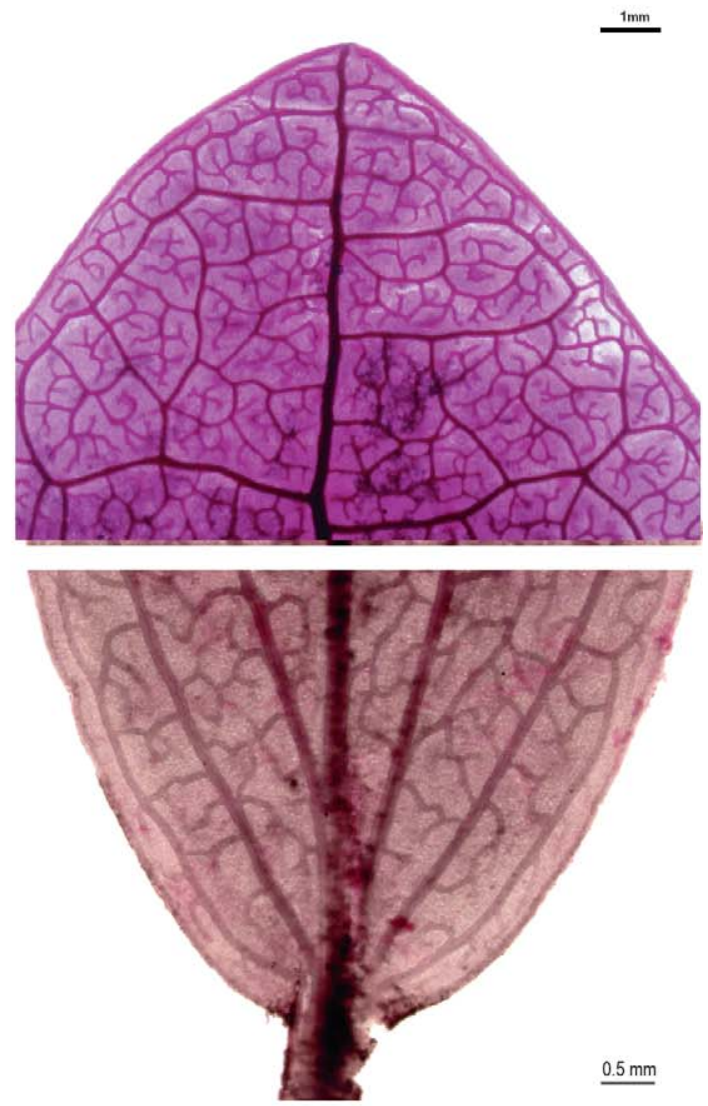

B. Detail of leaf apex and base.

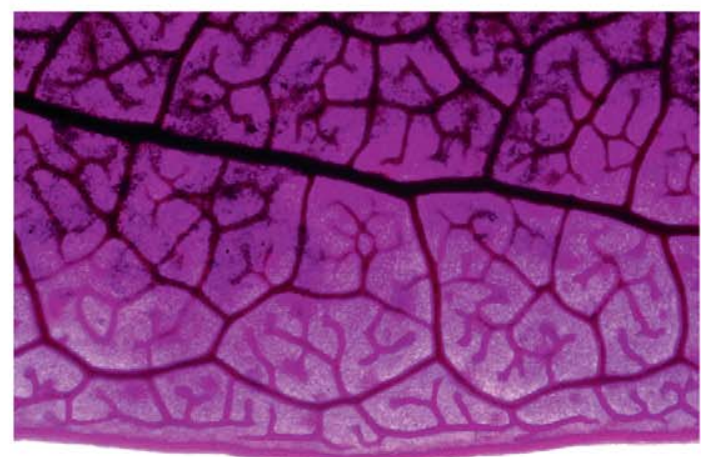

$\underline{0.5 \mathrm{sm}}$

D. Detail of leaf margin.

Venation description

1. Primary framework: acrodromous suprabasal.

2. Diameter ratio basal lateral vein/midvein: $0.57-0.8$.

12. Interior secondaries: present.

13. Intersecondaries: absent.

14. Course: brochidodromous.

3. Midvein apex: reaching the margin.

Secondary veins

4. Number: $3-7$ per side.

5. Insertion: opposite to alternate.

6. Spacing: concentrated in the base.

7. Course: apical veins pointing toward margin, basal veins pointing toward apex.

8. Insertion angle: ascendant to diffuse.

9. Insertion angle variability: increasing proximally.

Minor orders

10. Number of vein orders: four.

15. Areolation: irregular.

Freely Ending Veinlets (FEVs)

16. FEVs branching: simple or branched.

17. FEVs termination: tracheoid idioblast.

Margin

18. Shape: entire.

19. Sclerotization: lignified or not.

20. Marginal ultimate venation: present.

Glands

21. Glandular bodies: absent.

11. Intramarginal secondaries: absent.

FIGURE 10. Leaf venation of Demosthenesia mandonii (Britton) A.C.Smith 


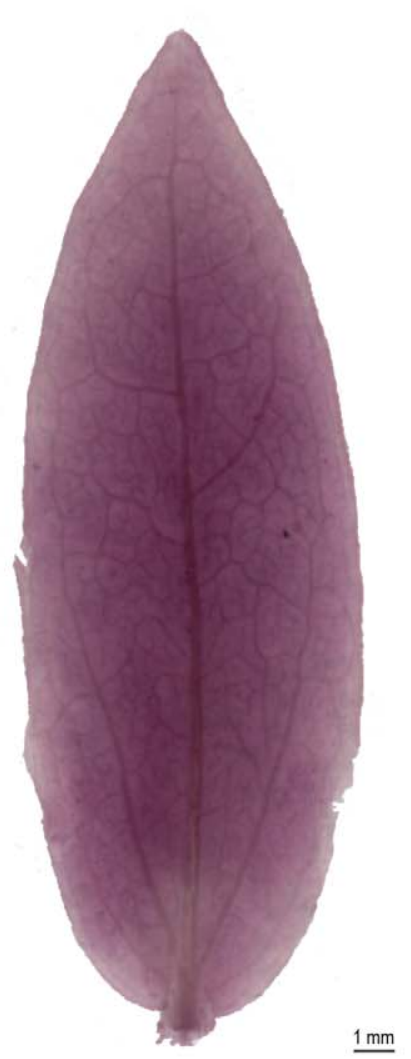

A. Leaf view.

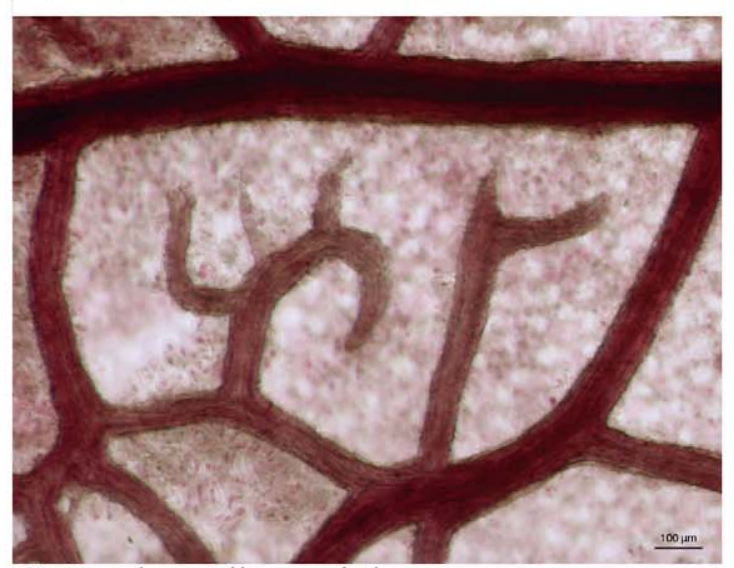

C. Freely ending veinlets.
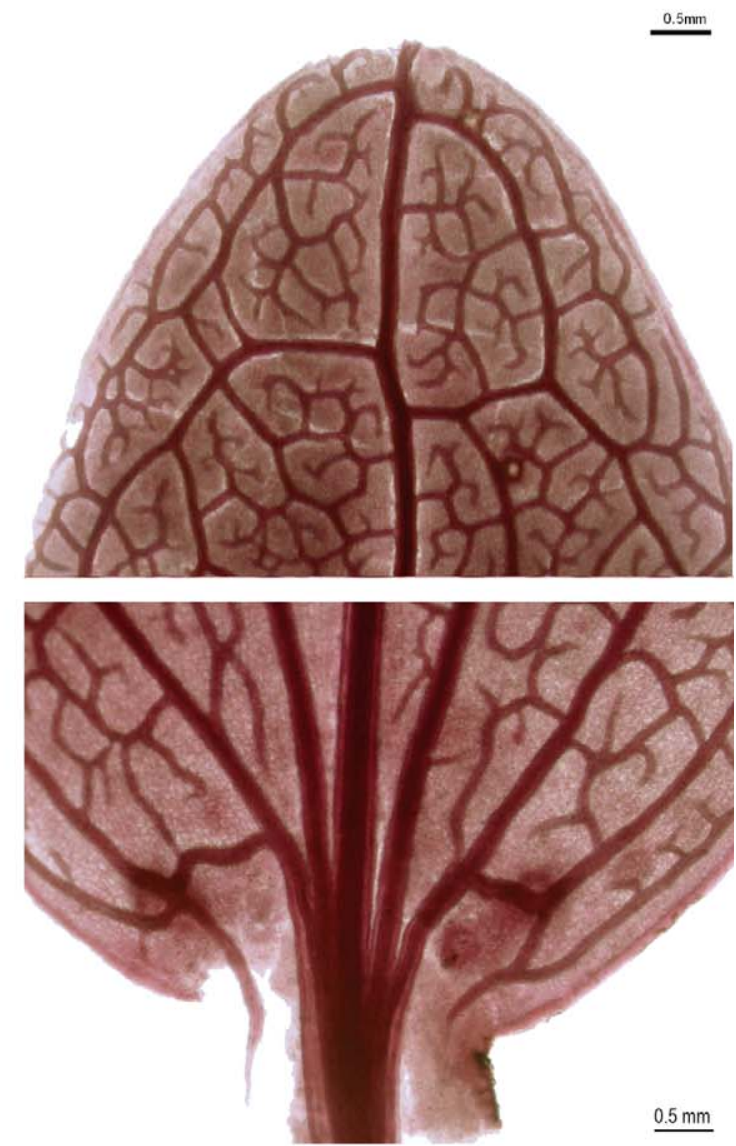

B. Detail of leaf apex and base.

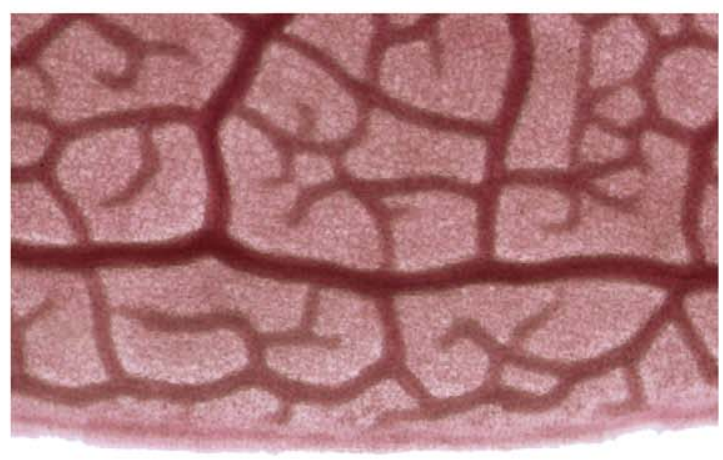

$\underline{0.2 \mathrm{~mm}}$

D. Detail of leaf margin.

\section{Venation Description}

1. Primary framework: acrodromous suprabasal.

2. Diameter ratio basal lateral vein/midvein: $0.53-0.65$.

3. Midvein apex: reaching apex.

Secondary veins

4. Number: 3 per side.

5. Insertion: opposite or alternate.

6. Spacing: concentrated in basal eigth.

7. Course: basal veins pointing toward apex, apical veins pointing toward margin.

8. Insertion angle: ascendant to diffuse.

9 . Insertion angle variability: mixed.

Minor orders

10. Number of vein orders: third.

11. Intramarginal secondaries: absent.
12. Interior secondaries: present.

13. Intersecondaries: absent.

14. Course: brochidodromous.

15. Areolation: irregular.

Freely Ending Veinlets (FEVs)

16. FEVs branching: simple, or branched.

17. FEVs termination: simple.

Margin

18. Shape: entire.

19. Sclerotization: not lignified.

20. Marginal ultimate venation: present.

Glands

21. Glandular bodies: absent.

FIGURE 11. Leaf venation of Demosthenesia spectabilis (Rusby) A.C.Smith 


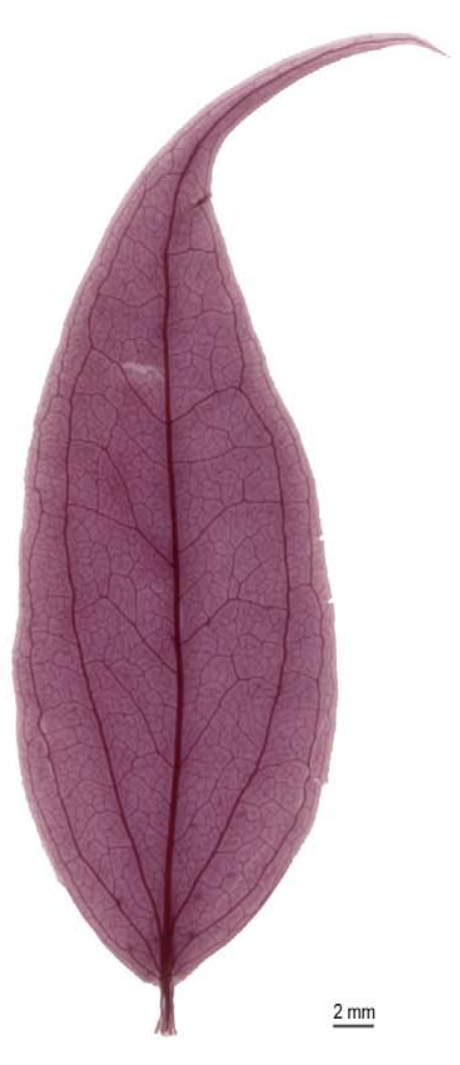

A. Leaf view.

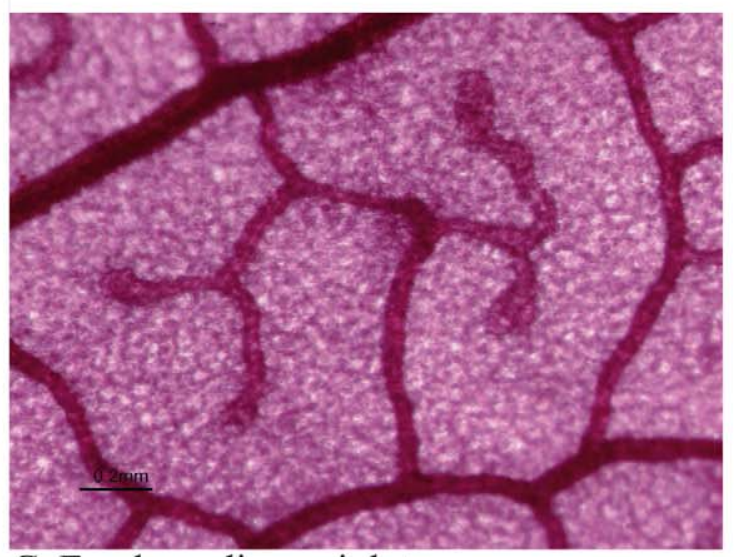

C. Freely ending veinlets.

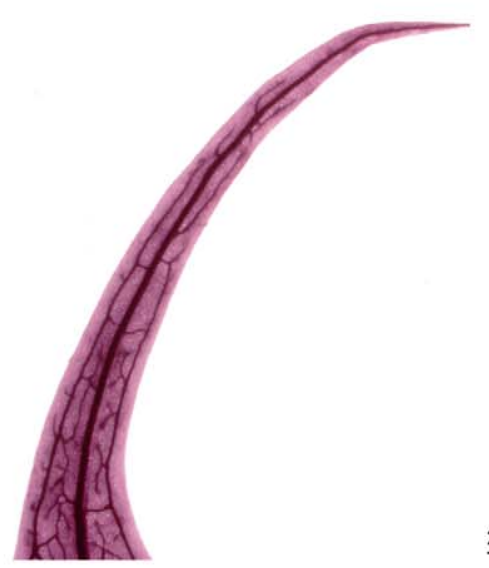

$\underline{2 \mathrm{~mm}}$

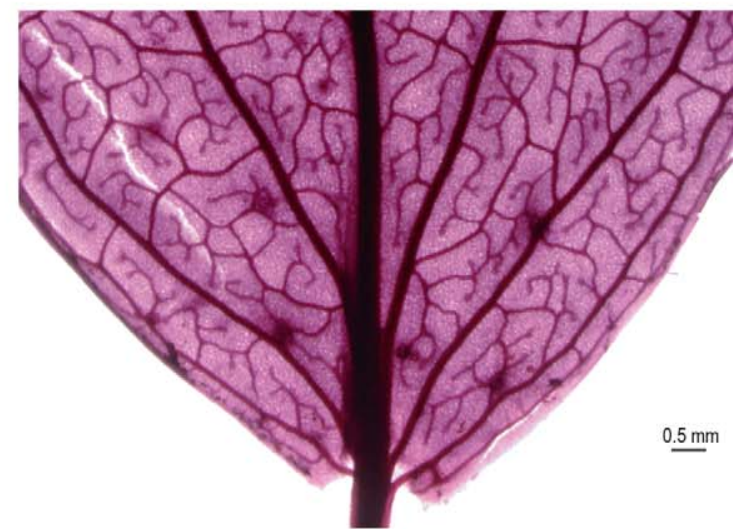

B. Detail of leaf apex and base.

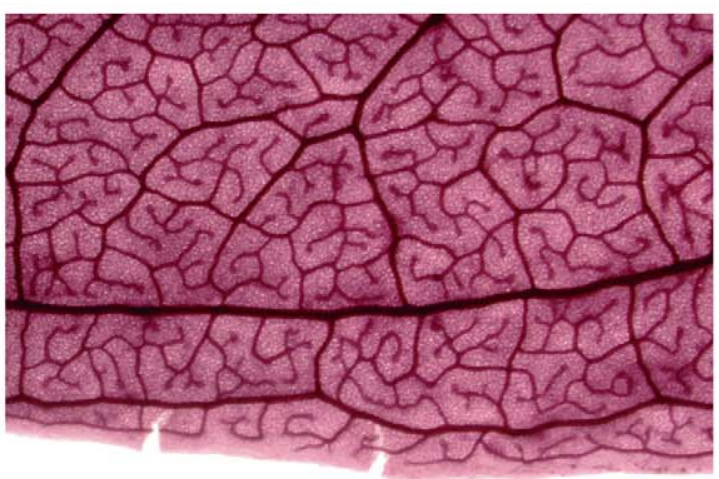

$1 \mathrm{~mm}$

D. Detail of leaf margin.

Venation description

1. Primary framework: acrodromous suprabasal.

2. Diameter ratio basal lateral vein/midvein: $0.4-0.45$.

3. Midvein apex: reaching the apex.

Secondary veins

4. Number: $2-3$ per side.

5. Insertion: opposite or subopposite.

6. Spacing: concentrated in basal fourth.

7. Course: veins pointing to apex.

8. Insertion angle: ascendant.

9. Insertion angle variability: increasing proximally.

Minor orders

10. Number of vein orders: four.

11. Intramarginal secondaries: absent.

12. Interior secondaries: present.
13. Intersecondaries: absent.

14. Course: brochidodromous.

15. Areolation: irregular.

Freely Ending Veinlets (FEVs)

16. FEVs branching: simple, or branched.

17. FEVs termination: tracheoid idioblast.

Margin

18. Shape: entire.

19. Sclerotization: not lignified.

20. Marginal ultimate venation: present.

Glands

21. Glandular bodies: laminar.

FIGURE 12. Leaf venation of Diogenesia alstoniana Sleumer 


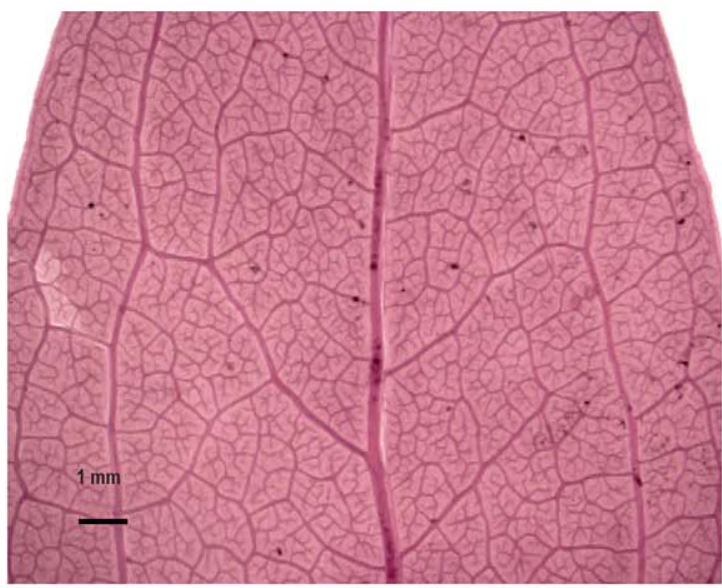

A. Detail of leaf mid-section.

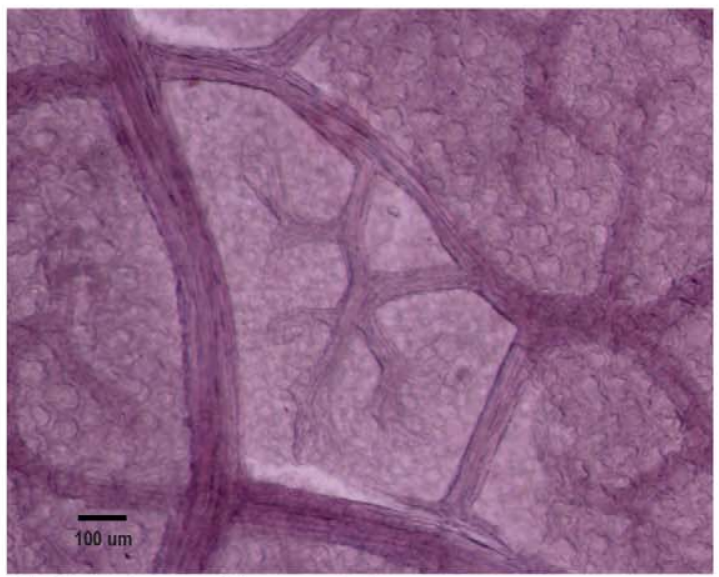

C. Freely ending veinlets.

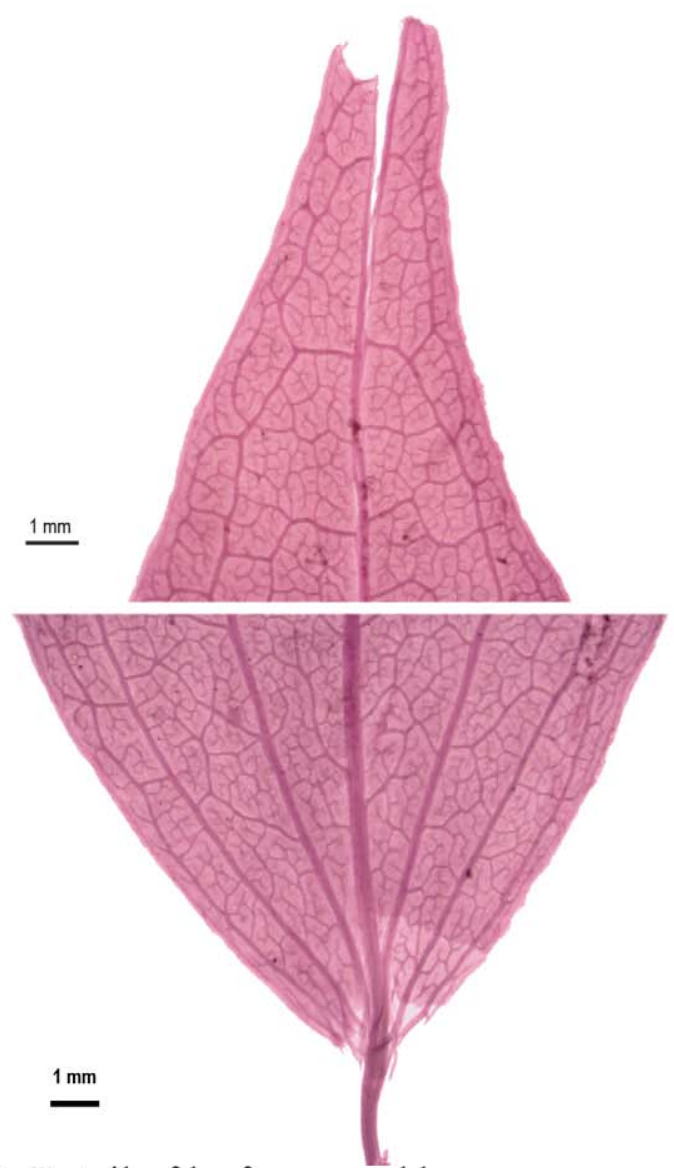

B. Detail of leaf apex and base.

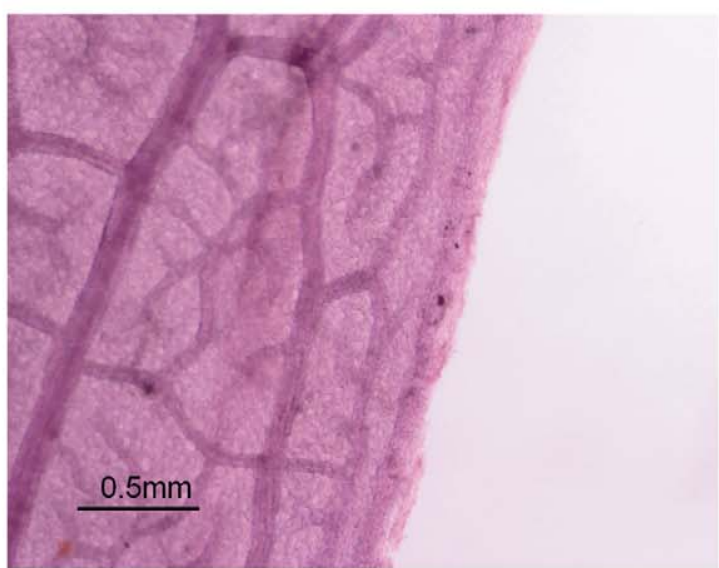

D. Detail of leaf margin.

\section{Venation description}

1. Primary framework: acrodromous suprabasal.

2. Diameter ratio basal lateral vein/midvein: $0.4-0.45$.

3. Midvein apex: reaching apex.

Secondary veins

4. Number: $2-3$ per side.

5. Insertion: opposite or subopposite.

6. Spacing: concentrated in basal fourth.

7. Course: veins pointing toward apex.

8. Insertion angle: ascendant.

9. Insertion angle variability: increasing proximally.

Minor orders

10. Number of vein orders: four.

11. Intramarginal secondaries: absent.
12. Interior secondaries: present.

13. Intersecondaries: absent.

14. Course: brochidodromous.

15. Areolation: irregular.

Freely Ending Veinlets (FEVs)

16. FEVs branching: simple, or branched.

17. FEVs termination: tracheoid idioblast.

Margin

18. Shape: entire.

19. Sclerotization: not lignified.

20. Marginal ultimate venation: present.

Glands

21. Glandular bodies: laminar.

FIGURE 13. Leaf venation of Diogenesia racemosa (Herzog) Sleumer 


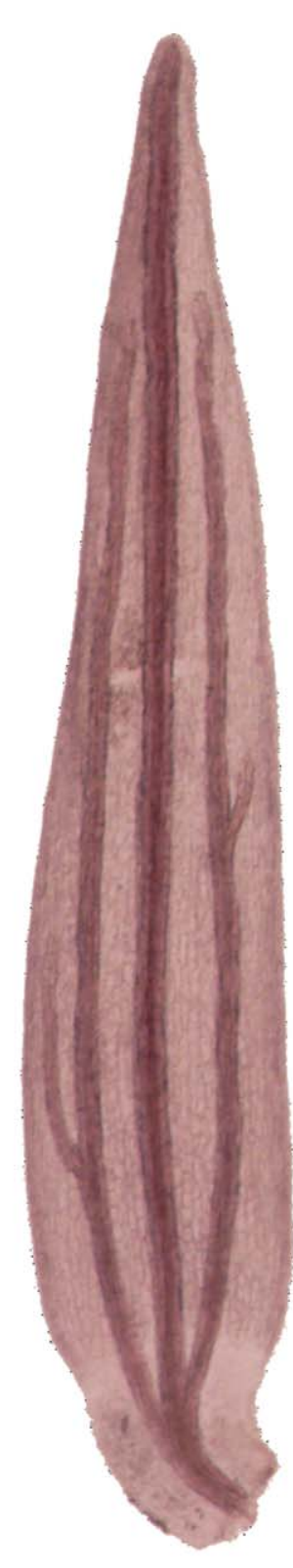

$\underline{3 \mathrm{~mm}}$
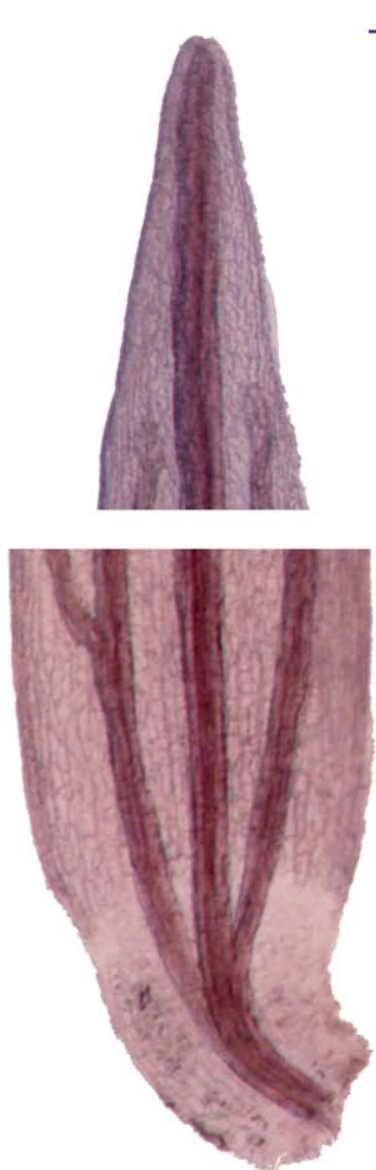

$\underline{0.1 \mathrm{~mm}}$

B. Detail of leaf apex and base.

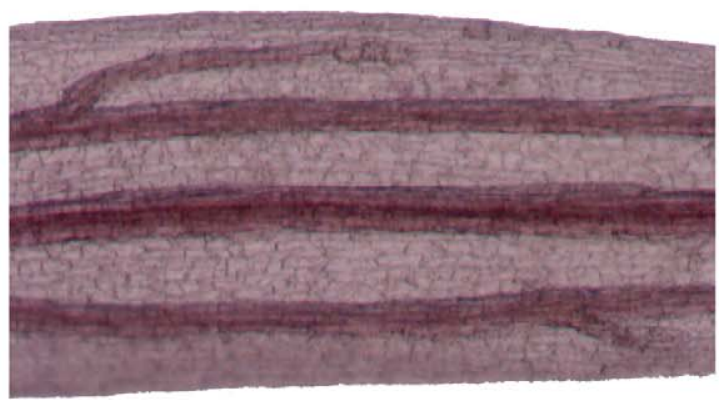

A. Leaf view.

C. Detail of leaf mid-section.

\section{Venation description}

1. Primary framework: acrodromous basal.

2. Diameter ratio basal lateral vein/midvein: $0.75-0.85$.

3. Midvein apex: reaching the apex.

Secondary veins

4. Number: 1 per side.

5. Insertion: opposite.

6. Spacing: concentrated in the base.

7. Course: veins pointing toward apex.

8. Insertion angle: ascendant.

9. Insertion angle variability: NA.

Minor orders

10. Number of vein orders: two.

11. Intramarginal secondaries: absent.
12. Interior secondaries: absent.

13. Intersecondaries: absent.

14. Course: eucamptodromous.

15. Areolation: lacking.

Freely Ending Veinlets (FEVs)

16. FEVs branching: simple.

17. FEVs termination: tracheoid idioblast.

Margin

18. Shape: entire.

19. Sclerotization: not lignified.

20. Marginal ultimate venation: present.

Glands

21. Glandular bodies: absent.

FIGURE 14. Leaf venation of Disterigma agathosmoides (Weddell) Niedenzu 


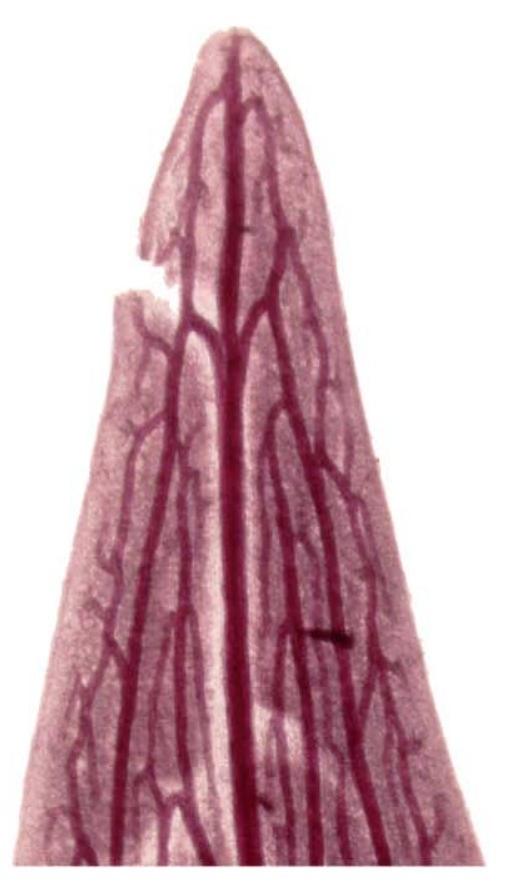

$\underline{0.2 \mathrm{~mm}}$

\section{A. Detail of leaf apex.}

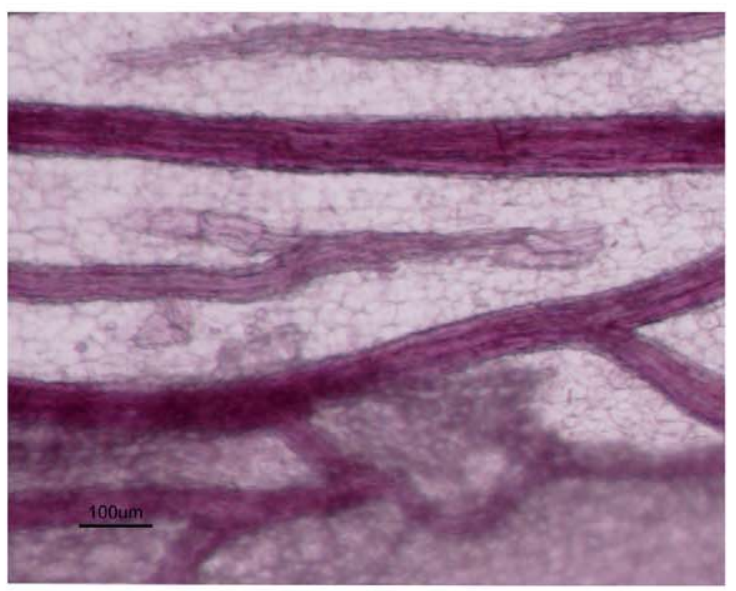

C. Freely ending veinlets.

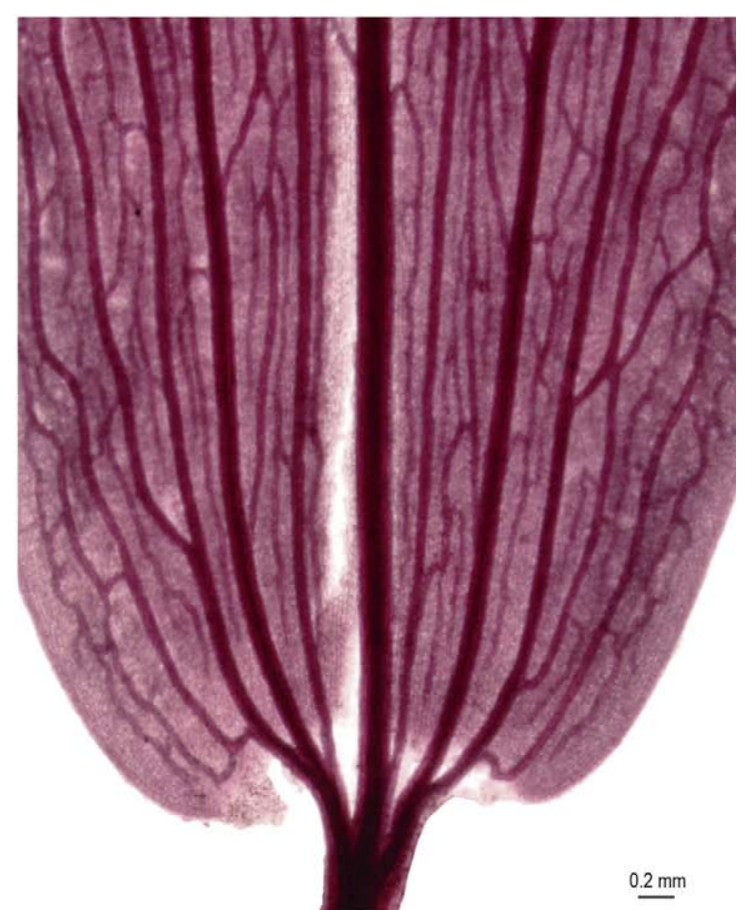

B. Detail of leaf base.

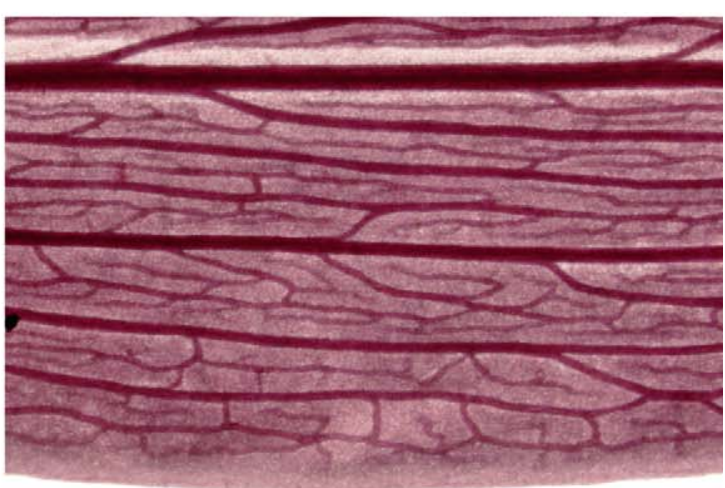

$\underline{0.5 \mathrm{~mm}}$

\section{Detail of leaf margin.}

\section{Venation description}

1. Primary framework: parallelodromous.

2. Diameter ratio basal lateral vein/midvein: 0.83 .

3. Midvein apex: reaching the apex.

Secondary veins

4. Number: $2-3$ per side.

5. Insertion: opposite.

6. Spacing: concentrated in basal fourth.

7. Course: veins pointing toward apex.

8. Insertion angle: adpressed or ascendant.

9. Insertion angle variability: NA.

Minor orders

10. Number of vein orders: three.

11. Intramarginal secondaries: absent.

12. Interior secondaries: present.
13. Intersecondaries: absent.

14. Course: brochidodromous.

15. Areolation: irregular.

Freely Ending Veinlets (FEVs)

16. FEVs branching: mostly simple.

17. FEVs termination: tracheoid idioblast.

Margin

18. Shape: entire.

19. Sclerotization: not lignified.

20. Marginal ultimate venation: present.

Glands

21. Glandular bodies: absent.

FIGURE 15. Leaf venation of Disterigma parallelinerve Pedraza 


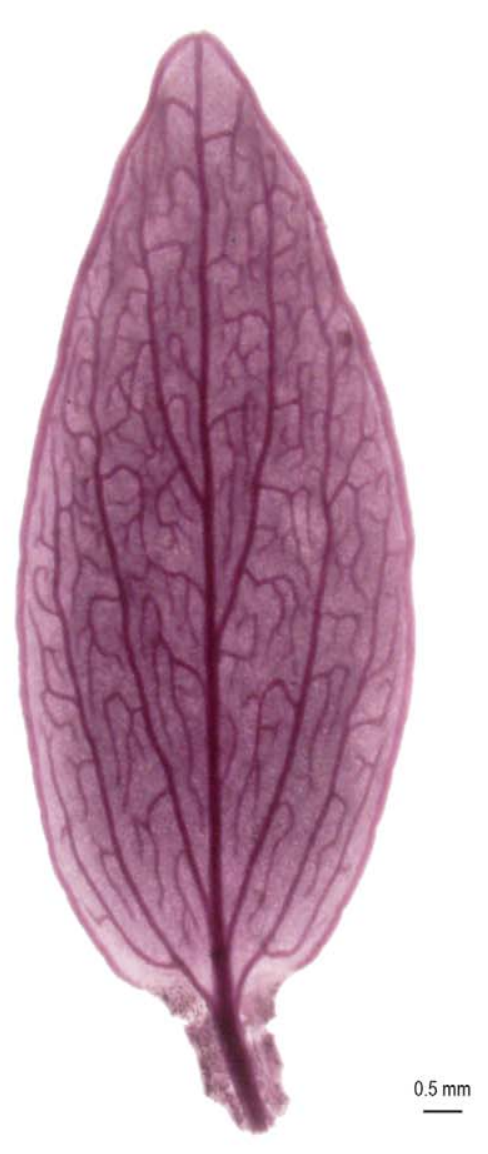

A. Leaf view.

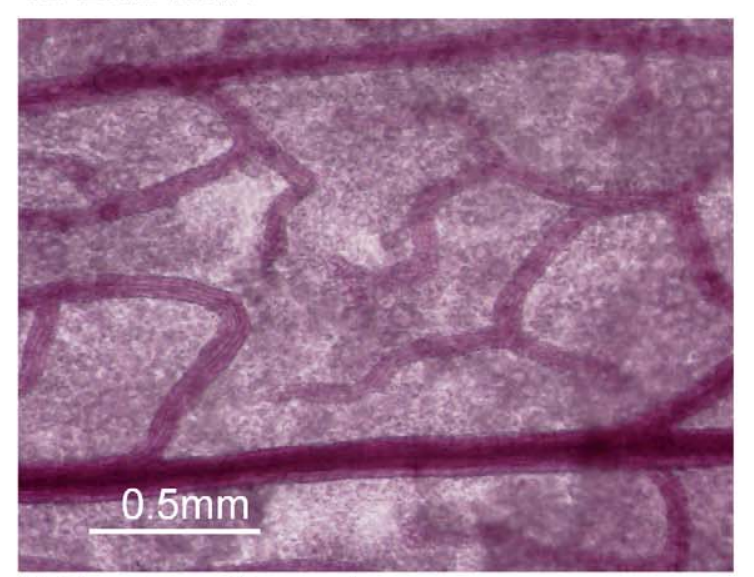

C. Freely ending veinlets.
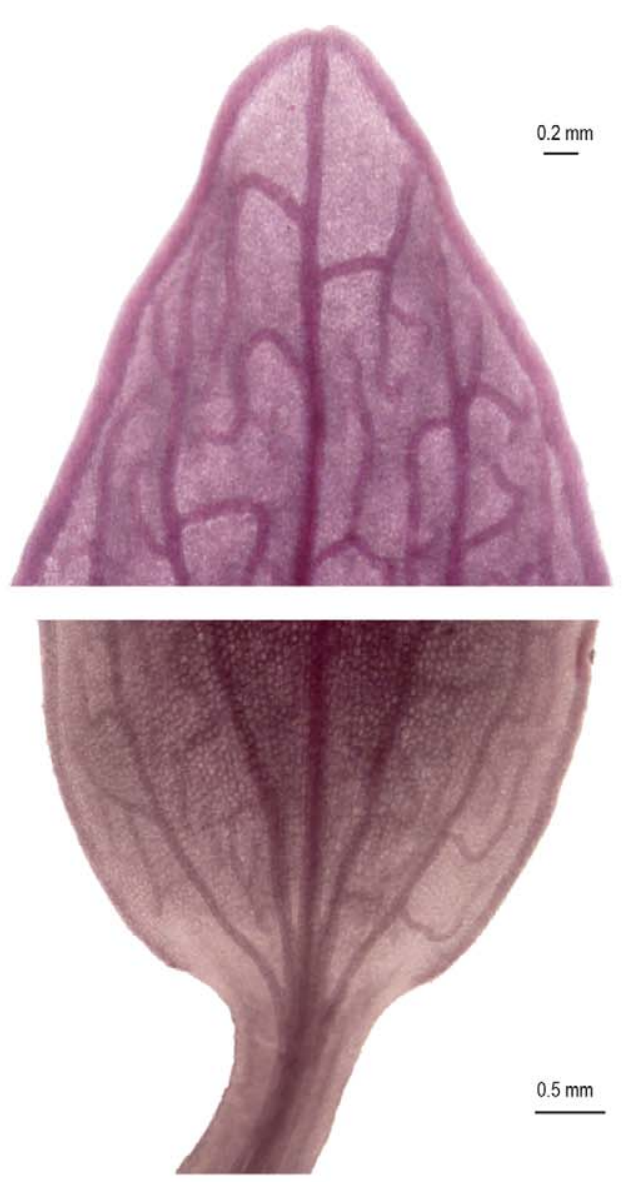

B. Detail of leaf apex and base.

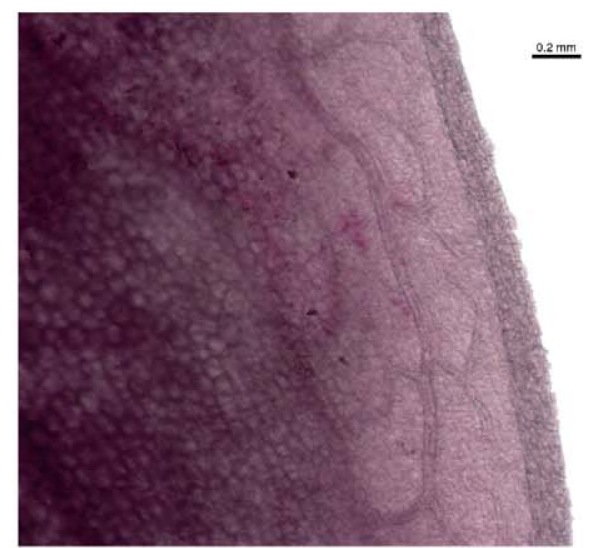

D. Detail of leaf margin.

\section{Venation description}

1. Primary framework: pinnate.

2. Diameter ratio basal lateral vein/midvein: $0.27-0.73$.

3. Midvein apex: reaching the apex.

Secondary veins

4. Number: 2-3 per side.

5. Insertion: opposite or alternate.

6. Spacing: concentrated in the basal $1 / 4-3 / 4$.

7. Course: veins pointing toward apex.

8. Insertion angle: ascendant.

9. Insertion angle variability: consistent.

Minor orders

10. Number of vein orders: three.

11. Intramarginal secondaries: absent.
12. Interior secondaries: absent.

13. Intersecondaries: absent.

14. Course: brochidodromous.

15. Areolation: lacking.

Freely Ending Veinlets (FEVs)

16. FEVs branching: simple.

17. FEVs termination: simple.

Margin

18. Shape: entire.

19. Sclerotization: lignified.

20. Marginal ultimate venation: present.

Glands

21. Glandular bodies: absent.

FIGURE 16. Leaf venation of Disterigma pentandrum S.F.Blake 

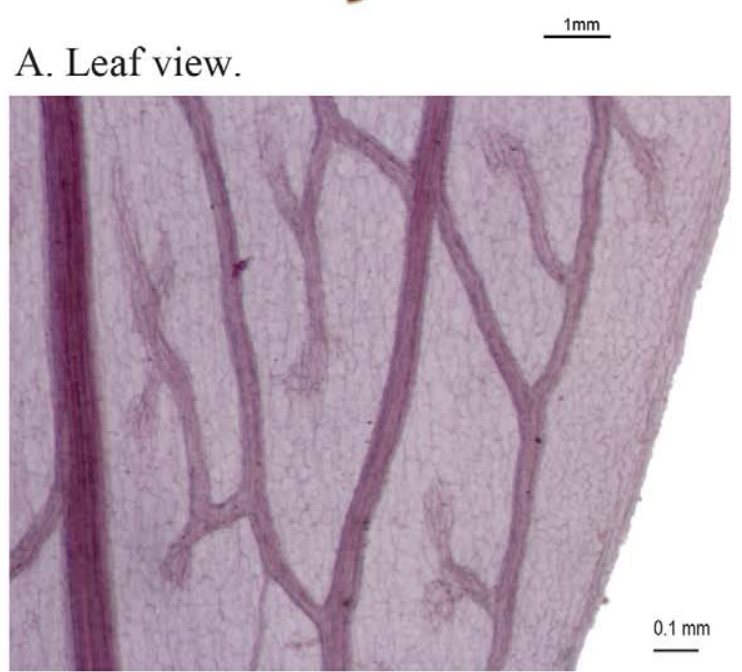

C. Freely ending veinlets.
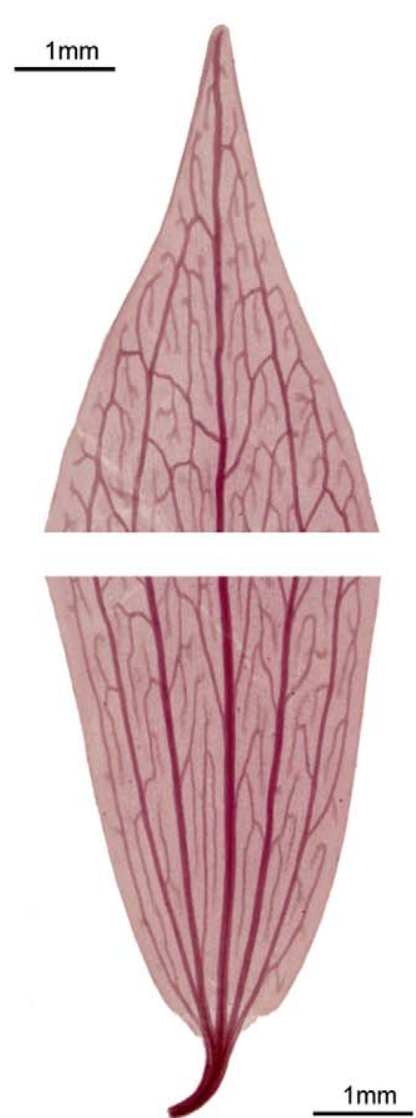

B. Detail of leaf apex and base.

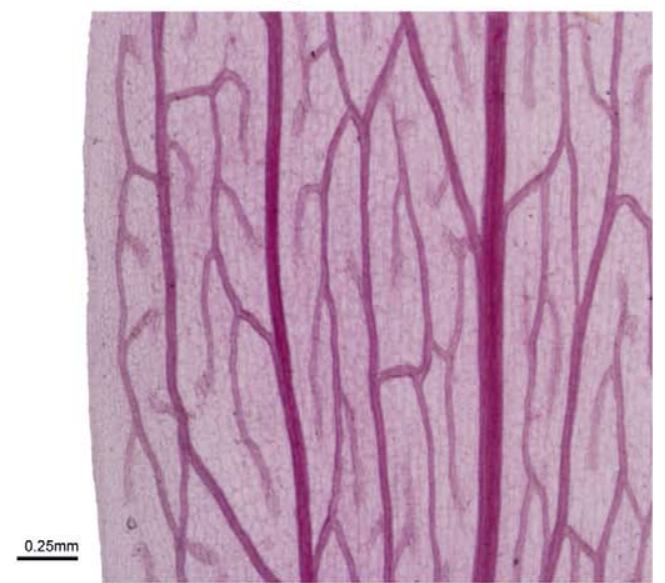

D. Detail of leaf margin.

\section{Venation description}

1. Primary framework: parallelodromous.

2. Diameter ratio basal lateral vein/midvein: $0.89-1.0$.

3. Midvein apex: not reaching the apex.

Secondary veins

4. Number: 2 per side.

5. Insertion: opposite.

6. Spacing: concentrated in basal tenth.

7. Course: veins pointing toward apex.

8. Insertion angle: ascendant.

9. Insertion angle variability: NA.

Minor orders

10. Number of vein orders: three.

11. Intramarginal secondaries: absent.
12. Interior secondaries: absent.

13. Intersecondaries: absent.

14. Course: brochidodromous.

15. Areolation: irregular.

Freely Ending Veinlets (FEVs)

16. FEVs branching: simple or branched.

17. FEVs termination: tracheoid idioblast.

Margin

18. Shape: entire.

19. Sclerotization: not lignified.

20. Marginal ultimate venation: present.

Glands

21. Glandular bodies: absent.

FIGURE 17. Leaf venation of Disterigma pseudokillipiella Luteyn 


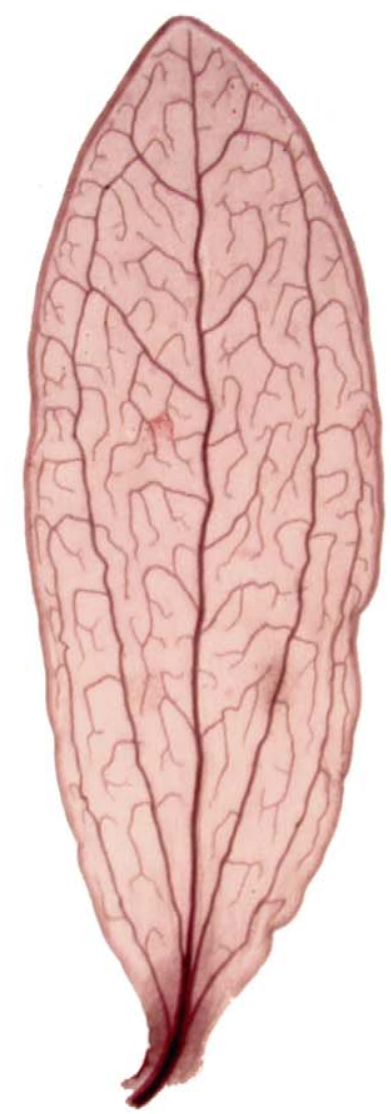

A. Leaf view.

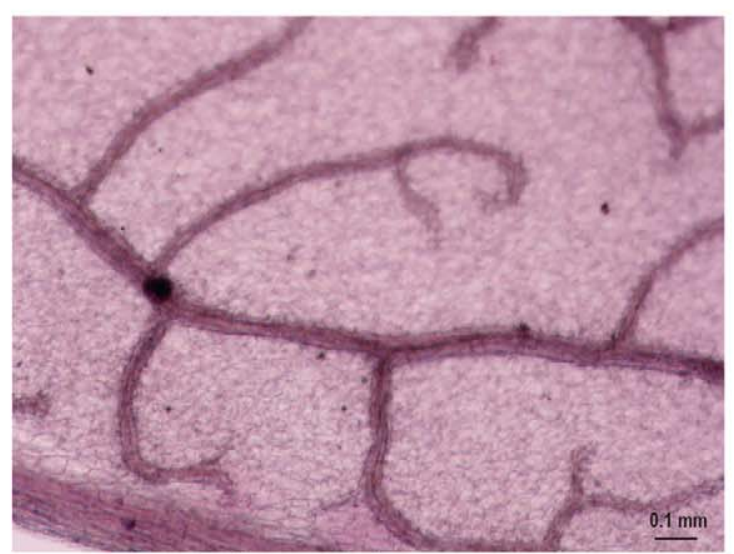

C. Freely ending veinlets.
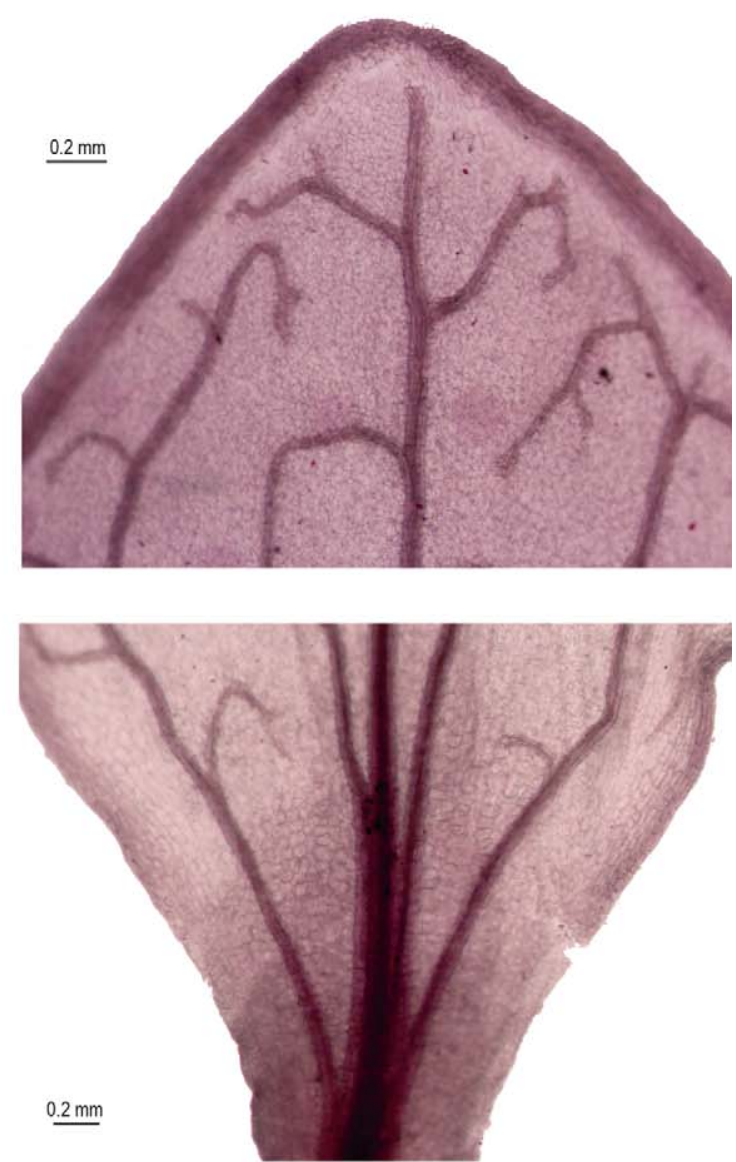

B. Detail of leaf apex and base.

$0.2 \mathrm{~mm}$

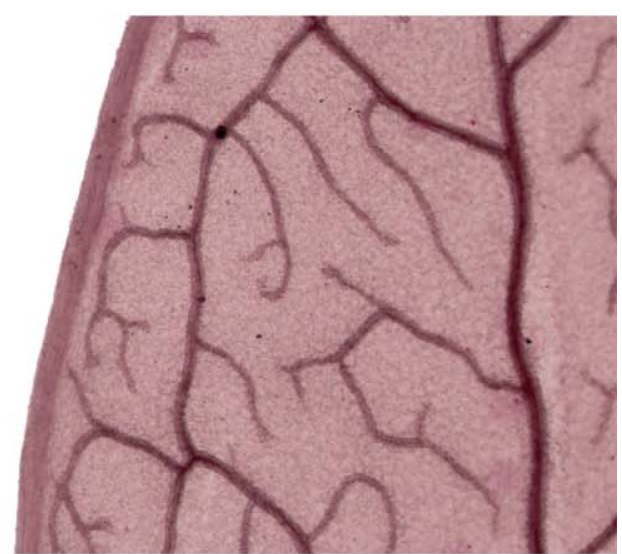

D. Detail of leaf margin.

\section{Venation description}

1. Primary framework: acrodromous suprabasal.

2. Diameter ratio basal lateral vein/midvein: $0.5-0.64$.

3. Midvein apex: reaching the apex or not.

Secondary veins

4. Number: $3-4$ per side.

5. Insertion: opposite, subopposite or alternate.

6. Spacing: concentrated in the basal eight and the apical half.

7. Course: basal veins pointing toward apex, apical veins toward margin.

8. Insertion angle: ascendant or diffuse.

9 . Insertion angle variability: mixed.

Minor orders

10. Number of vein orders: three.
11. Intramarginal secondaries: absent.

12. Interior secondaries: absent.

13. Intersecondaries: present.

14. Course: brochidodromous.

15. Areolation: lacking.

Freely Ending Veinlets (FEVs)

16. FEV s branching: simple or branched.

17. FEVs termination: simple.

Margin

18. Shape: entire.

19. Sclerotization: lignified.

20. Marginal ultimate venation: present.

Glands

21. Glandular bodies: absent.

FIGURE 18. Leaf venation of Disterigma rimbachii (A.C.Smith) Luteyn 


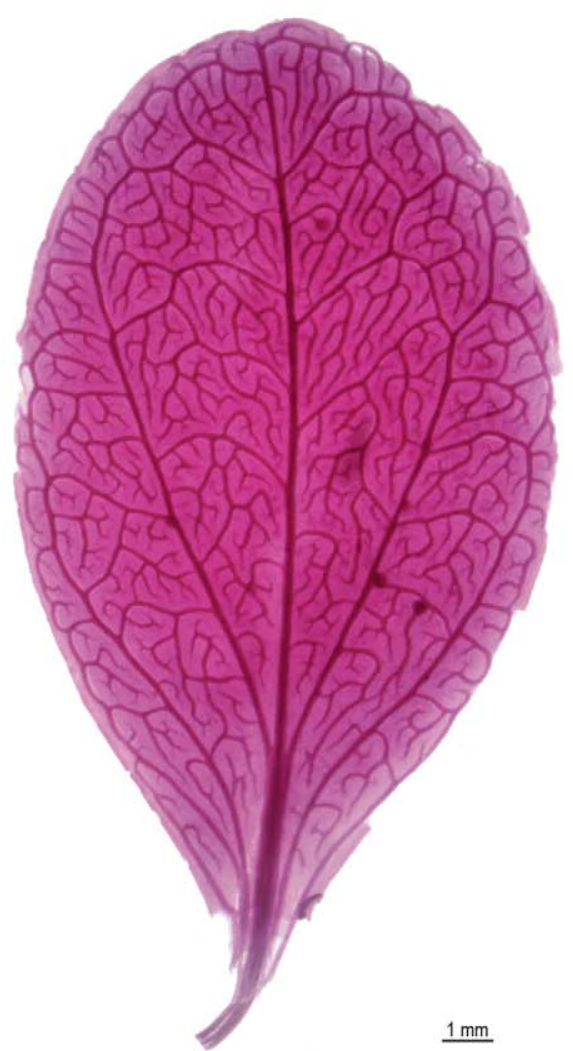

A. Leaf view.

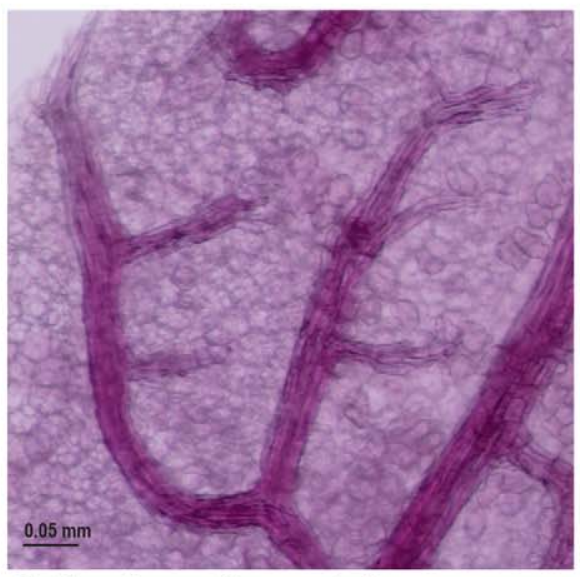

C. Freely ending veinlets.
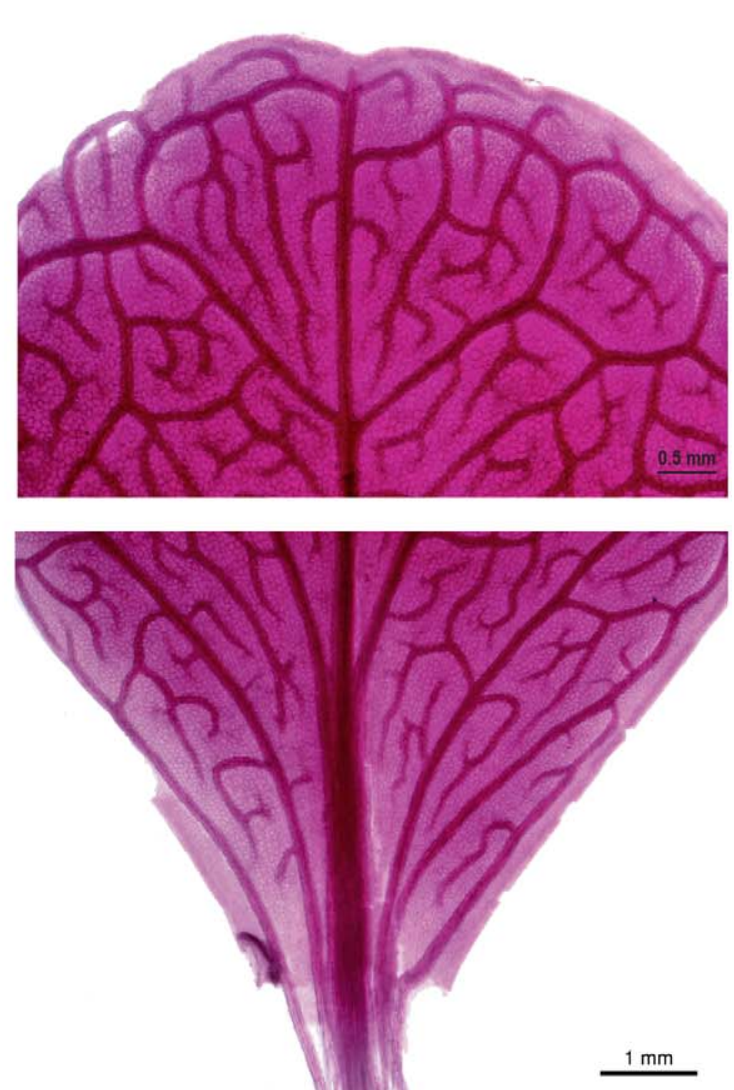

B. Detail of leaf apex and base.

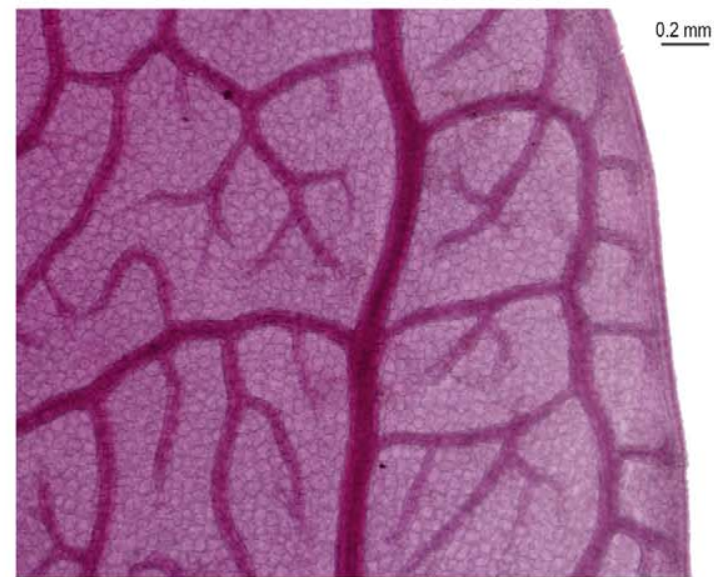

D. Detail of leaf margin.

\section{Venation description}

1. Primary framework: acrodromous suprabasal.

2. Diameter ratio basal lateral vein/midvein: $0.55-0.78$.

3. Midvein apex: reaching the apex or not.

Secondary veins

4. Number: $2-4$ per side.

5. Insertion: opposite or alternate.

6. Spacing: concentrated in the basal fourth.

7. Course: veins pointing toward apex.

8. Insertion angle: adpressed.

9. Insertion angle variability: consistent.

Minor orders

10. Number of vein orders: three.

11. Intramarginal secondaries: absent.
12. Interior secondaries: present.

13. Intersecondaries: present.

14. Course: brochidodromous.

15. Areolation: irregular.

Freely Ending Veinlets (FEVs)

16. FEVs branching: simple or branched.

17. FEVs termination: simple.

Margin

18. Shape: entire.

19. Sclerotization: not lignified.

20. Marginal ultimate venation: present.

Glands

21. Glandular bodies: absent.

FIGURE 19. Leaf venation of Disterigma trimerum Wilber \& Luteyn 


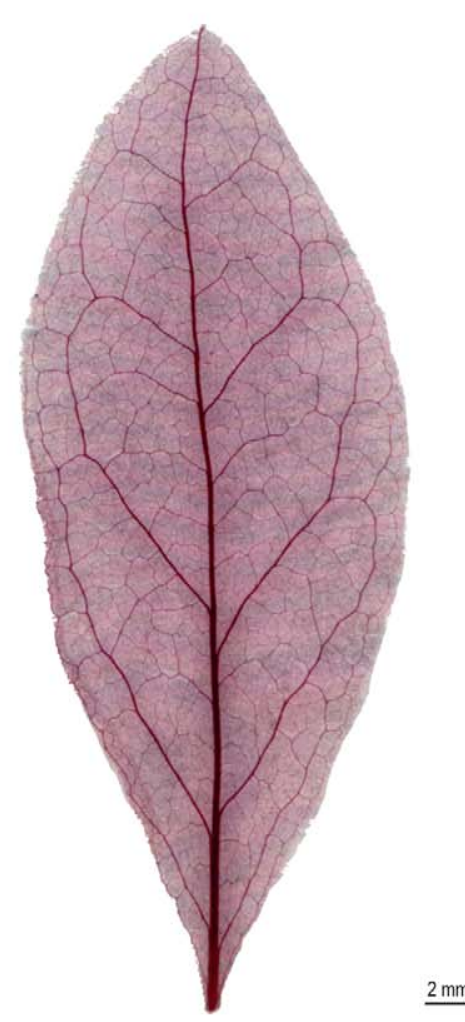

A. Leaf view.

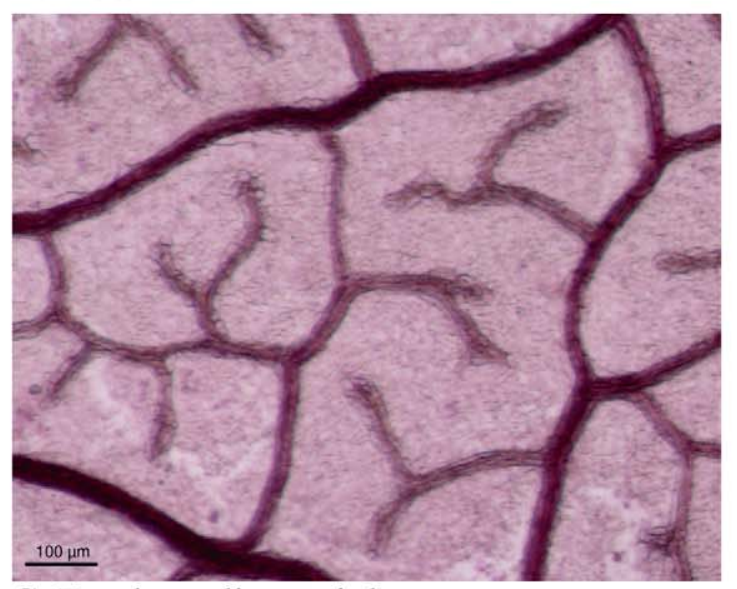

C. Freely ending veinlets.

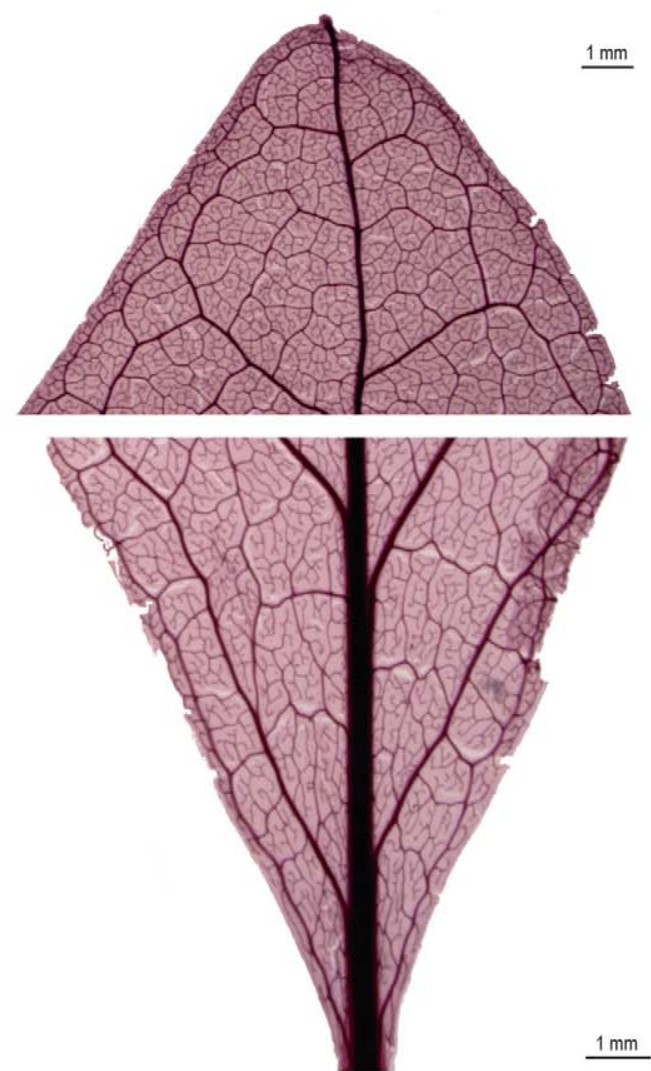

B. Detail of leaf apex and base.

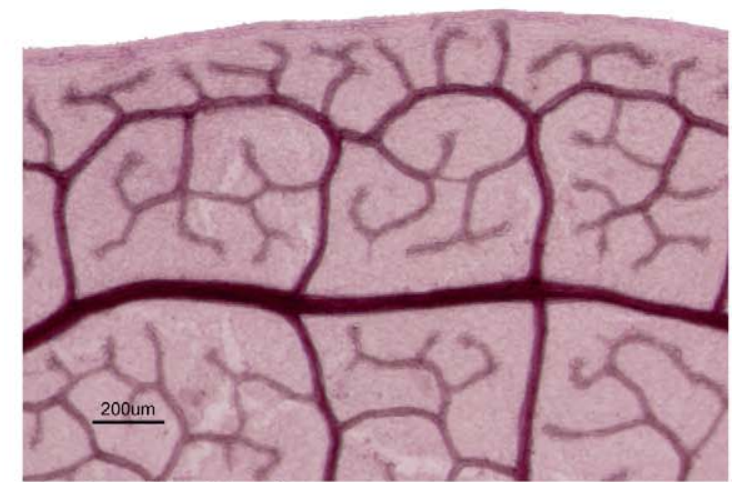

D. Detail of leaf margin.

\section{Venation description}

1. Primary framework: pinnate.

2. Diameter ratio basal lateral vein/midvein: $0.38-0.40$.

3. Midvein apex: reaching the apex.

Secondary veins

4. Number: 4-6 per side.

5. Insertion: alternate.

6. Spacing: dispersed along the lamina.

7. Course: veins pointing toward margin.

8. Insertion angle: diffuse.

9. Insertion angle variability: consistent.

Minor orders

10. Number of vein orders: five.

11. Intramarginal secondaries: present.
12. Interior secondaries: absent.

13. Intersecondaries: present.

14. Course: brochidodromous.

15. Areolation: irregular.

Freely Ending Veinlets (FEVs)

16. FEVs branching: simple, or branched.

17. FEVs termination: simple.

Margin

18. Shape: entire.

19. Sclerotization: not lignified.

20. Marginal ultimate venation: present.

Glands

21. Glandular bodies: absent.

FIGURE 20. Leaf venation of Gaylussacia baccata K.Koch 


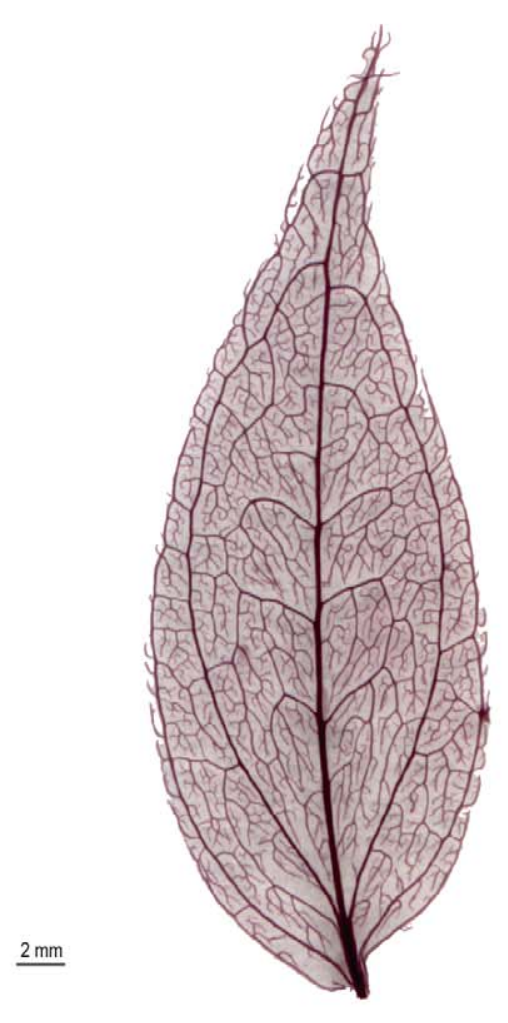

A. Leaf view.

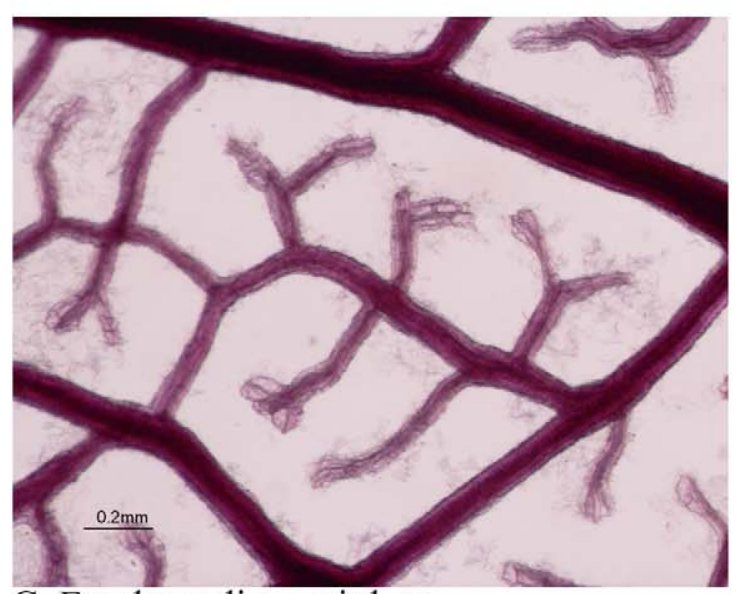

C. Freely ending veinlets.

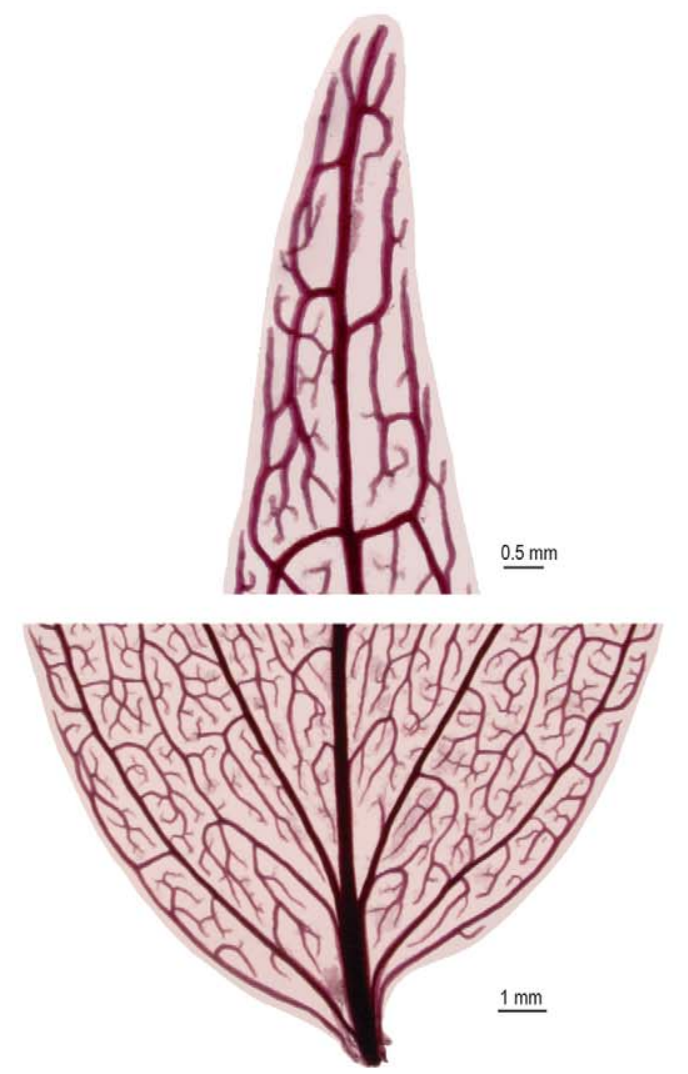

B. Detail of leaf apex and base.

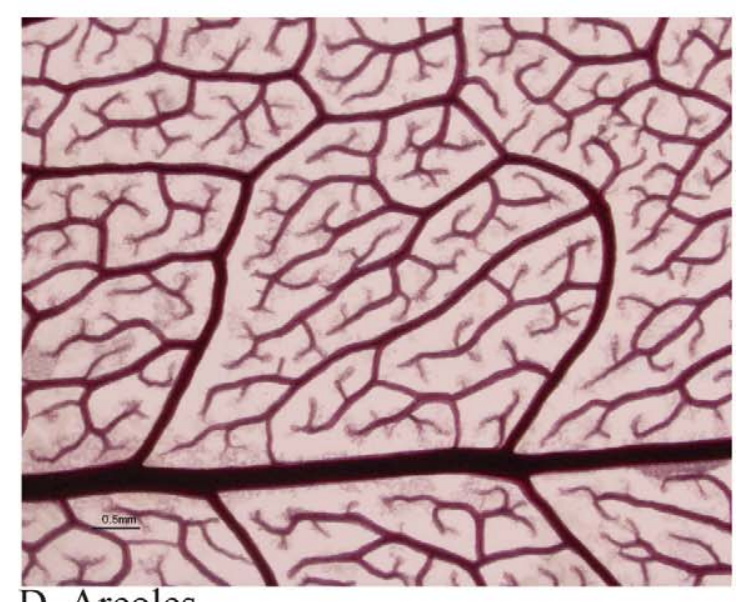

D. Areoles.

\section{Venation description}

1. Primary framework: mixed.

2. Diameter ratio basal lateral vein/midvein: $0.43-0.64$.

3. Midvein apex: reaching the apex.

Secondary veins

4. Number: $2-3$ per side.

5. Insertion: opposite or alternate.

6. Spacing: concentrated in the basal fourth.

7. Course: apical veins pointing to the apex, basal towards margin.

8. Insertion angle: ascendant.

9. Insertion angle variability: increasing proximally or consistent.

Minor orders

10. Number of vein orders: four.
11. Intramarginal secondaries: absent.

12. Interior secondaries: present.

13. Intersecondaries: absent.

14. Course: brochidodromous.

15. Areolation: irregular.

Freely Ending Veinlets (FEVs)

16. FEVs branching: simple, or branched.

17. FEVs termination: tracheoid idioblast.

Margin

18. Shape: entire.

19. Sclerotization: not lignified.

20. Marginal ultimate venation: present.

Glands

21. Glandular bodies: absent.

FIGURE 21. Leaf venation of Gonocalyx costaricensis Luteyn 


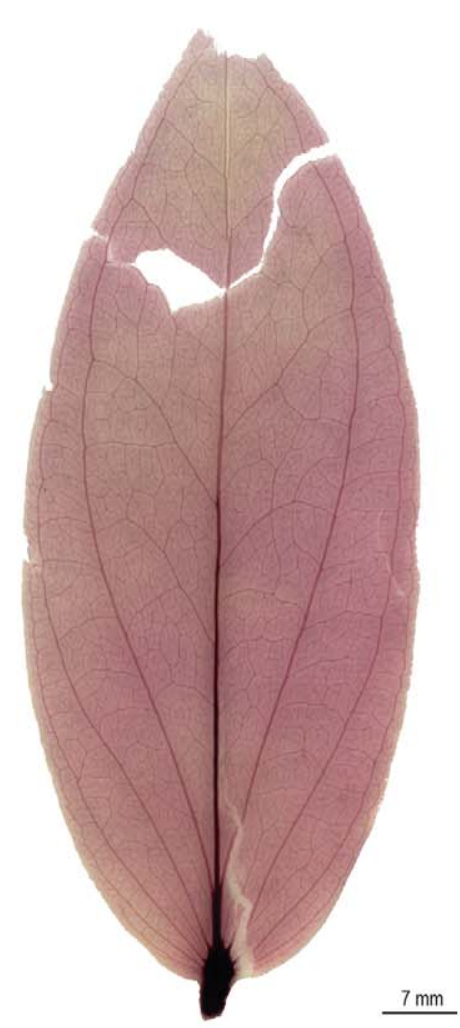

A. Leaf view.

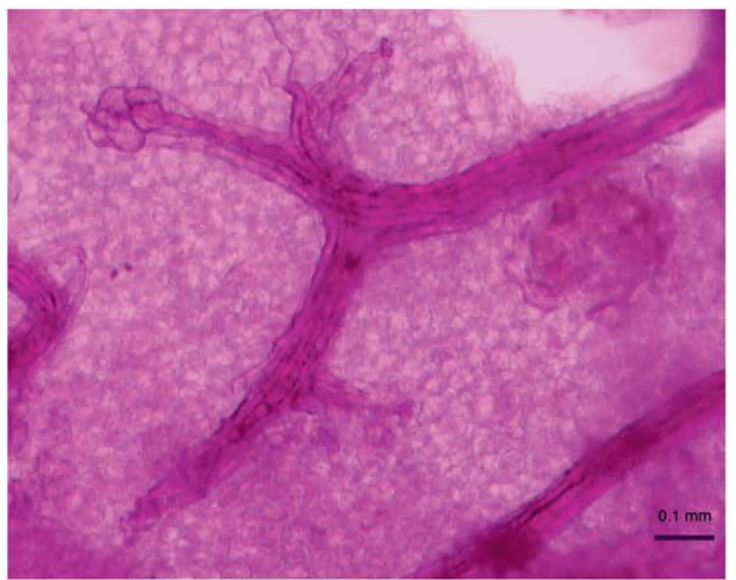

C. Freely ending veinlets.

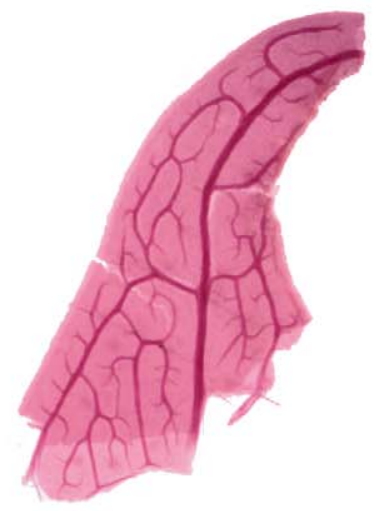

$\underline{1 \mathrm{~mm}}$

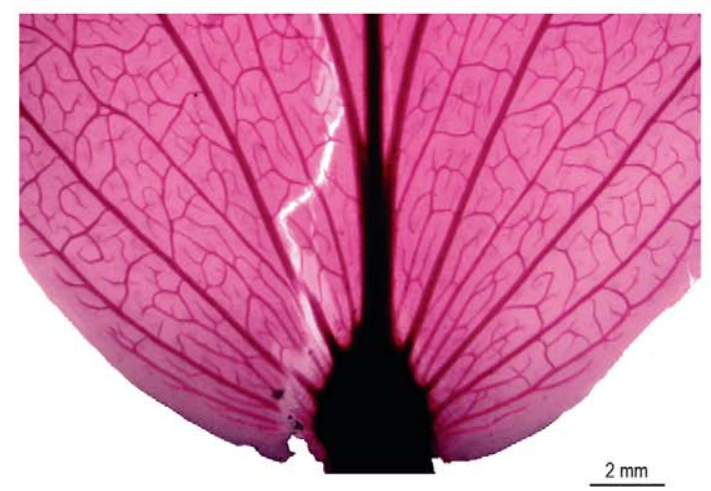

B. Detail of leaf apex and base.

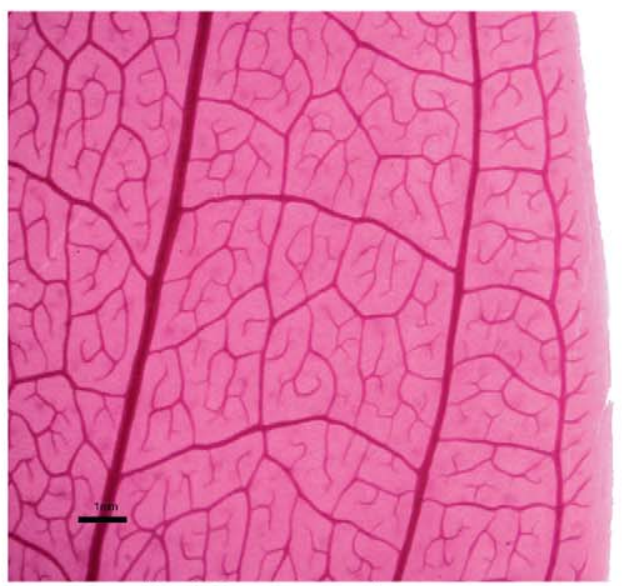

D. Detail of leaf margin.

\section{Venation description}

1. Primary framework: acrodromous suprabasal.

2. Diameter ratio basal lateral vein/midvein: $0.6-0.7$.

3. Midvein apex: NA.

Secondary veins

4. Number: 5 per side.

5. Insertion: opposite.

6. Spacing: concentrated in the basal fourth.

7. Course: veins pointing toward apex.

8. Insertion angle: ascendant.

9. Insertion angle variability: increasing proximally.

Minor orders

10. Number of vein orders: five.

11. Intramarginal secondaries: absent.
12. Interior secondaries: present.

13. Intersecondaries: absent.

14. Course: brochidodromous.

15. Areolation: irregular.

Freely Ending Veinlets (FEVs)

16. FEVs branching: simple, or branched.

17. FEVs termination: tracheoid idioblast.

Margin

18. Shape: entire.

19. Sclerotization: not lignified.

20. Marginal ultimate venation: present.

Glands

21. Glandular bodies: laminar.

FIGURE 22. Leaf venation of Gonocalyx megabracteolatus (Wilbur \& Luteyn) Luteyn 


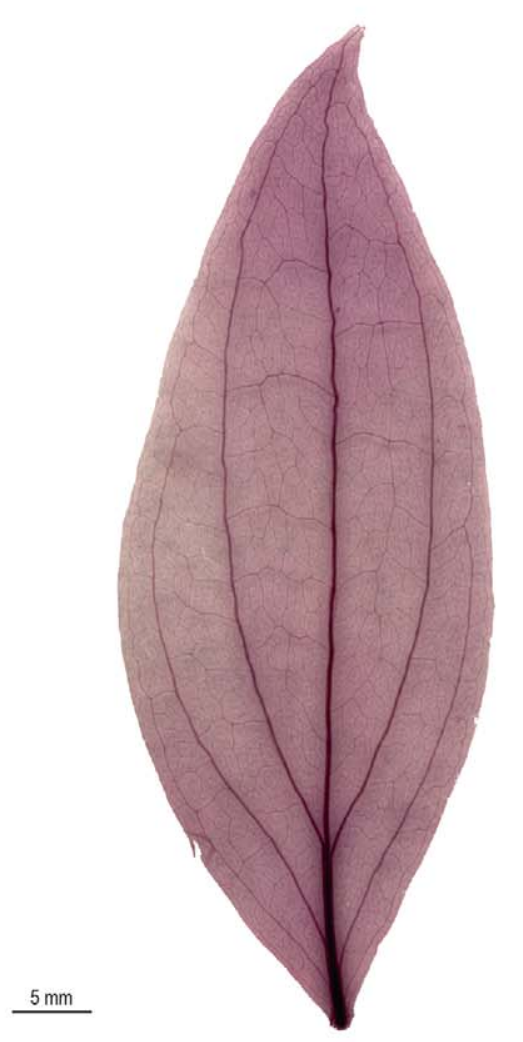

A. Leaf view.

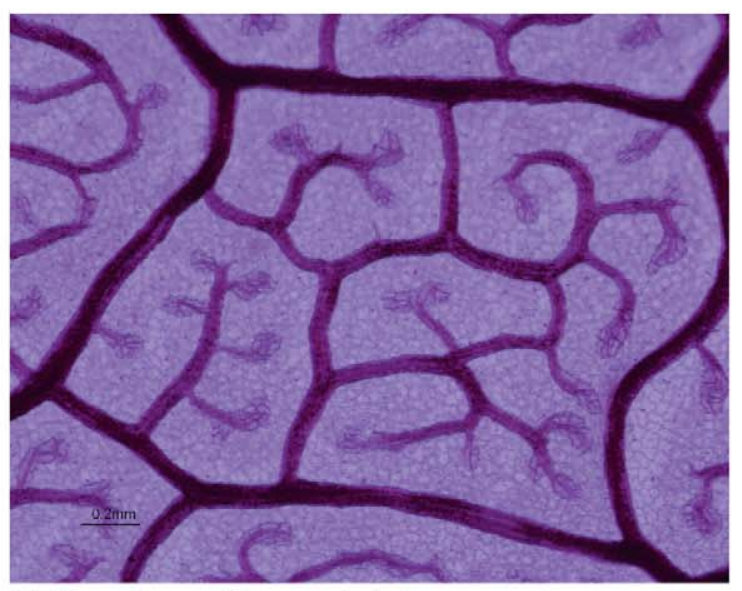

C. Freely ending veinlets.

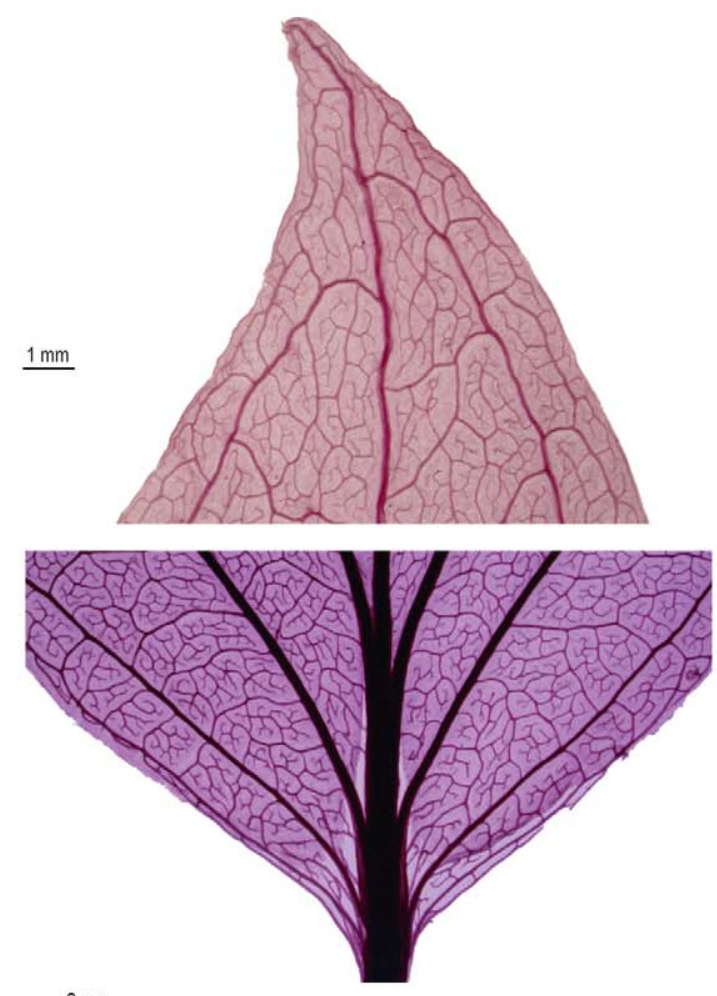

$2 \mathrm{~mm}$

B. Detail of leaf apex and base.

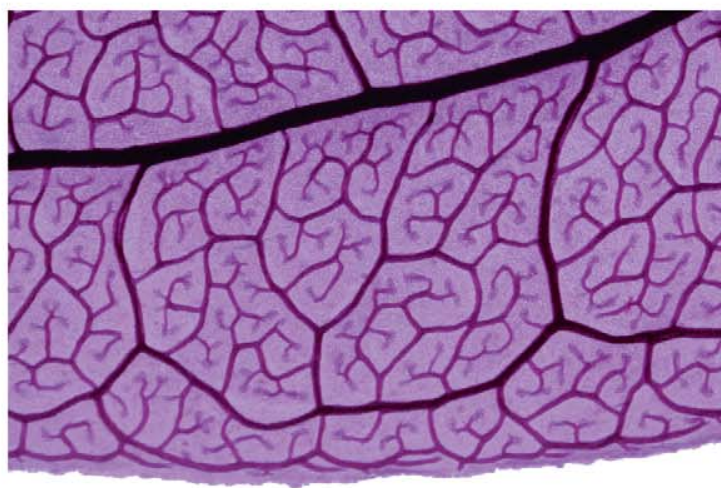

$\underline{0.5 \mathrm{~mm}}$

D. Detail of leaf margin.

Venation description

1. Primary framework: acrodromous suprabasal.

2. Diameter ratio basal lateral vein/midvein: $0.5-0.83$.

3. Midvein apex: reaching the apex.

Secondary veins

4. Number: $2-3$ per side.

5. Insertion: alternate or subopposite.

6. Spacing: concentrated in basal fifth.

7. Course: veins pointing toward apex.

8. Insertion angle: ascendant.

9. Insertion angle variability: consistent.

Minor orders

10. Number of vein orders: four.

11. Intramarginal secondaries: absent.
12. Interior secondaries: present.

13. Intersecondaries: absent.

14. Course: brochidodromous.

15. Areolation: irregular.

Freely Ending Veinlets (FEVs)

16. FEV s branching: simple, or branched.

17. FEVs termination: tracheoid idioblast.

Margin

18. Shape: entire.

19. Sclerotization: not lignified.

20. Marginal ultimate venation: present.

Glands

21. Glandular bodies: absent.

FIGURE 23. Leaf venation of Macleania bullata Yeo 


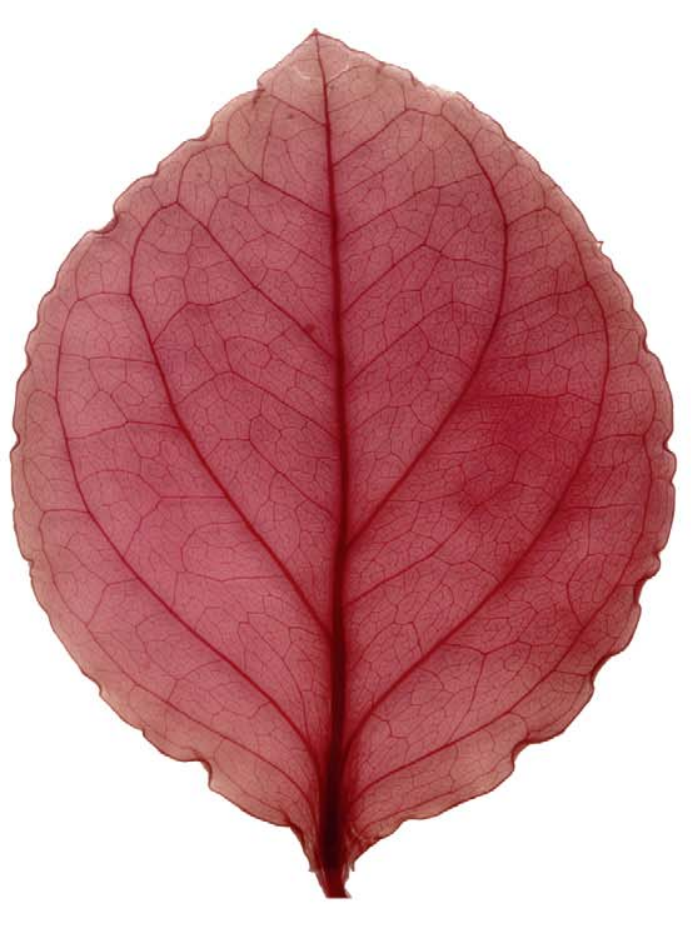

$7 \mathrm{~mm}$

A. Leaf view.

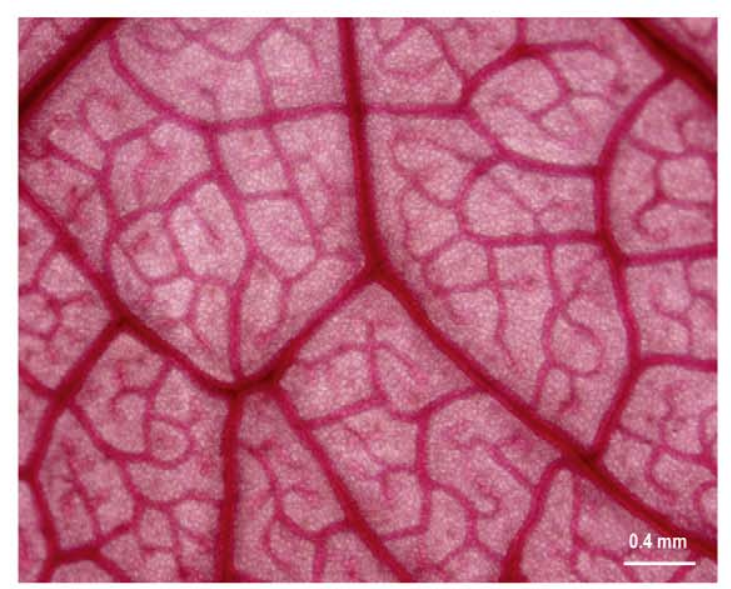

C. Freely ending veinlets.
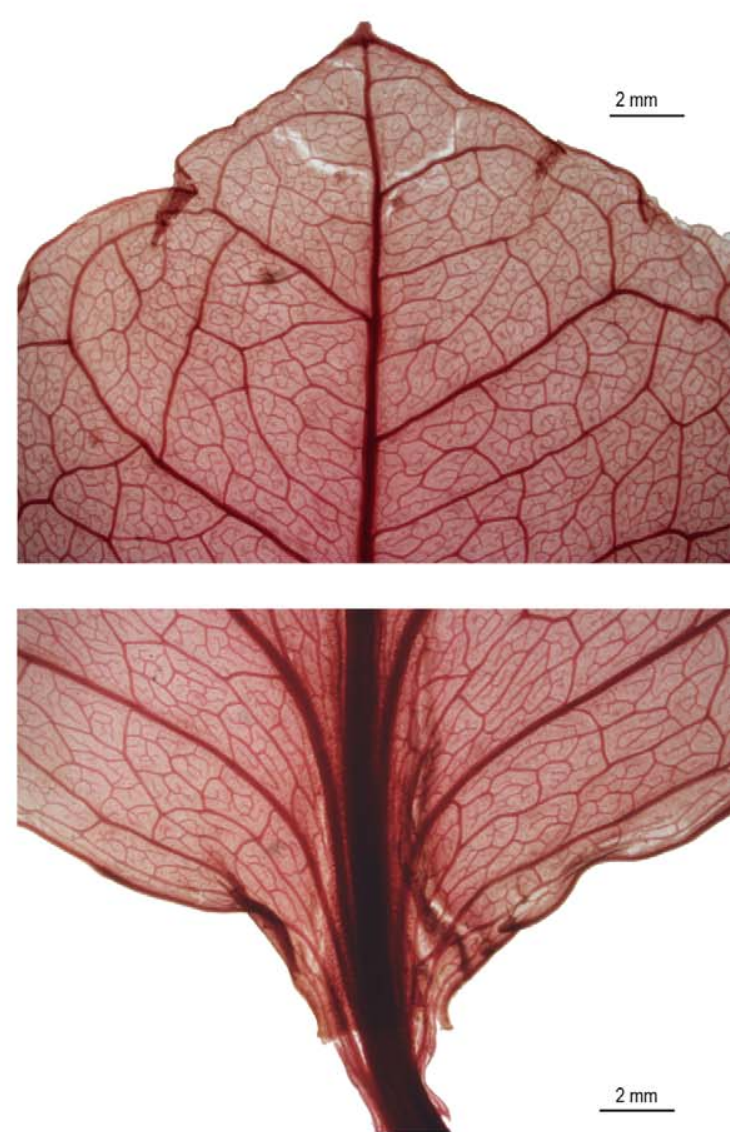

B. Detail of leaf apex and base.

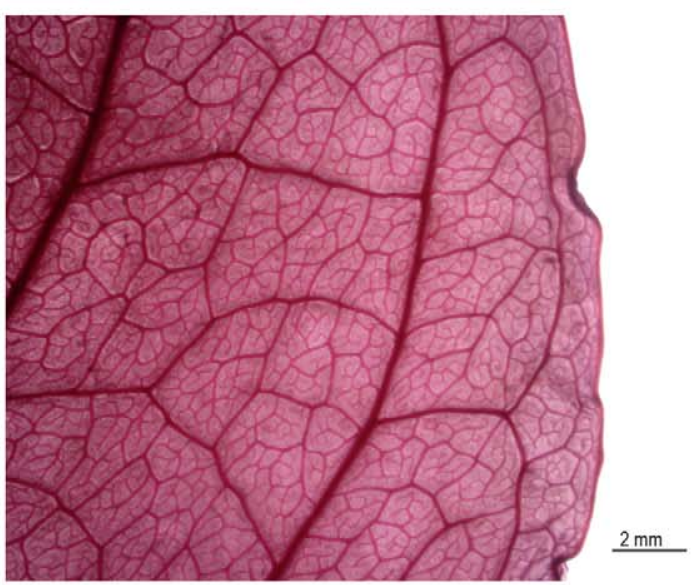

D. Detail of leaf margin.

\section{Venation description}

1. Primary framework: acrodromous suprabasal, occasionally pinnate.

2. Diameter ratio basal lateral vein/midvein: $0.65-0.74$.

3. Midvein apex: reaching the apex.

Secondary veins

4. Number: 4 per side.

5. Insertion: alternate.

6. Spacing: concentrated in basal half.

7. Course: veins pointing toward margin.

8. Insertion angle: ascendant.

9 . Insertion angle variability: mixed.

Minor orders

10. Number of vein orders: four.

11. Intramarginal secondaries: absent.

12. Interior secondaries: present.

13. Intersecondaries: present.

14. Course: brochidodromous.

15. Areolation: irregular.

Freely Ending Veinlets (FEVs)

16. FEV branching: simple, or branched.

17. FEVs termination: tracheoid idioblast.

Margin

18. Shape: entire.

19. Sclerotization: lignified.

20. Marginal ultimate venation: present.

Glands

21. Glandular bodies: absent.

FIGURE 24. Leaf venation of Macleania coccoloboides A.C.Smith 


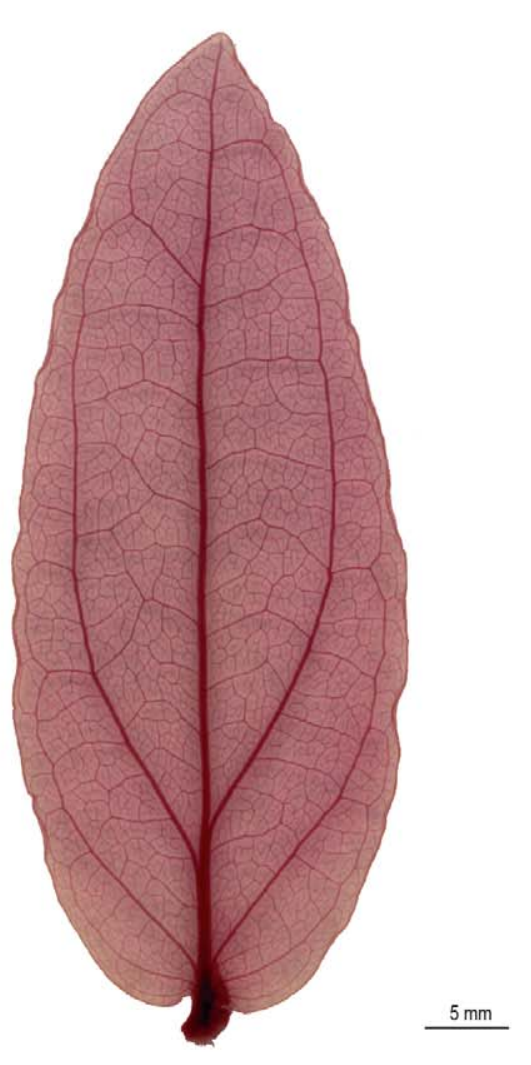

A. Leaf view.

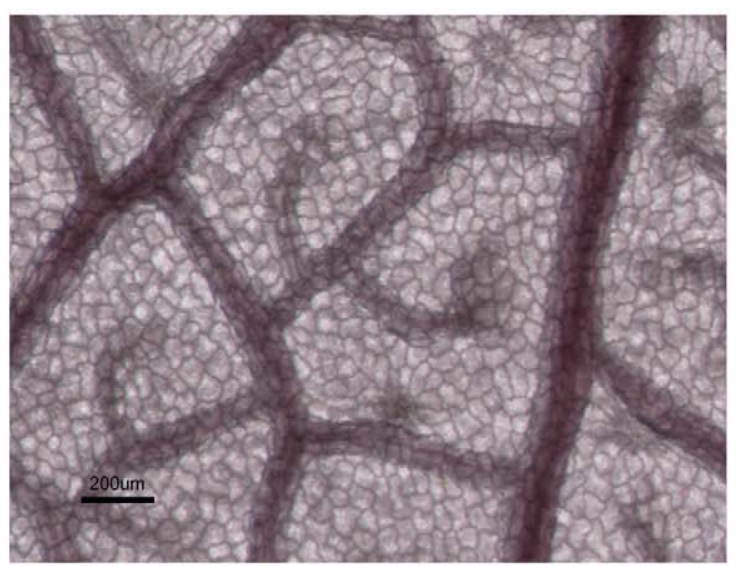

C. Freely ending veinlets.
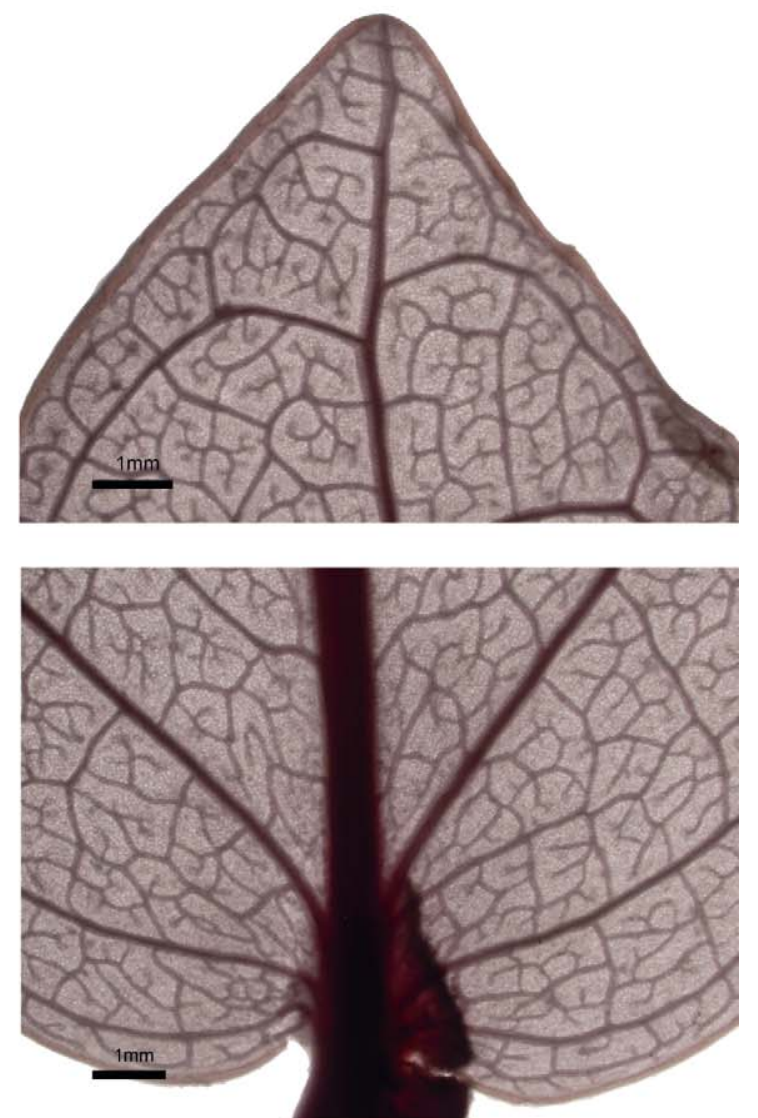

B. Detail of leaf apex and base.

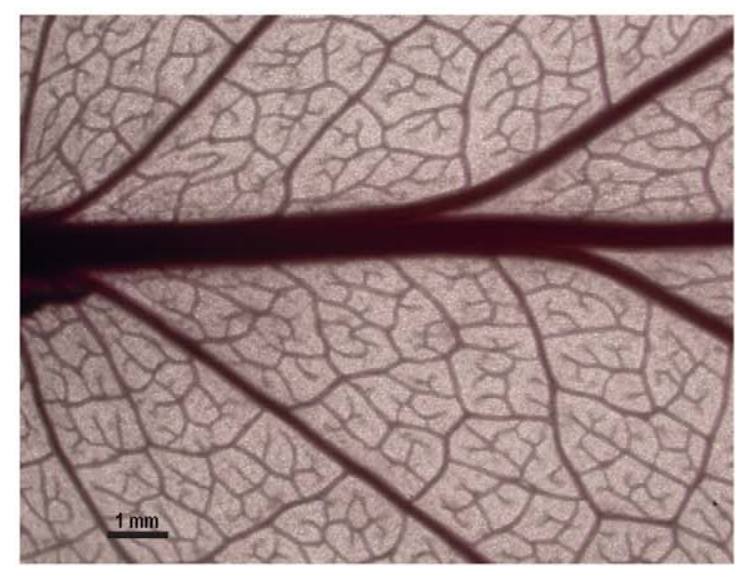

D. Detail of leaf mid-section.

1. Primary framework: acrodromous suprabasal.

Venation description

2. Diameter ratio basal lateral vein/midvein: 0.6.

12. Interior secondaries: present.

13. Intersecondaries: absent.

14. Course: brochidodromous.

15. Areolation: irregular.

Secondary veins

4. Number: 3 per side.

5. Insertion: alternate or subopposite.

6. Spacing: concentrated in the basal fifth.

7. Course: veins pointing toward apex.

8. Insertion angle: ascendant to diffuse.

9. Insertion angle variability: increasing proximally. Minor orders

10. Number of vein orders: four, occasionally five.

11. Intramarginal secondaries: absent.

Freely Ending Veinlets (FEVs)

16. FEVs branching: simple, or branched.

17. FEVs termination: tracheoid idioblast.

Margin

18. Shape: entire.

19. Sclerotization: lignified.

20. Marginal ultimate venation: present.

Glands

21. Glandular bodies: absent.

FIGURE 25. Leaf venation of Macleania cordifolia Benth. 


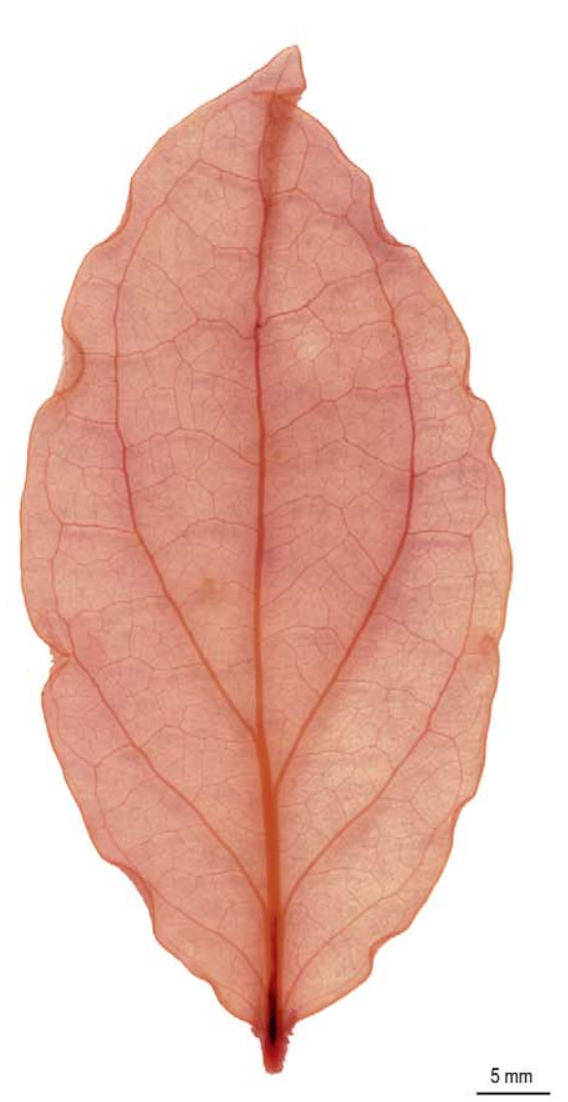

A. Leaf view.

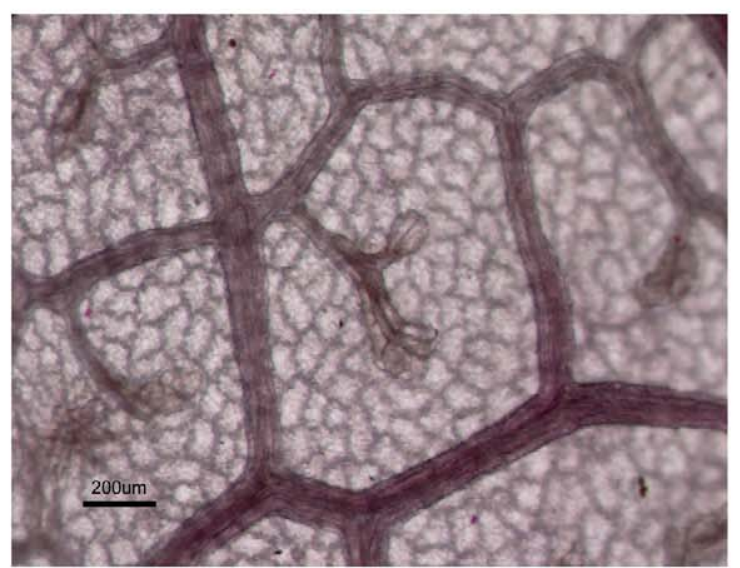

C. Freely ending veinlets.
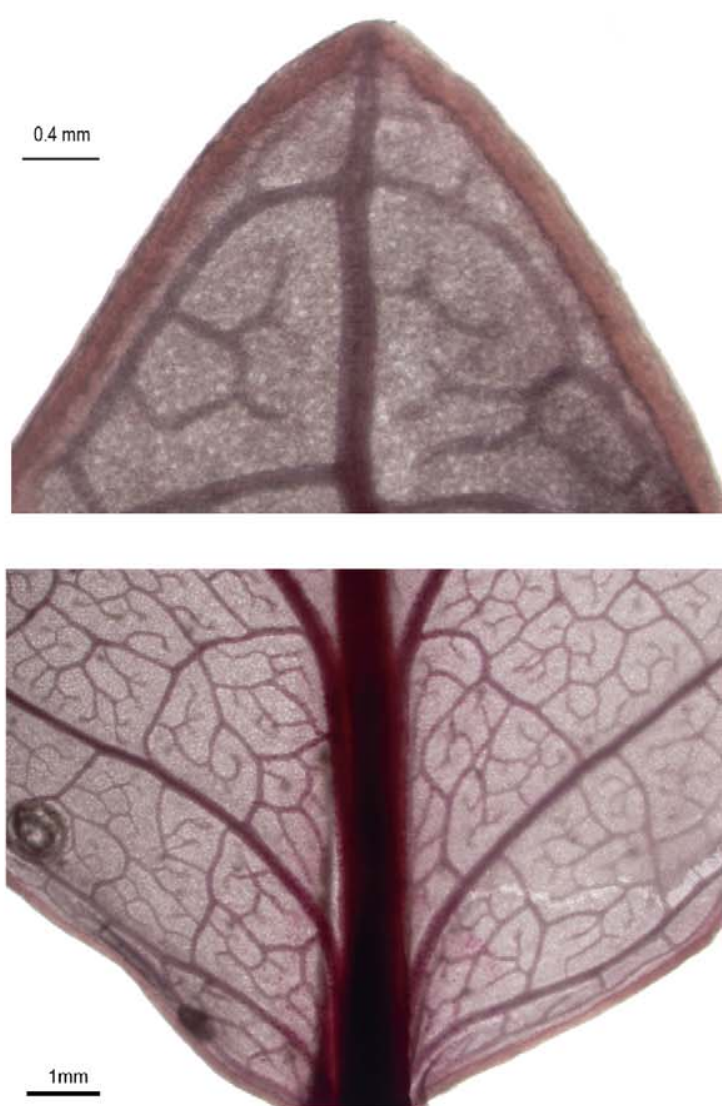

B. Detail of leaf apex and base.

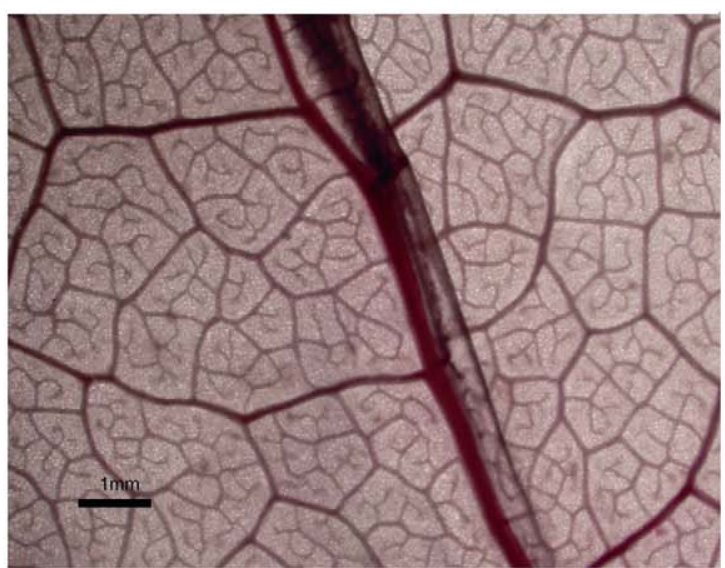

D. Detail of leaf mid-section.

Venation description

1. Primary framework: pinnate, occasionally acrodromous and suprabasal.

2. Diameter ratio basal lateral vein/midvein: 0.39-0.44.

3. Midvein apex: reaching the apex.

Secondary veins

4. Number: 4 per side.

5. Insertion: alternate or opposite.

6. Spacing: concentrated in the basal third.

7. Course: veins pointing toward apex.

8. Insertion angle: adpressed.

9. Insertion angle variability: consistent.

Minor orders

10. Number of vein orders: five.

11. Intramarginal secondaries: absent.
12. Interior secondaries: present.

13. Intersecondaries: absent.

14. Course: brochidodromous.

15. Areolation: irregular.

Freely Ending Veinlets (FEVs)

16. FEVs branching: simple, or branched.

17. FEVs termination: tracheoid idioblast.

Margin

18. Shape: entire.

19. Sclerotization: lignified.

20. Marginal ultimate venation: present.

Glands

21. Glandular bodies: absent.

FIGURE 26. Leaf venation of Macleania rupestris (Kunth) A.C.Smith 


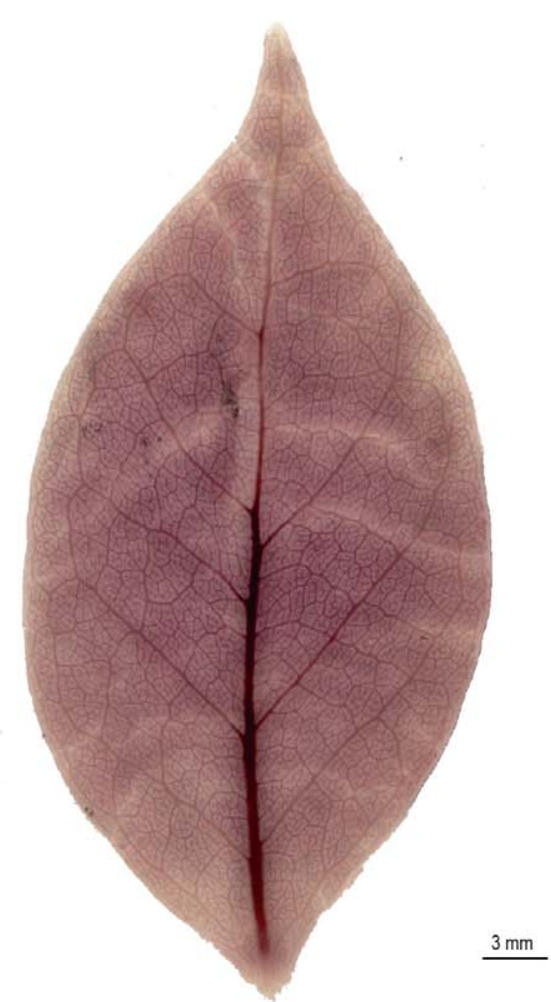

A. Leaf view.

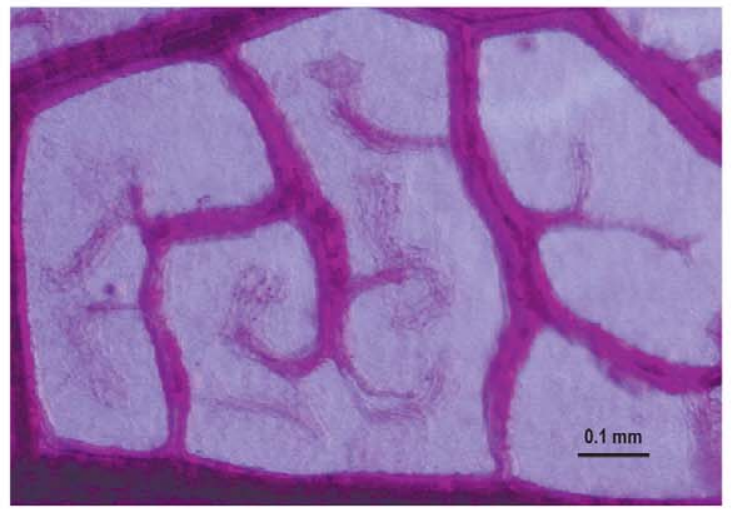

C. Freely ending veinlets.
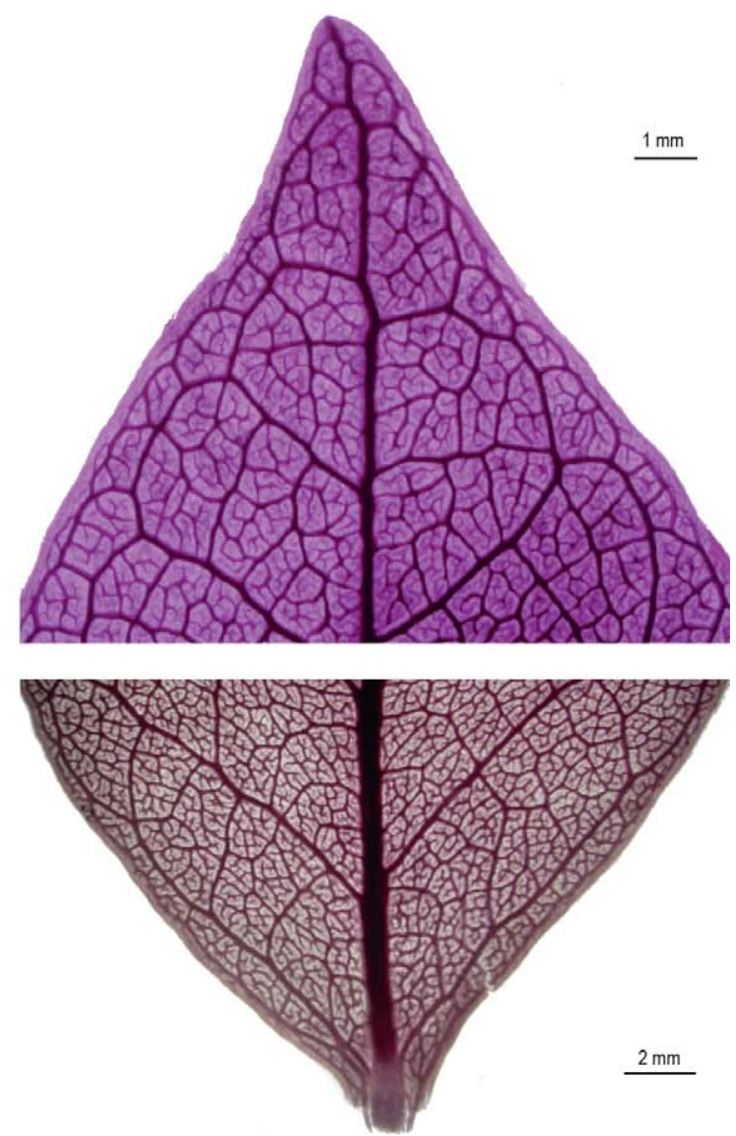

B. Detail of leaf apex and base.

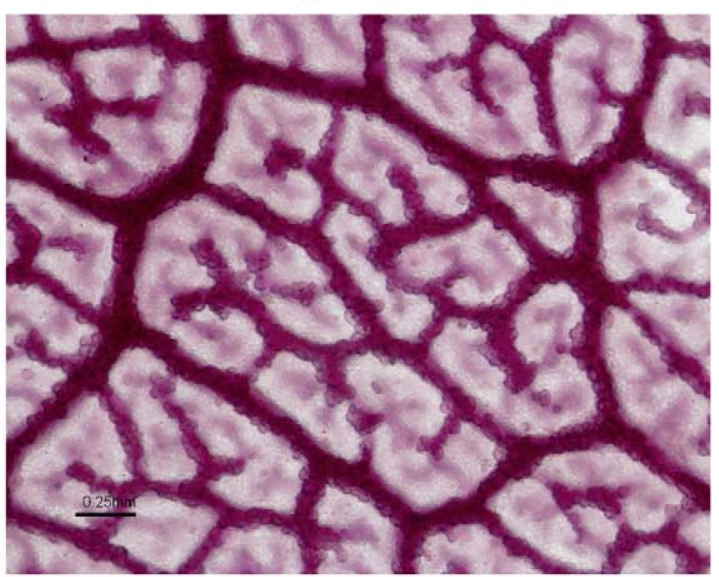

D. Areoles and sheathed veins.

\section{Venation description}

1. Primary framework: pinnate.

2. Diameter ratio basal lateral vein/midvein: $0.35-0.56$.

3. Midvein apex: reaching the apex.

Secondary veins

4. Number: 5-6 per side.

5. Insertion: alternate or subopposite.

6. Spacing: dispersed along the lamina.

7. Course: veins pointing toward margin.

8. Insertion angle: ascendant.

9. Insertion angle variability: consistent or decreasing proximally.

Minor orders

10. Number of vein orders: five.

11. Intramarginal secondaries: absent.
12. Interior secondaries: absent.

13. Intersecondaries: present or absent.

14. Course: brochidodromous.

15. Areolation: irregular.

Freely Ending Veinlets (FEVs)

16. FEVs branching: branched.

17. FEVs termination: simple.

Margin

18. Shape: entire.

19. Sclerotization: lignified.

20. Marginal ultimate venation: present.

Glands

21. Glandular bodies: absent

FIGURE 27. Leaf venation of Notopora schomburgkii Hook.f. 


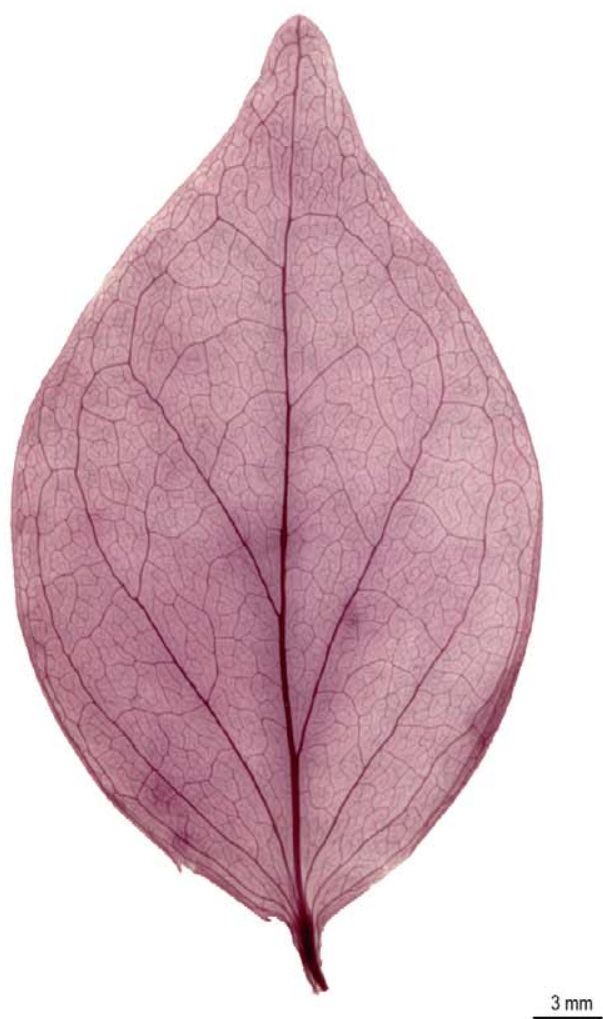

A. Leaf view.

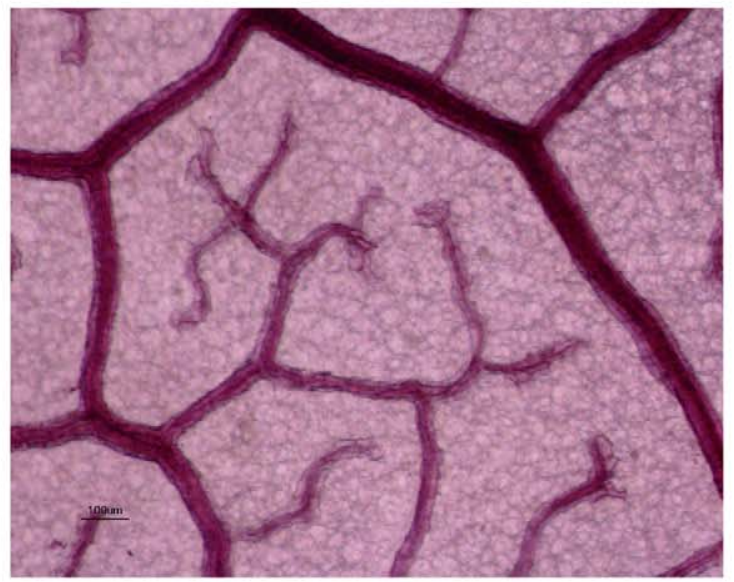

C. Freely ending veinlets.
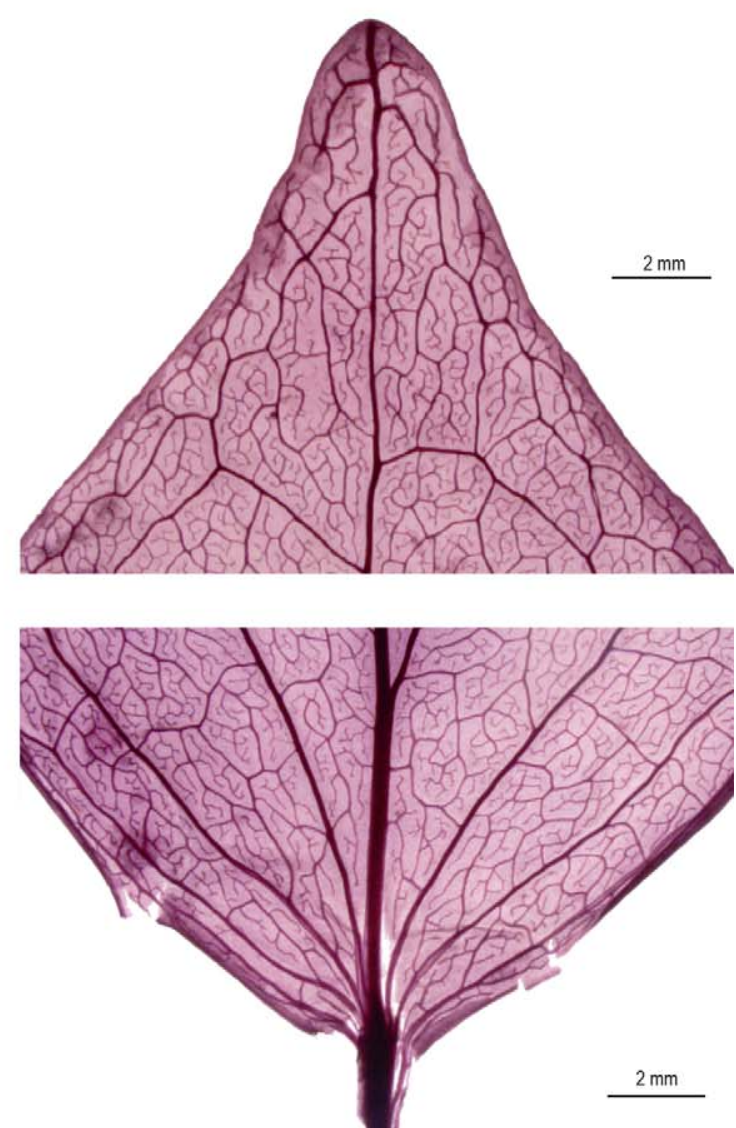

B. Detail of leaf apex and base.

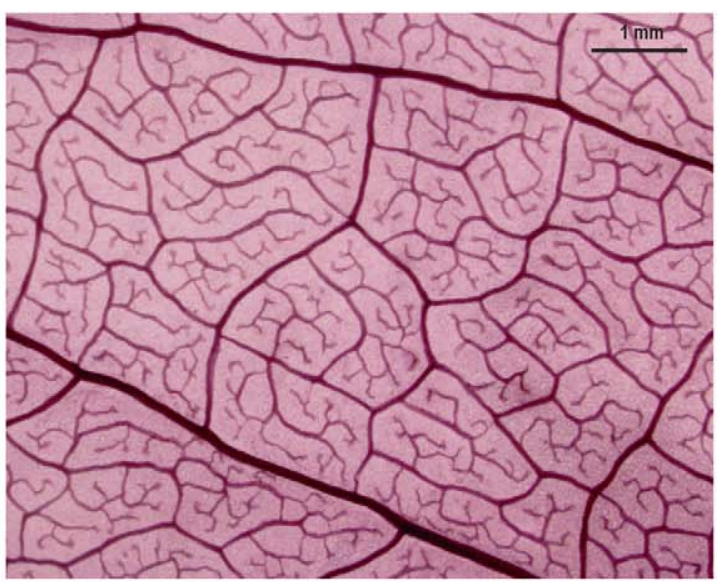

D. Detail of leaf mid-section.

\section{Venation description}

1. Primary framework: acrodromous suprabasal.

2. Diameter ratio basal lateral vein/midvein: 0.4-0.61.

3. Midvein apex: reaching the apex.

Secondary veins

4. Number: 4-6 per side.

5. Insertion: opposite or alternate.

6. Spacing: concentrated in the basal half.

7. Course: veins pointing to the margin.

8. Insertion angle: ascendant or diffuse.

9. Insertion angle variability: decreasing proximally.

Minor orders

10. Number of vein orders: four.

11. Intramarginal secondaries: absent.
12. Interior secondaries: present.

13. Intersecondaries: absent.

14. Course: brochidodromous.

15. Areolation: irregular.

Freely Ending Veinlets (FEVs)

16. FEVs branching: simple, or branched.

17. FEVs termination: tracheoid idioblast.

Margin

18. Shape: entire.

19. Sclerotization: not lignified.

20. Marginal ultimate venation: present.

Glands

21. Glandular bodies: laminar and marginal.

FIGURE 28. Leaf venation of Orthaea apophysata (Griseb.) A.C.Smith 


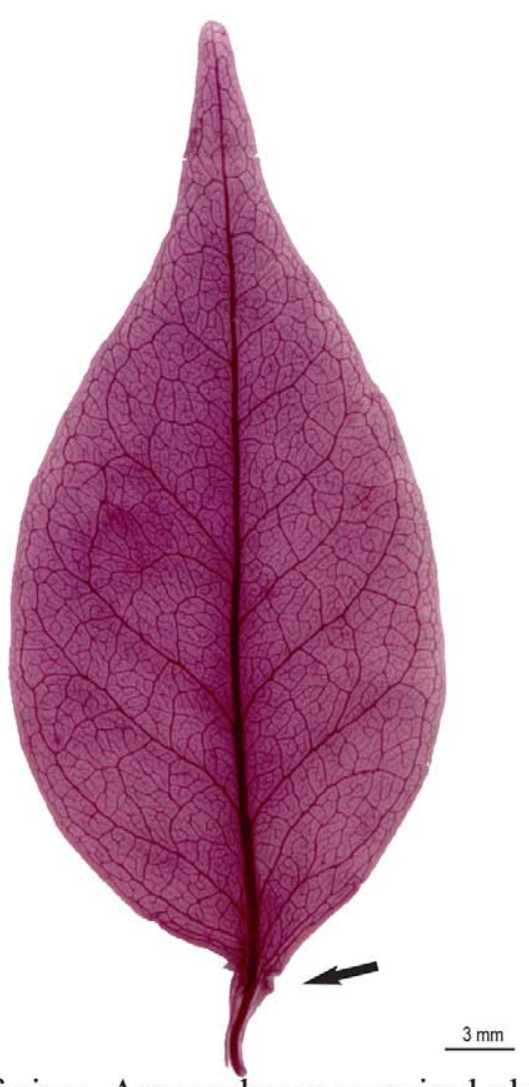

A. Leaf view. Arrow shows marginal gland.

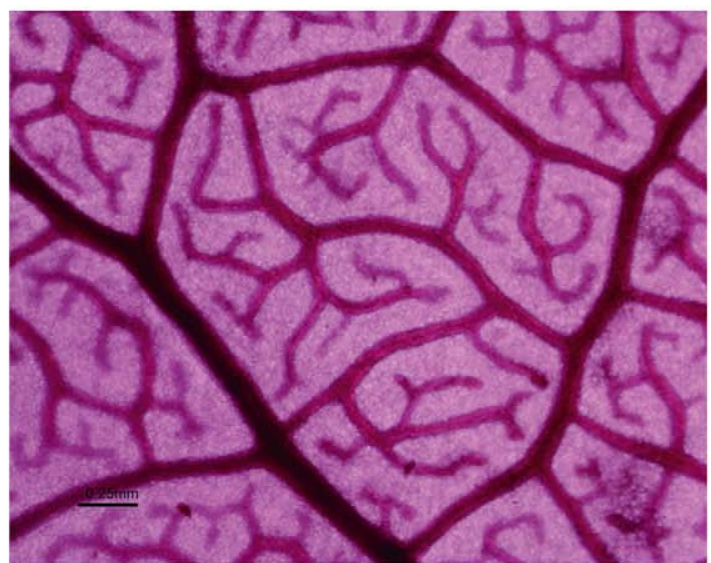

C. Freely ending veinlets.
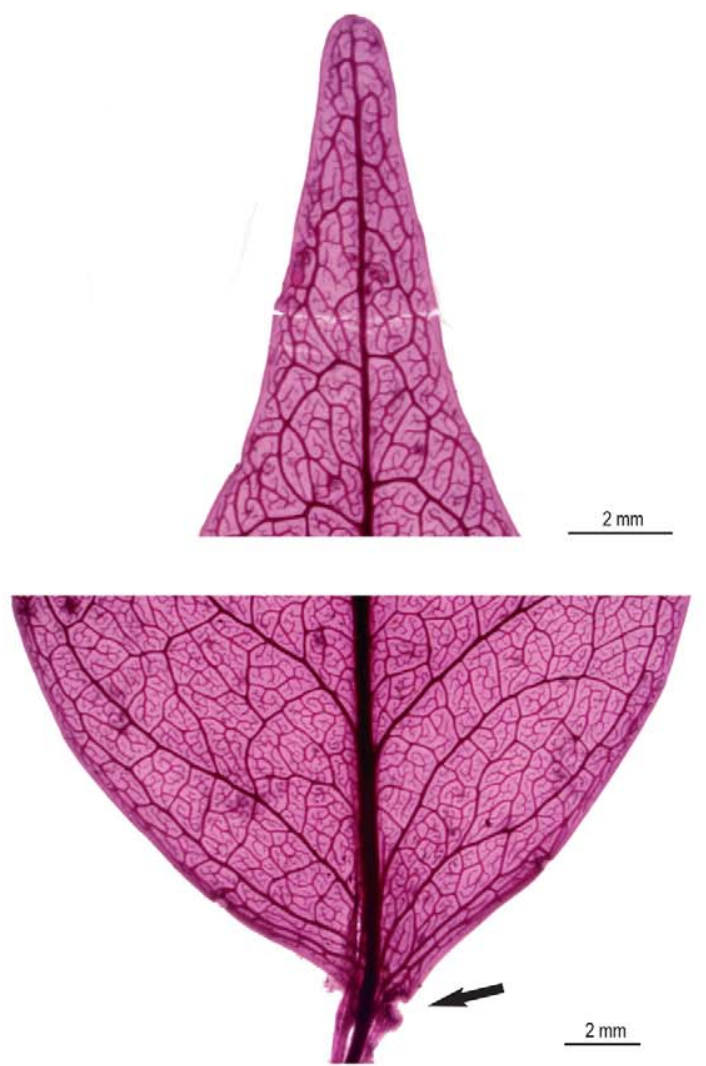

B. Detail of leaf apex and base. Arrow shows marginal gland.

$1 \mathrm{~mm}$

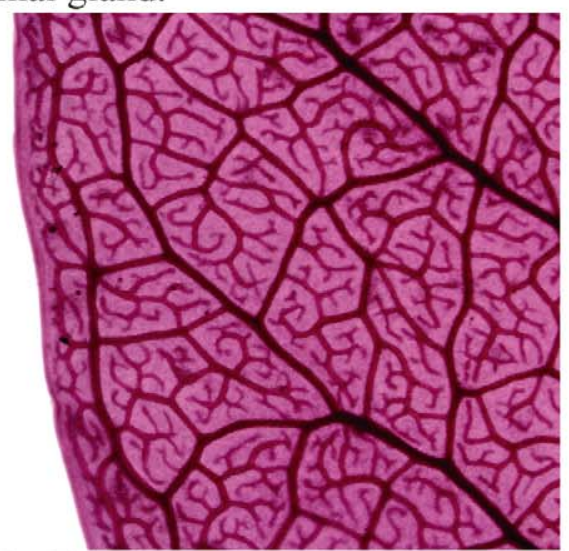

D. Detail of leaf margin.

\section{Venation Description}

1. Primary framework: pinnate.

12. Interior secondaries: absent.

2. Diameter ratio basal lateral vein/midvein: $0.38-0.5$. 13. Intersecondaries: present.

3. Midvein apex: reaching the apex.

14. Course: brochidodromous.

Secondary veins

4. Number: 6-7 per side.

5. Insertion: alternate, opposite or subopposite.

6. Spacing: dispersed along the lamina.

7. Course: veins pointing toward margin

8. Insertion angle: ascendant or diffuse.

9. Insertion angle variability: mixed.

Minor orders

10. Number of vein orders: four.

11. Intramarginal secondaries: absent.

15. Areolation: irregular.

Freely Ending Veinlets (FEVs)

16. FEVs branching: simple, or branched.

17. FEVs termination: tracheoid idioblast.

Margin

18. Shape: entire.

19. Sclerotization: not lignified.

20. Marginal ultimate venation: present.

Glands

21. Glandular bodies: marginal.

FIGURE 29. Leaf venation of Orthaea venamensis Maguire, Steyermark \& Luteyn 


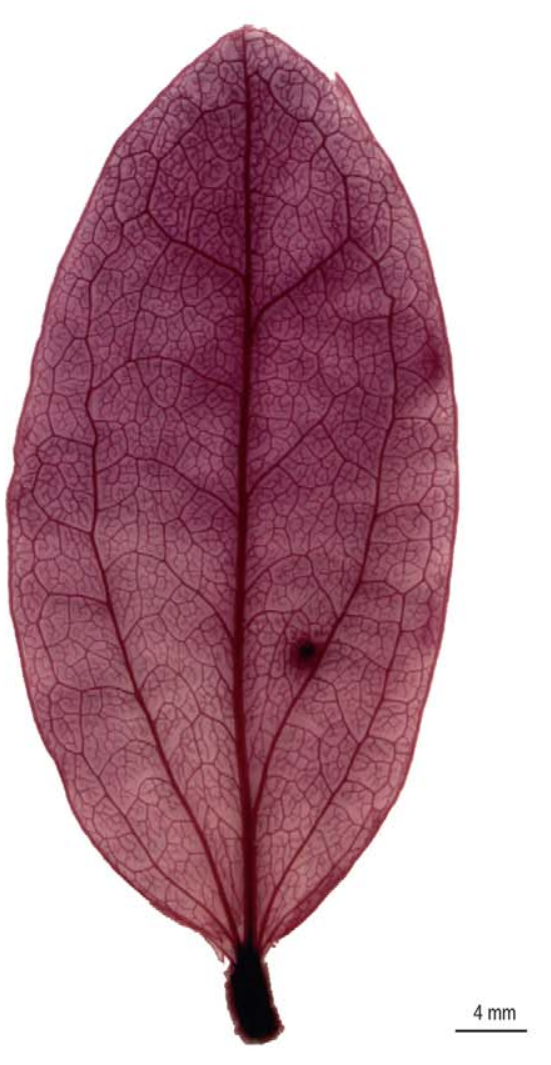

A. Leaf view.

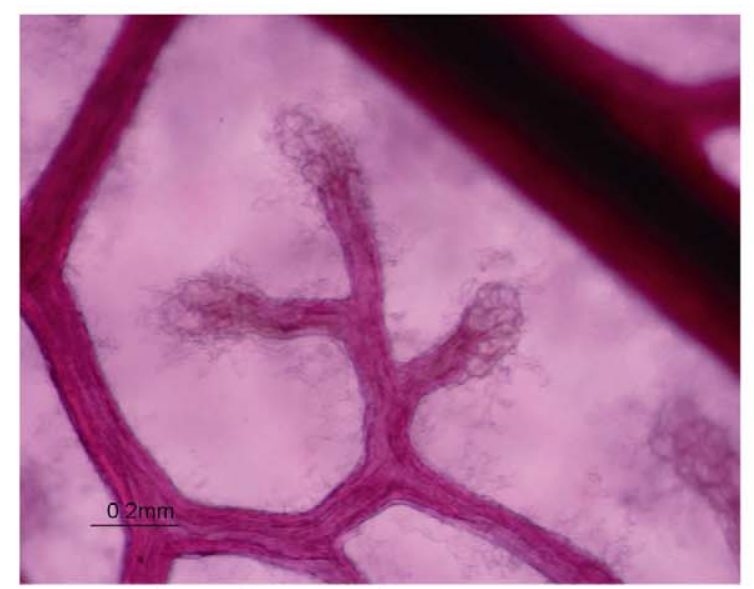

C. Freely ending veinlets.
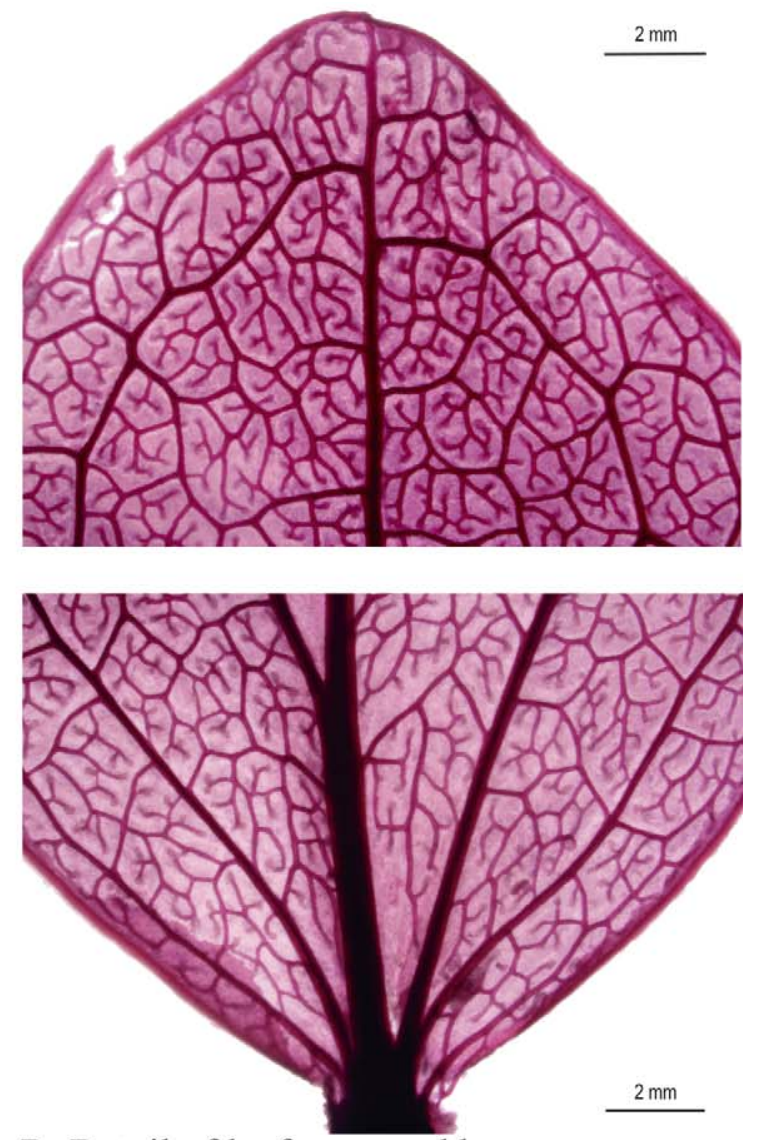

B. Detail of leaf apex and base.

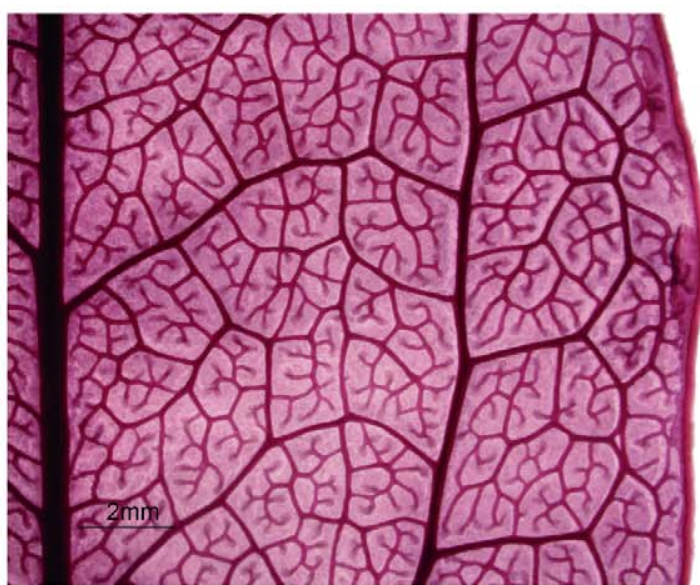

D. Detail of leaf mid-section.

Venation description

1. Primary framework: acrodromous suprabasal.

2. Diameter ratio basal lateral vein/midvein: 0.55 .

3. Midvein apex: reaching the apex.

Secondary veins

4. Number: $4-5$ per side.

5. Insertion: opposite or alternate.

6. Spacing: concentrated in the basal fourth.

7. Course: basal veins pointing toward apex,

the apical toward margin.

8. Insertion angle: adpressed or ascendant.

9. Insertion angle variability: decreasing proximally.

Minor orders

10. Number of vein orders: four.

11. Intramarginal secondaries: absent.

12. Interior secondaries: present.

13. Intersecondaries: absent.

14. Course: brochidodromous.

15. Areolation: irregular.

Freely Ending Veinlets (FEVs)

16. FEVs branching: simple, or branched.

17. FEVs termination: tracheoid idioblast. Margin

18. Shape: entire.

19. Sclerotization: lignified.

20. Marginal ultimate venation: present.

Glands

21. Glandular bodies: absent.

FIGURE 30. Leaf venation of Orthaea sp. 2 


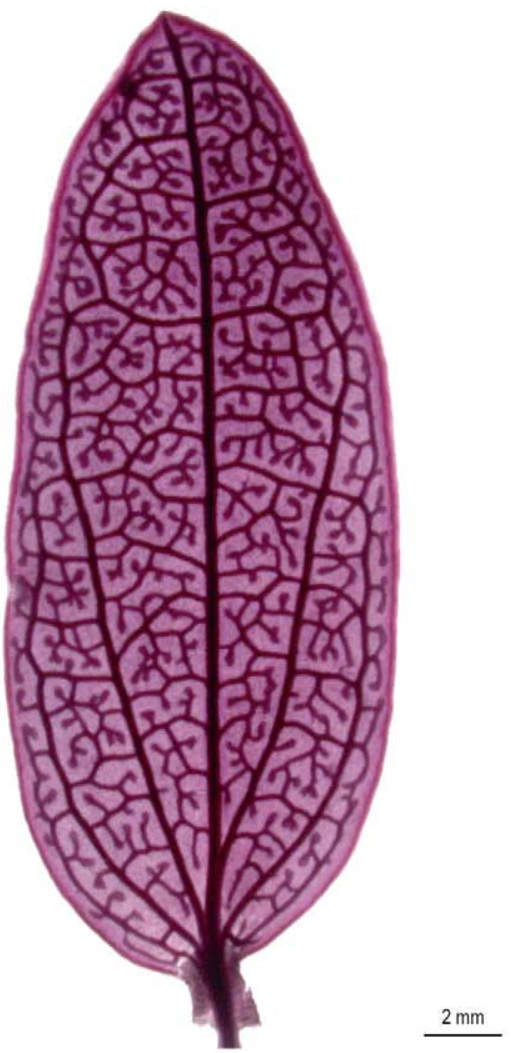

A. Leaf view.

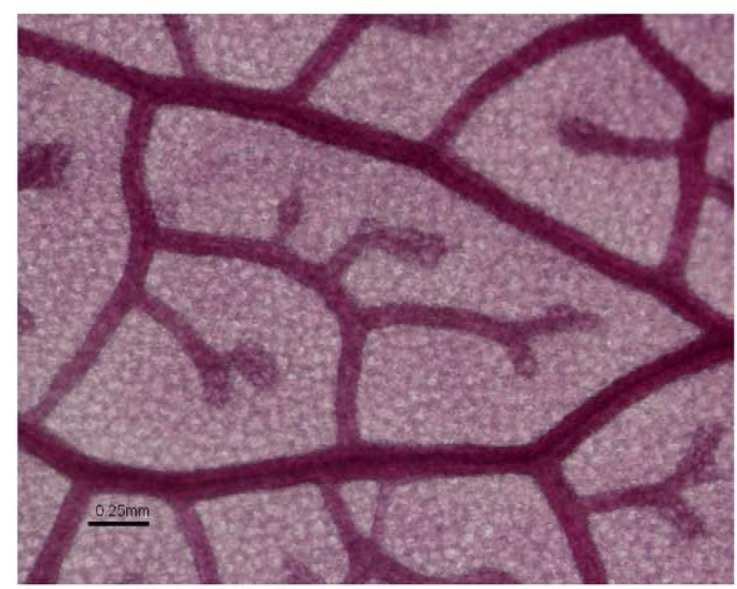

C. Freely ending veinlets.

\section{Venation description}

1. Primary framework: pinnate.

2. Diameter ratio basal lateral vein/midvein: $0.38-0.7$.

3. Midvein apex: reaching the apex.

Secondary veins

4. Number: 4-5 per side.

5. Insertion: opposite or alternate.

6. Spacing: dispersed along the lamina.

7. Course: basal veins pointing to the apex, apical toward the margin.

8. Insertion angle: ascendant or diffuse.

9. Insertion angle variability: decreasing proximally.

Minor orders

10. Number of vein orders: four.

11. Intramarginal secondaries: absent.
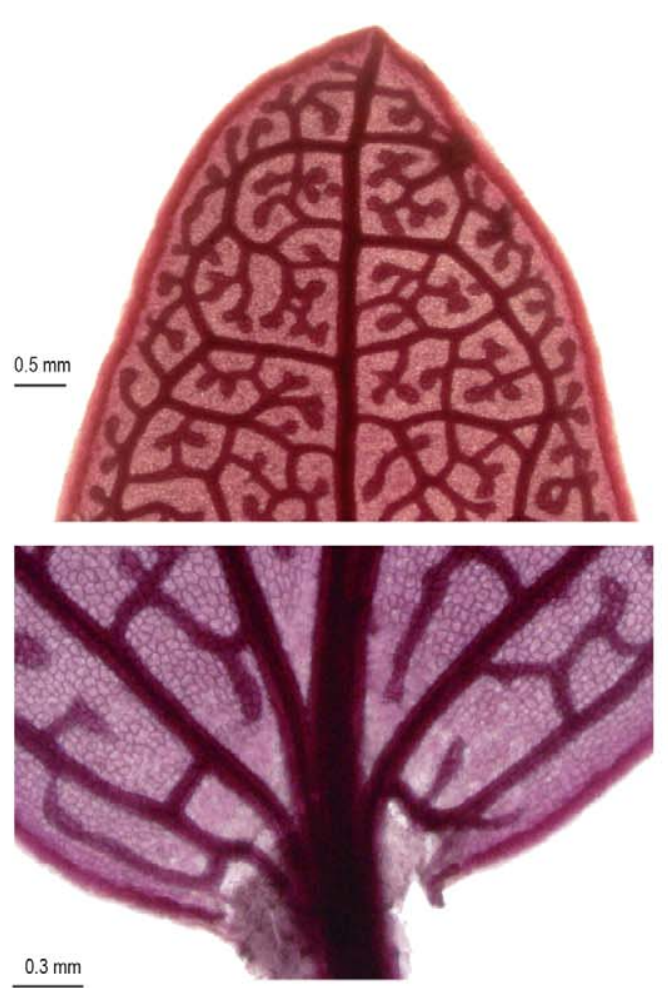

B. Detail of leaf apex and base.

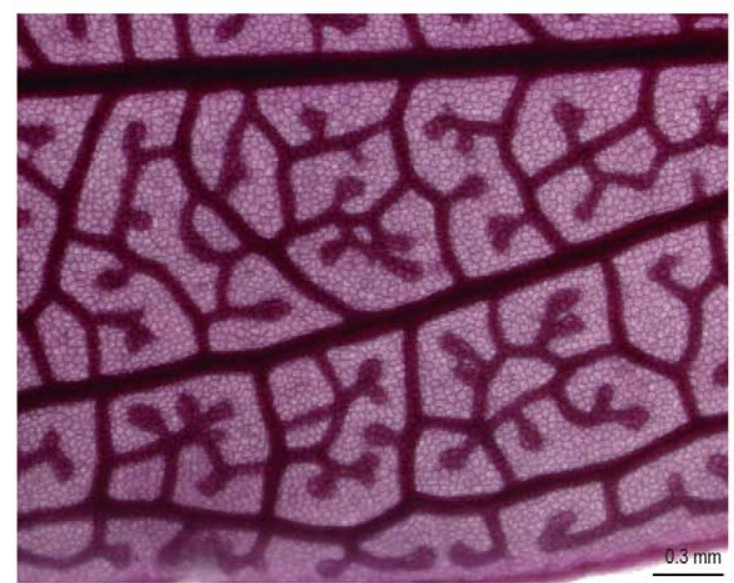

D. Detail of leaf mid-section.

12. Interior secondaries: present.

13. Intersecondaries: absent.

14. Course: brochidodromous.

15. Areolation: irregular.

Freely Ending Veinlets (FEVs)

16. FEVs branching: simple, or branched.

17. FEVs termination: tracheoid idioblast.

Margin

18. Shape: entire.

19. Sclerotization: lignified.

20. Marginal ultimate venation: present.

Glands

21. Glandular bodies: absent.

FIGURE 31. Leaf venation of Pellegrinia coccinea (Hoerold) Sleumer 


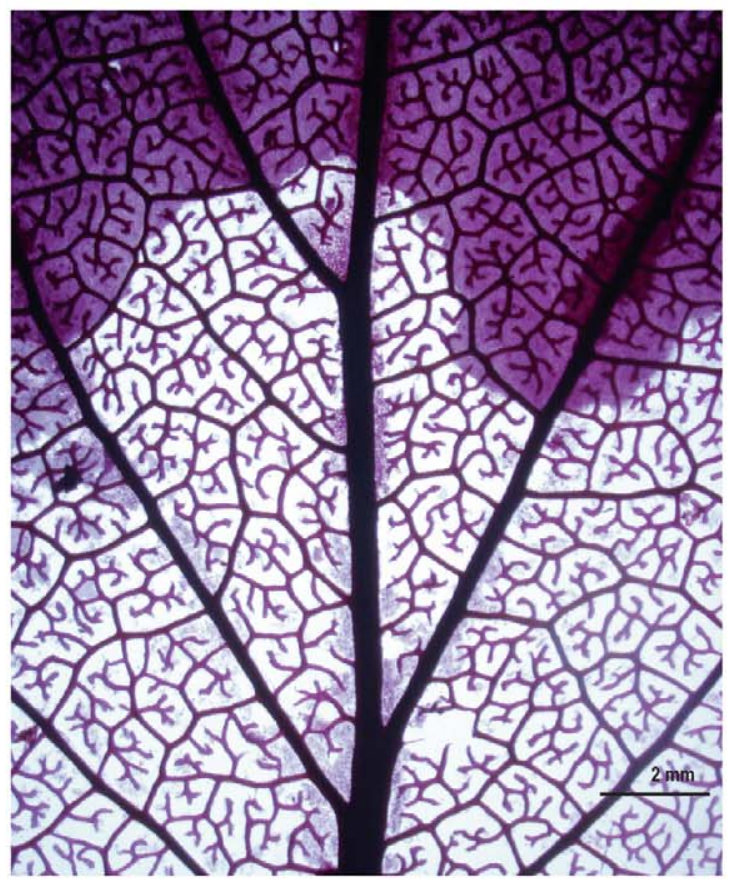

A. Leaf mid-section.

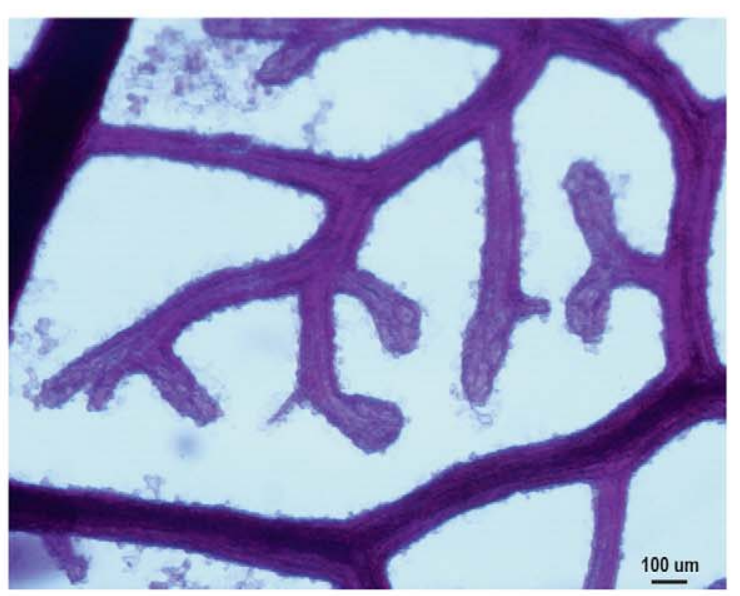

C. Freely ending veinlets.
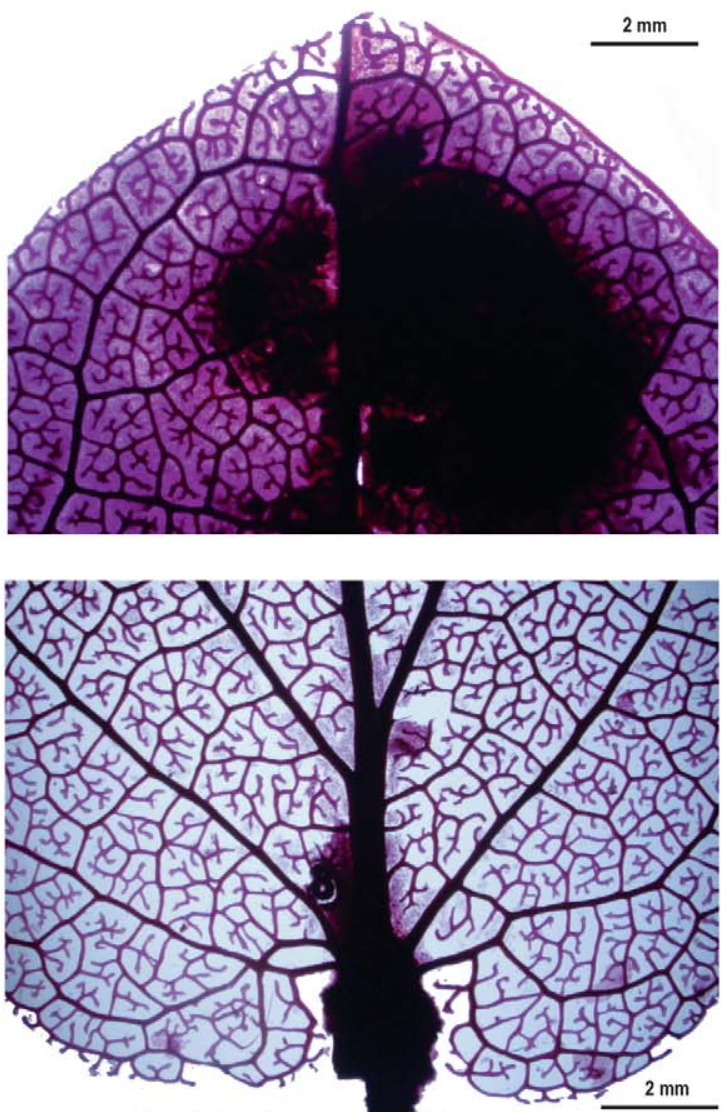

B. Detail of leaf apex and base.

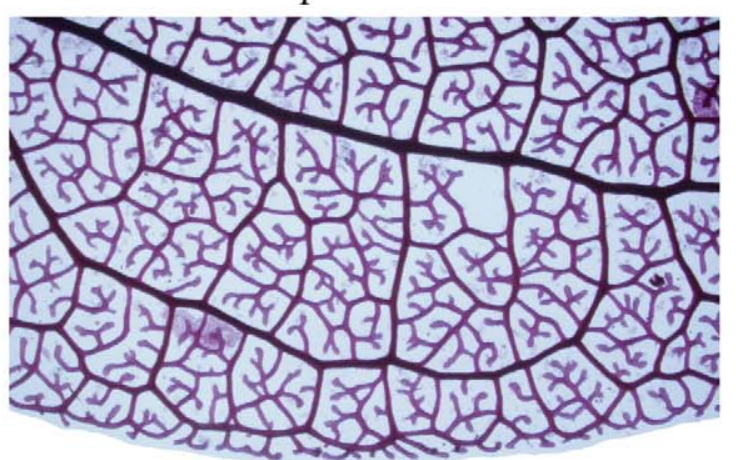

$1 \mathrm{~mm}$

Venation description

1. Primary framework: acrodromous suprabasal.

2. Diameter ratio basal lateral vein/midvein: $0.63-0.7$.

3. Midvein apex: reaching the apex.

Secondary veins

4. Number: 4 per side.

5. Insertion: opposite or alternate.

6. Spacing: concentrated in the basal fourth.

7. Course: veins pointing to the apex.

8. Insertion angle: ascendant.

9. Insertion angle variability: increasing proximally.

Minor orders

10. Number of vein orders: four.

11. Intramarginal secondaries: absent.
12. Interior secondaries: present.

13. Intersecondaries: absent.

14. Course: brochidodromous.

15. Areolation: irregular.

Freely Ending Veinlets (FEVs)

16. FEVs branching: simple, or branched.

17. FEVs termination: simple.

Margin

18. Shape: entire.

19. Sclerotization: lignified.

20. Marginal ultimate venation: present.

Glands

21. Glandular bodies: absent.

FIGURE 32. Leaf venation of Pellegrinia hirsuta (Ruiz \& Pavon ex G.Don) Sleumer 


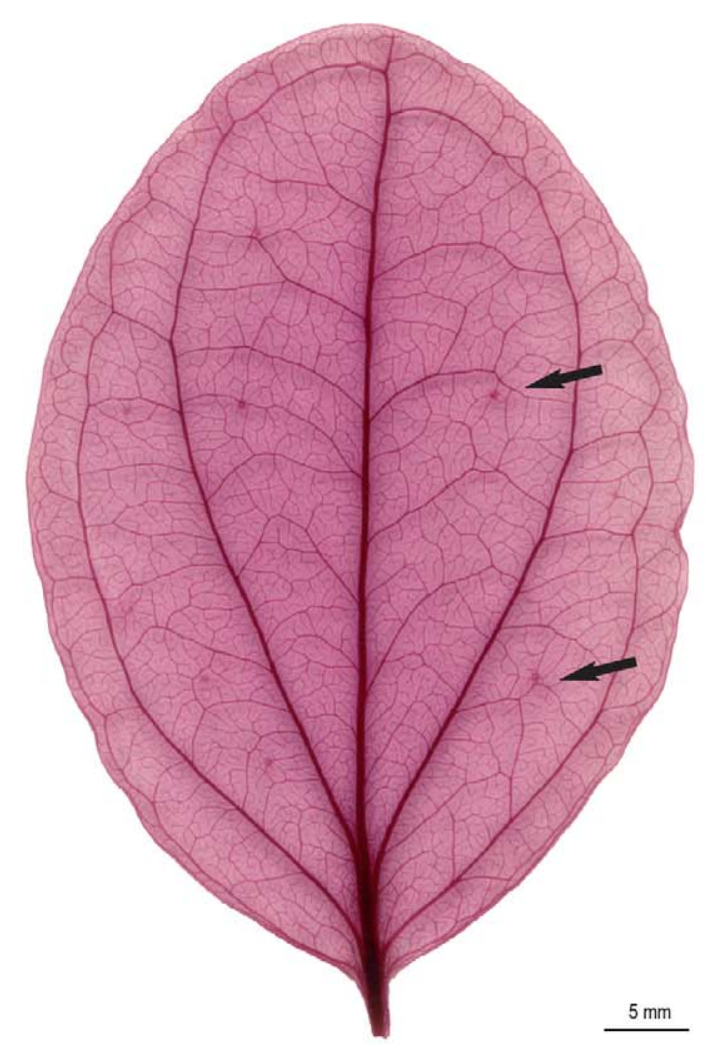

A. Leaf view. Arrows show glands.

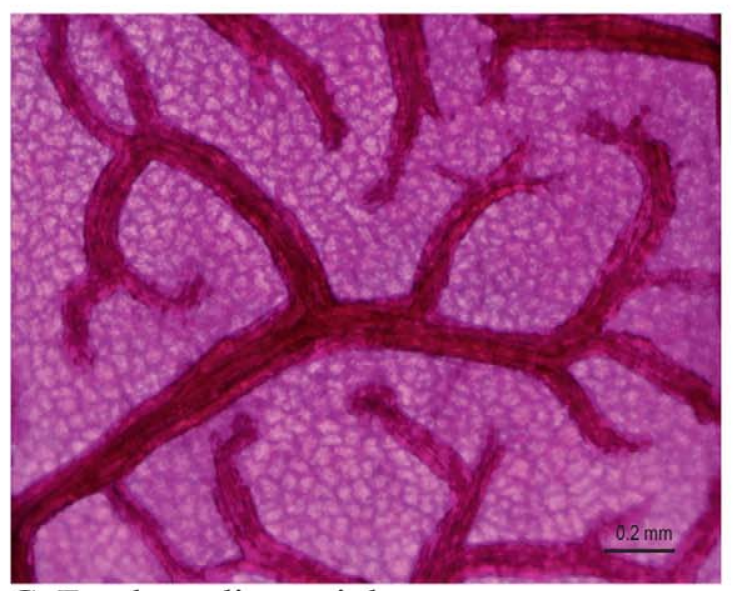

C. Freely ending veinlets.
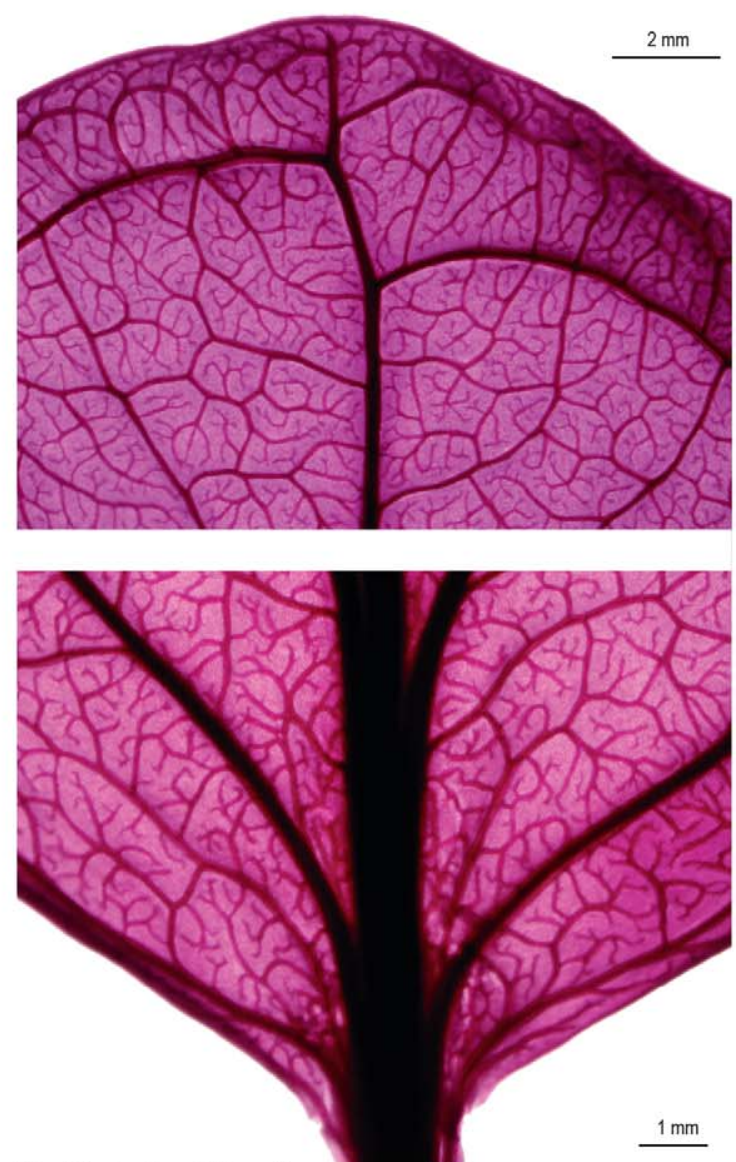

B. Detail of leaf apex and base.

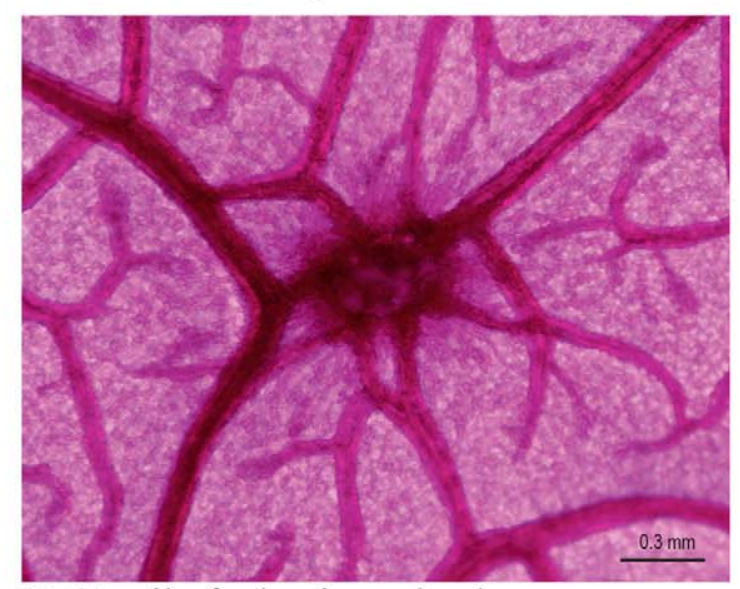

D. Detail of a laminar gland.

\section{Venation description}

1. Primary framework: acrodromous suprabasal.

2. Diameter ratio basal lateral vein/midvein: 0.62 .

12. Interior secondaries: present.

13. Intersecondaries: absent.

14. Course: brochidodromous.

3. Midvein apex: not reaching the apex.

Secondary veins

4. Number: 3 per side.

5. Insertion: subopposite.

6. Spacing: concentrated in the basal fifth.

7. Course: veins pointing to the apex.

8. Insertion angle: ascendant or diffuse.

9. Insertion angle variability: increasing proximally.

Minor orders

10. Number of vein orders: four.

11. Intramarginal secondaries: absent.

15. Areolation: irregular.

Freely Ending Veinlets (FEVs)

16. FEVs branching: branched.

17. FEVs termination: simple.

Margin

18. Shape: entire.

19. Sclerotization: lignified.

20. Marginal ultimate venation: present.

Glands

21. Glandular bodies: laminar.

FIGURE 33. Leaf venation of Psammisia amazonica Luteyn 


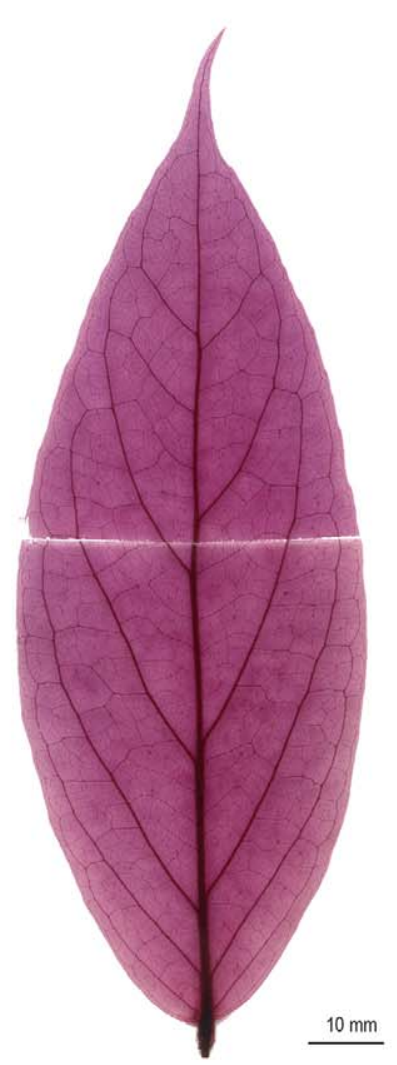

A. Leaf view.

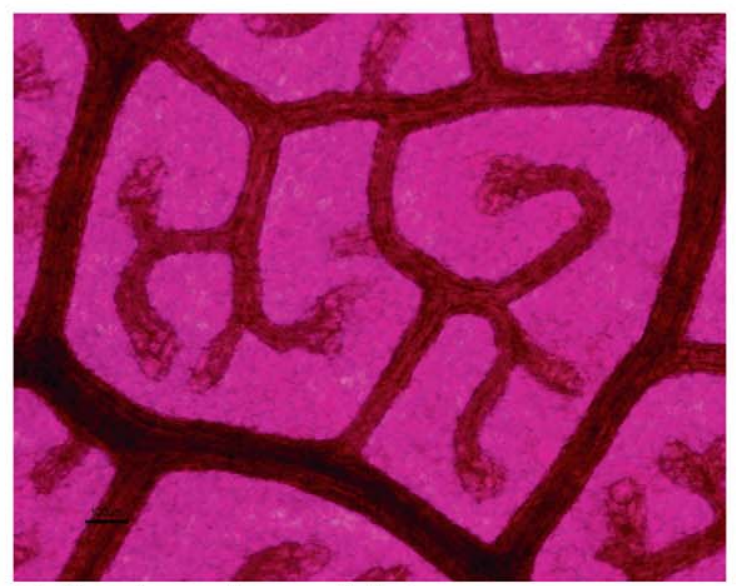

C. Freely ending veinlets.

\section{Venation description}

1. Primary framework: pinnate.

2. Diameter ratio basal lateral vein/midvein: $0.62-0.73$.

3. Midvein apex: reaching the apex.

Secondary veins

4. Number: $6-7$ per side.

5. Insertion: alternate or subopposite.

6. Spacing: disperse along the lamina.

7. Course: veins pointing to the margin.

8. Insertion angle: ascendant.

9. Insertion angle variability: consistent.

Minor orders

10. Number of vein orders: five.

11. Intramarginal secondaries: absent.
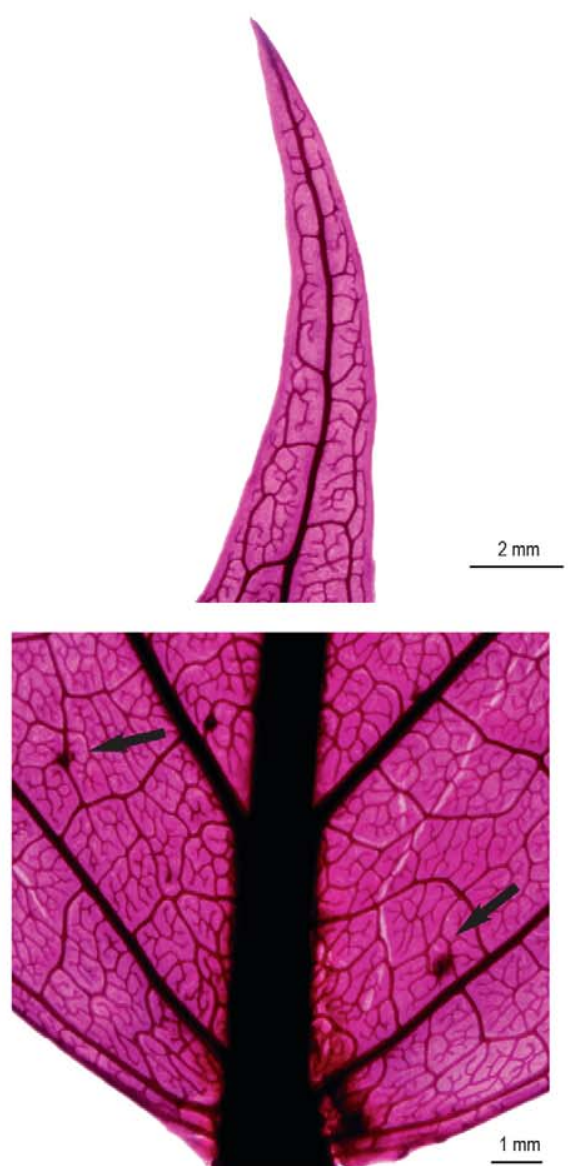

B. Detail of leaf apex and base. Arrows show glands.

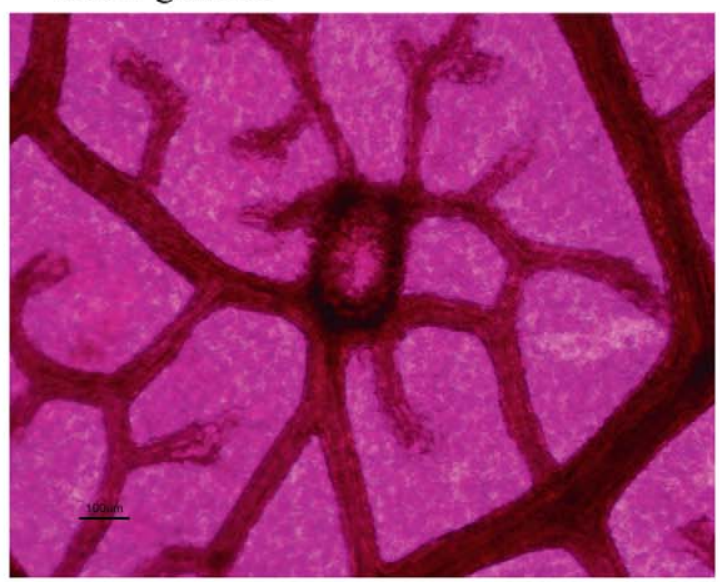

D. Detail of a laminar gland.

12. Interior secondaries: absent.

13. Intersecondaries: present.

14. Course: brochidodromous.

15. Areolation: irregular.

Freely Ending Veinlets (FEVs)

16. FEVs branching: simple, or branched.

17. FEVs termination: tracheoid idioblast

Margin

18. Shape: incipiently crenulate.

19. Sclerotization: not lignified.

20. Marginal ultimate venation: present.

Glands

21. Glandular bodies: laminar.

FIGURE 34. Leaf venation of Psammisia sodiroi Hoerold 


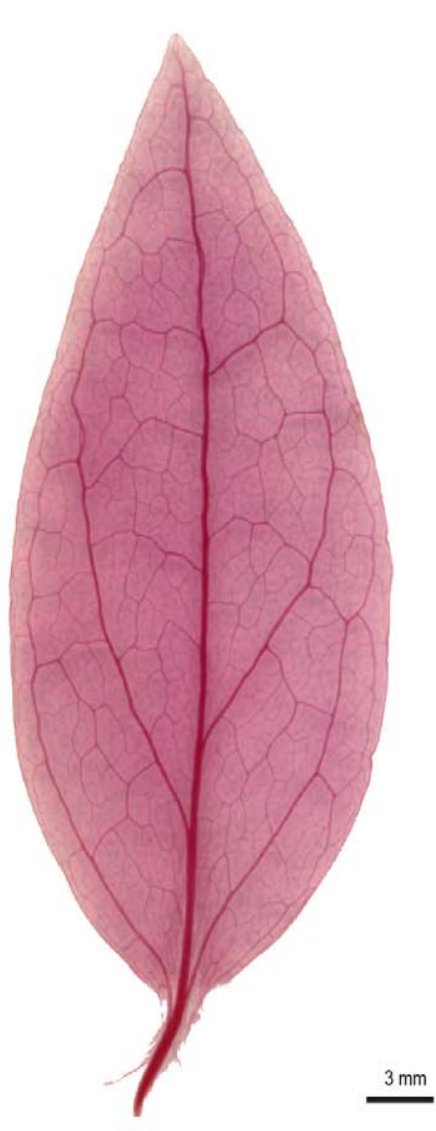

A. Leaf view.

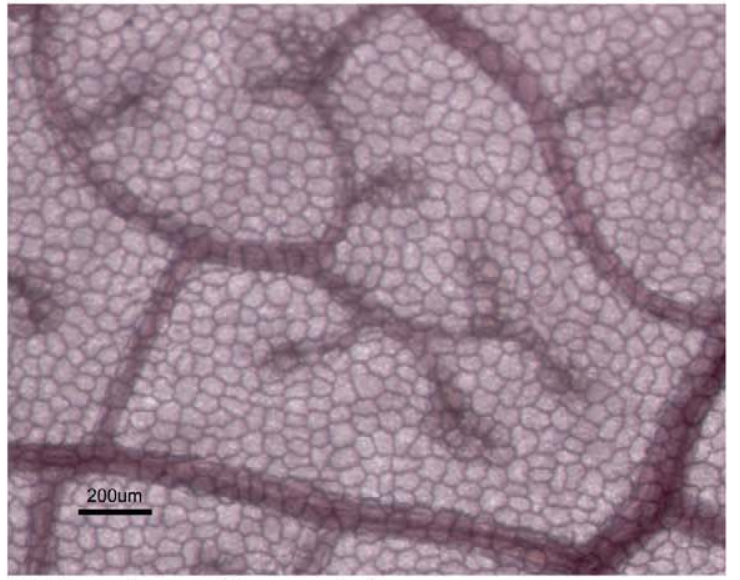

C. Freely ending veinlets.
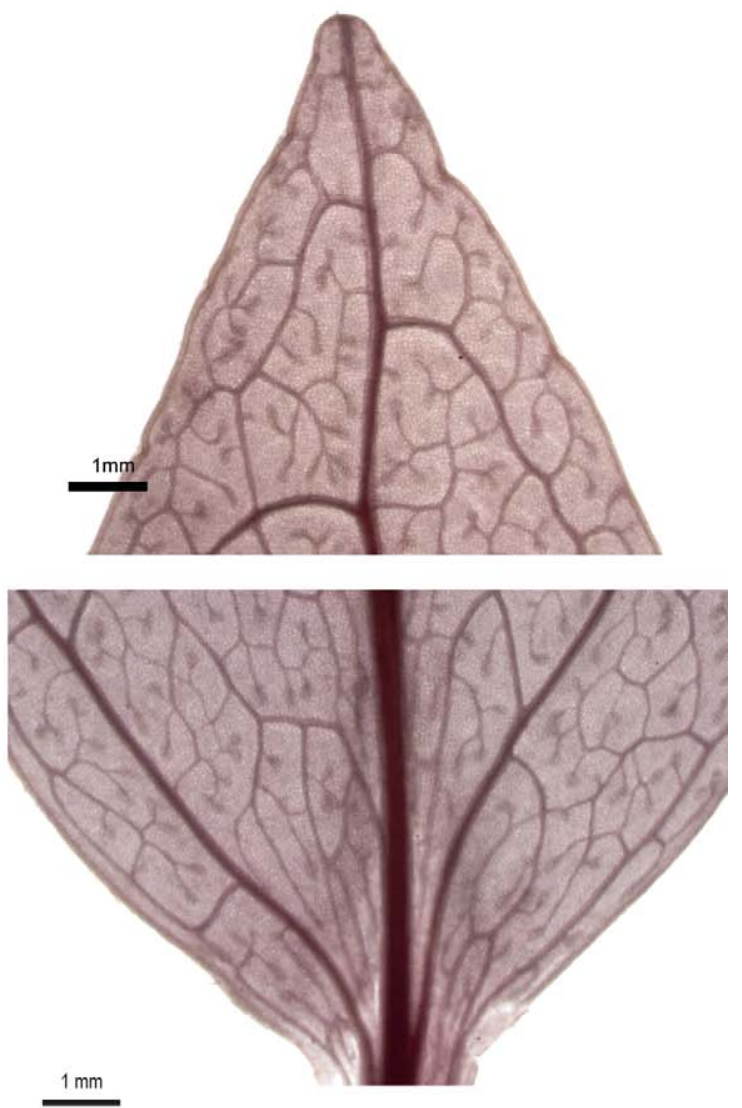

B. Detail of leaf apex and base.

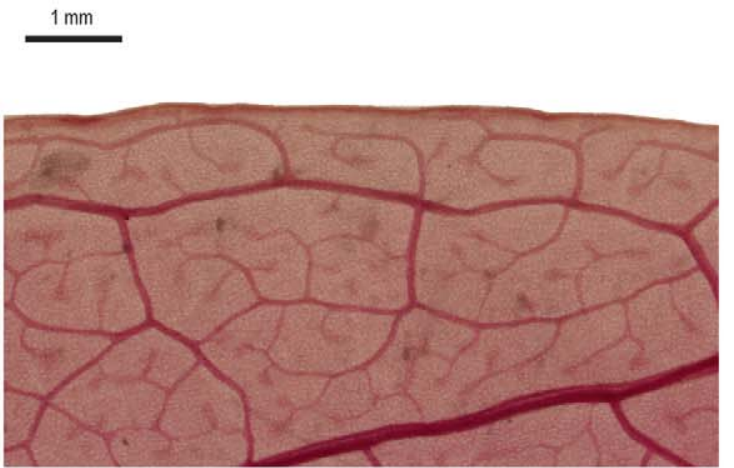

D. Detail of leaf margin.

\section{Venation description}

1. Primary framework: mixed.

2. Diameter ratio basal lateral vein/midvein: $0.55-0.67$.

3. Midvein apex: reaching the apex.

Secondary veins

4. Number: $2-3$ per side.

5. Insertion: alternate or subopposite.

6. Spacing: dispersed along the lamina.

7. Course: veins pointing to the margin.

8. Insertion angle: adpressed or ascendant.

9. Insertion angle variability: decreasing proximally.

Minor Framework

10. Number of vein orders: four.

11. Intramarginal secondaries: absent
12. Interior secondaries: absent.

13. Intersecondaries: absent.

14. Course: brochidodromous.

15. Areolation: irregular.

Freely Ending Veinlets (FEVs)

16. FEVs branching: simple, or branched.

17. FEVs termination: tracheoid idioblast.

Margin

18. Shape: entire.

19. Sclerotization: not lignified.

20. Marginal ultimate venation: present.

Glands

21. Glandular bodies: absent.

FIGURE 35. Leaf venation of Satyria boliviana Luteyn 


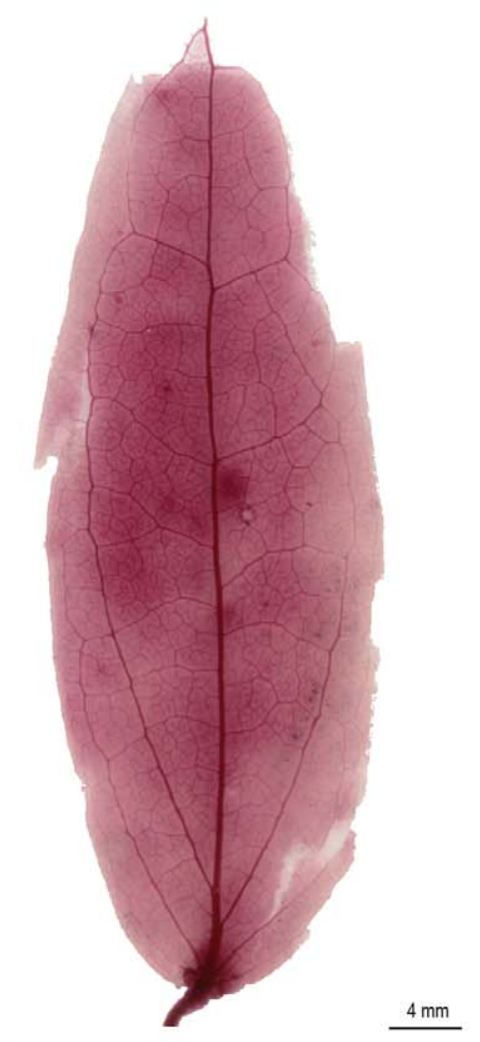

A. Leaf view.

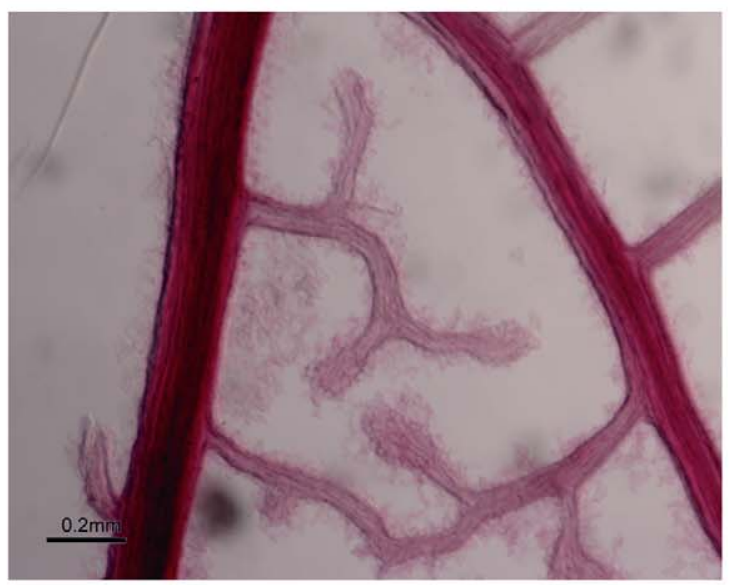

C. Freely ending veinlets.

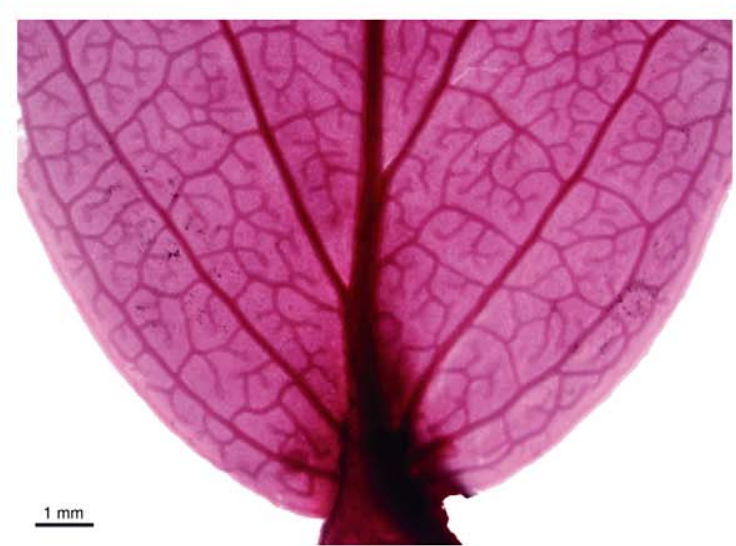

B. Detail of leaf base.

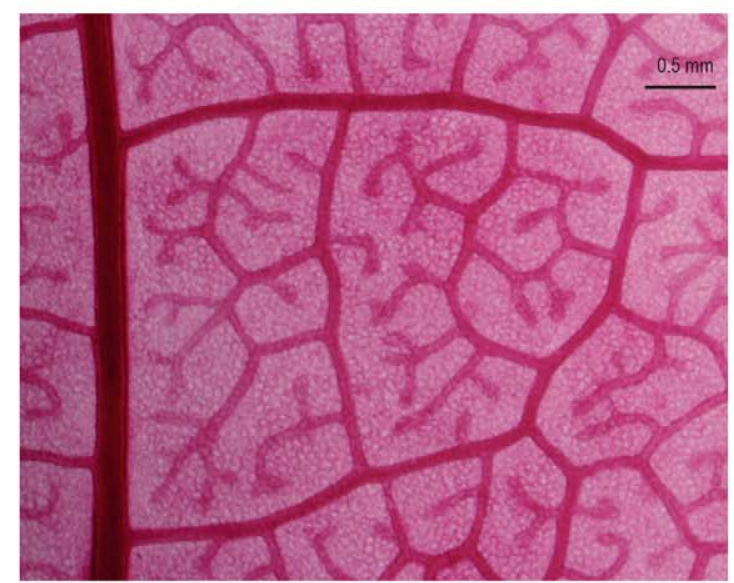

D. Detail of leaf mid-section.

\section{Venation description}

1. Primary framework: acrodromous suprabasal

2. Diameter ratio basal lateral vein/midvein: 0.5 .

3. Midvein apex: NA.

Secondary veins

4. Number: 4-5 per side.

5. Insertion: subopposite.

6. Spacing: concentrated in the basal fourth.

7. Course: basal veins pointing toward apex, the apical toward margin.

8. Insertion angle: ascendant or diffuse.

9. Insertion angle variability: mixed.

Minor orders

10 . Number of vein orders: four.

11. Intramarginal secondaries: absent.

12. Interior secondaries: present.

13. Intersecondaries: absent.

14. Course: brochidodromous.

15. Areolation: irregular.

Freely Ending Veinlets (FEVs)

16. FEVs branching: simple, or branched.

17. FEVs termination: tracheoid idioblast.

Margin

18. Shape: entire.

19. Sclerotization: not lignified.

20. Marginal ultimate venation: present.

Glands

21. Glandular bodies: basilaminar.

FIGURE 36. Leaf venation of Themistoclesia sp. 1 


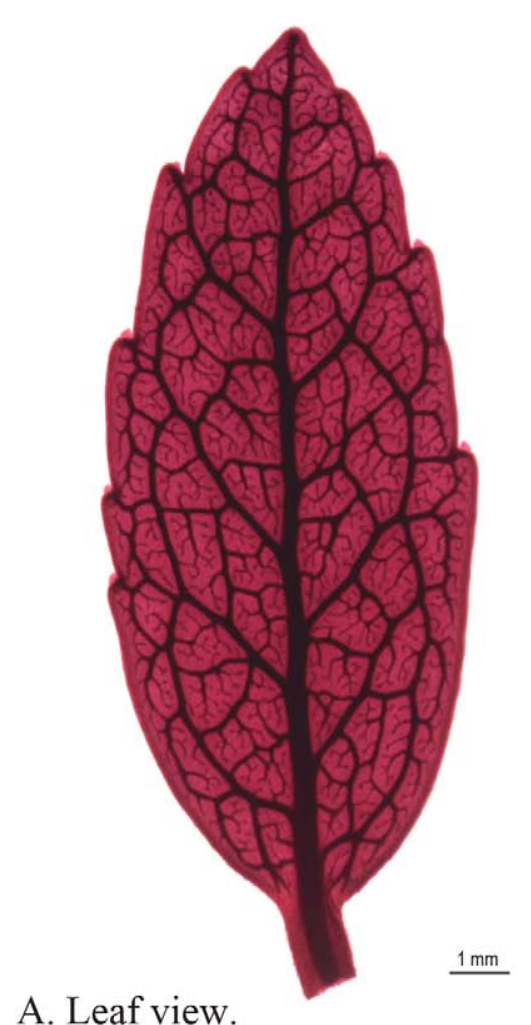

A. Leaf view.

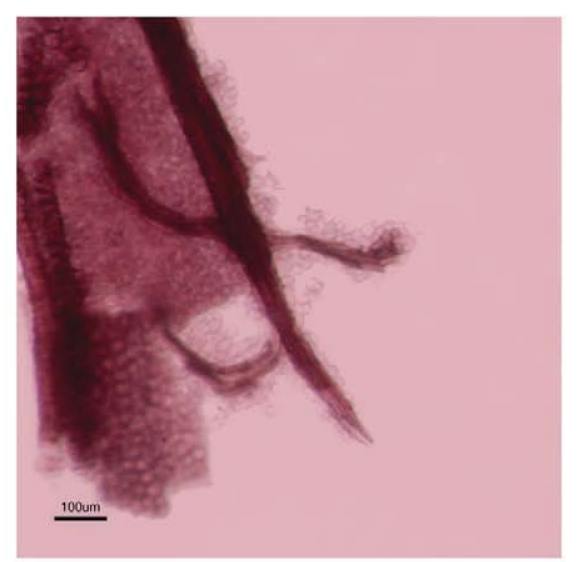

C. Freely ending veinlets.
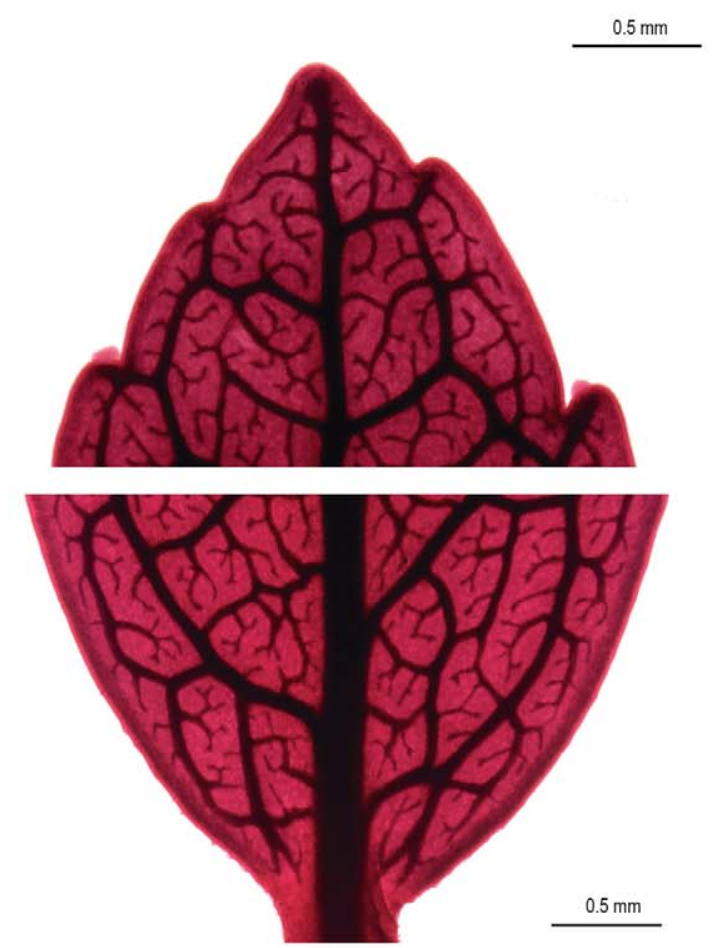

B. Detail of leaf apex and base.

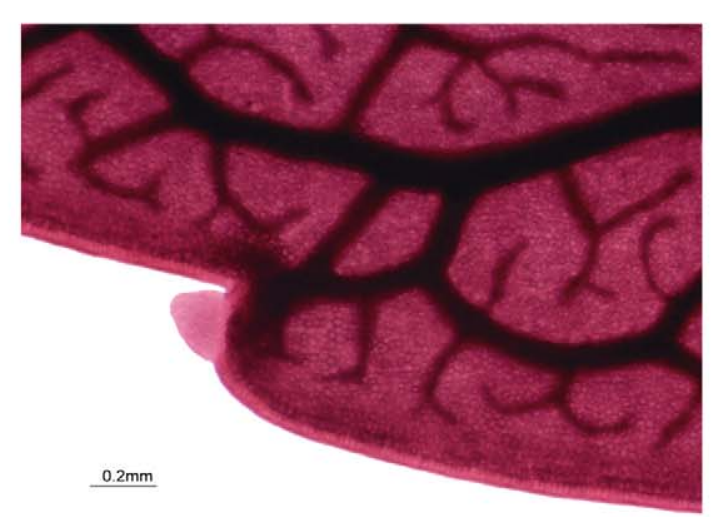

D. Leaf margin.

\section{Venation description}

1. Primary framework: pinnate.

2. Diameter ratio basal lateral vein/midvein: 0.29-0.67.

12. Interior secondaries: absent.

13. Intersecondaries: present.

14. Course: semicraspedodromous.

3. Midvein apex: reaching the margin.

15. Areolation: isodiametric.

4. Number: 4-8 per side.

5. Insertion: opposite or alternate.

6. Spacing: dispersed along midvein.

7. Course: pointing to the margin.

8. Insertion angle: ascendant.

9. Insertion angle variability: consistent or decreasing proximally.

Minor orders

10. Number of vein orders: four.

11. Intramarginal secondaries: absent.

Freely Ending Veinlets (FEVs)

16. FEVs branching: simple, dichotomous, or dendritic.

17. FEVs termination: simple.

Margin

18. Shape: crenulate.

19. Sclerotization: not lignified.

20. Marginal ultimate venation: absent.

Glands

21. Glandular bodies: absent.

FIGURE 37. Leaf venation of Vaccinium crenatum (G.Don) Sleumer 
APPENDIX 1. Morphological character matrix for 32 species of Vaccinieae. Polymorphism key: $\mathrm{A}=0 \& 1 ; \mathrm{B}=2 \& 3$.

\begin{tabular}{lllllllllll}
\hline & 0 & 1 & 2 & 3 & 4 & 5 & 6 & 7 & 8 & 9 \\
\hline Anthopterus revolutus & 1 & - & 0 & 0 & 2 & 1 & 0 & 1 & 1 & 0 \\
Anthopterus wardii & 0 & 1 & 0 & 0 & 2 & 1 & 0 & 1 & 1 & 0 \\
Cavendishia micayensis & 0 & 1 & 0 & 0 & 2 & 1 & 1 & 1 & 0 & 0 \\
Ceratostema megabracteatum & 0 & 1 & 0 & 0 & 3 & 0 & 2 & 1 & 0 & 0 \\
Ceratostema rauhii & 0 & 0 & 0 & 0 & 1 & 0 & 2 & 1 & 0 & 0 \\
Demosthenesia mandonii & 0 & 1 & 0 & 0 & 2 & 1 & 0 & 1 & 0 & 0 \\
Demosthenesia spectabilis & 0 & 1 & 0 & 0 & 1 & 0 & 2 & 1 & 0 & 0 \\
Diogenesia alstoniana & 0 & 1 & 0 & 0 & 2 & 1 & 0 & 1 & 1 & 0 \\
Diogenesia racemosa & 0 & 1 & 0 & 0 & 2 & 1 & 0 & 1 & 1 & 0 \\
Disterigma agathosmoides & 0 & 0 & 0 & 1 & 0 & 1 & 1 & 0 & 0 & 0 \\
Disterigma parallelinerve & 2 & - & 0 & 0 & 1 & 1 & 1 & 0 & 0 & 0 \\
Disterigma pentandrum & 1 & - & 0 & $\mathrm{~A}$ & 1 & 0 & 1 & 0 & 0 & 0 \\
Disterigma pseudokillipiella & 2 & - & 0 & 0 & 1 & 1 & 0 & 1 & 0 & 0 \\
Disterigma rimbachii & 0 & 1 & 0 & 0 & 1 & 0 & 1 & 1 & 0 & 0 \\
Disterigma trimerum & 0 & 1 & $\mathrm{~A}$ & 0 & 1 & 0 & 2 & 1 & 0 & 0 \\
Gaylussacia baccata & 1 & - & 0 & 0 & 3 & 0 & 1 & 1 & 0 & 0 \\
Gonocalyx costaricensis & 3 & 1 & 1 & 0 & 2 & 1 & $\mathrm{~A}$ & 1 & 0 & 0 \\
Gonocalyx megabracteolatus & 0 & 1 & 0 & 0 & 3 & 1 & 0 & 1 & 0 & 0 \\
Macleania bullata & 0 & 1 & 0 & 0 & 2 & 1 & 0 & 1 & 0 & 0 \\
Macleania coccoloboides & $\mathrm{A}$ & 1 & 1 & 0 & 2 & 1 & 0 & 1 & 0 & 0 \\
Macleania cordifolia & 0 & 1 & 0 & 0 & $\mathrm{~B}$ & 1 & 0 & 1 & 0 & 0 \\
Macleania rupestris & $\mathrm{A}$ & 1 & 0 & 0 & 3 & 1 & 0 & 1 & 0 & 0 \\
Notopora schomburgkii & 1 & - & 0 & 0 & 3 & 0 & 2 & 1 & 0 & 0 \\
Orthaea apophysata & 0 & 1 & 0 & 0 & 2 & 1 & 0 & 1 & 1 & 1 \\
Orthaea venamensis & 1 & - & 0 & 0 & 2 & 1 & $\mathrm{~A}$ & 1 & 0 & 1 \\
Orthaea sp. 2 & 0 & 1 & 0 & 0 & 2 & 1 & 0 & 1 & 0 & 0 \\
Pellegrinia coccinea & 1 & - & 0 & 0 & 2 & 1 & 0 & 1 & 0 & 0 \\
Pellegrinia hirsuta & 1 & - & 0 & 0 & 2 & 0 & $\mathrm{~A}$ & 1 & 0 & 0 \\
Psammisia sodiroi & 1 & - & 0 & 0 & 3 & 1 & 0 & 1 & 1 & 0 \\
Satyria boliviana & 3 & 0 & 1 & 0 & 2 & 1 & 0 & 1 & 0 & 0 \\
Themistoclesia sp. 1 & 0 & 1 & 0 & 0 & 2 & 1 & 0 & 1 & 1 & 0 \\
Vaccinium crenatum & 1 & - & 0 & 2 & 2 & 0 & 2 & 1 & 0 & 0 \\
\hline & & & & & & & & & & \\
\hline & & & &
\end{tabular}

